\title{
Special Report 3: A Study of China's Technology Revolution
}

\author{
Song Zifeng and Nigel Dickens
}

Energy is a key driver of social development. The energy transition correlates strongly with social and economic reform. Among the many drivers of the energy transition, a revolution in energy technology is undoubtedly one of the most critical.

DRC Team Lead of Special Report 3:

Song Zifeng from the Research Department of Industrial Economy, DRC of the State Council of China.

Shell Team Lead of Special Report 3:

Nigel Dickens, Economics and Analysis Manager-New Fuels, Shell International Petroleum Company Ltd.

\section{Contributors:}

Philip Gradwell from Vivid Economics; Cameron Hepburn, Huang Yanghua from the Chinese Academy of Social Sciences (CASS); Kang Xiaowan from the Energy Research Institute, National Development Reform Commission (NDRC); Huang Bibin from the State Grid Energy Research Institute Co., Ltd.; Tu Junming from China National Travel Service Group Corporation Limited; Xing Lu from China National Petroleum Corporation (CNPC); and Zhang Jun from the State Grid Energy Research Institute Co., Ltd.

\section{S. Zifeng ( $\bowtie)$}

Research Department of Industrial Economy, DRC of the State Council of China, Beijing, China

\section{N. Dickens}

Economics and Analysis Manager-New Fuels, Shell International Petroleum Company Ltd.,

London, UK

e-mail: Nigel.Dickens@shell.com
To build modern energy systems that are affordable, secure and sustainable, countries need to push technological innovation. Although innovation in energy is at a relatively high level, it is unlikely to be high enough to achieve the needed revolution in energy technology. The International Energy Agency's 2017 Tracking Clean Energy Progress scorecard of 26 technologies finds that only three are on track for wide-scale deployment. To deliver a low-carbon energy system, more effort is needed in 15 technologies and eight are not on track. As many of the current set of new energy technologies are based on a pipeline of innovation that was started in the 1970s, it is important to understand the energy technology issues of the current era.

\section{The Implications of Energy Technology Revolution}

It is extremely rare for innovations to be evenly distributed across time and space. Instead, innovations tend to occur in a concentrated manner, which is likely to trigger a technology revolution. Technology revolution usually refers to the transition process, in which a technology or technologies is/are replaced by another technology or technologies in the short term. This processfrom emergence to deployment and diffusionwill eventually impact socioeconomic development. Up to now, countless energy-related 
technologies have been invented, but few qualify as an energy technology revolution. To understand the deep implications of energy technology revolution, multiple dimensions and perspectives must be taken into account.

\subsection{Energy Technology Revolution Is a Long-Term Process}

The history of technology shows that it often takes several decades for new technologies to flourish. It can take as long as 30 years for a new technology to gain a $1 \%$ market share, and even longer for it to be deployed at scale. There are many such examples: the steam engine appeared in the late 18th century, but the number of workers employed by steam engine-powered factories and manual workshops did not pass $50 \%$ of the total until $1880^{1}$; the history of electric vehicles (EVs) can be traced back to the 1830 s, with the world's first commercially operated EV unveiled in New York in 1897, although little progress was made in the next 100 years; the modern oil industry took shape in 1859 , but didn't take off until the early 20th century; fracturing and horizontal well drilling technologies have a history of more than 50 and 30 years respectively, but the shale gas revolution did not occur until after the global financial crisis in 2008.

For those technologies that qualify as revolutionary, the deployment life cycle of their core technology is often far more than 100 years. Rail, electricity and motor vehicles are typical examples. $^{2}$ This tells us that energy technology revolution is typically a long-term process.

\footnotetext{
${ }^{1}$ Vaclav Smil, Made in the USA: The Rise and Retreat of American Manufacturing, The MIT Press, 2015.

${ }^{2}$ Jan Fagerberg, David C. Mowery and Richard R. Nelson, The Oxford Handbook of Innovation, Oxford University Press, 2006.
}

\subsection{Energy Technology Revolution Is Strongly Correlated with Industrial Revolution}

Human society has witnessed two energy revolutions - from wood and biomass to coal, and from coal to oil and gas. These two revolutions spawned or were accompanied by technological or industrial revolutions, including the steam engine, the internal combustion engine and electrification. Together, they drove productivity and enabled civilisation to leap forward. As summarised by Freeman and Soete, ${ }^{3}$ over the past 200 years, the energy system has undergone several transitions - from hydraulic power to steam, to electricity, oil, and oil and gas. These transitions underpin the Kondratiev waves of economic and technological cycles. The rationale behind these waves is that a rapid drop in the price of critical energy resources is enabled only by a technology revolution, such as steam, that eventually boosts productivity significantly (Table 1).

\subsection{Energy Technology Revolution Triggers New and Important Energy Sectors}

There is a strong correlation between energy technology revolution and industrial revolution. Every energy technology revolution in history has enabled new and important energy sectors to emerge. These include coal and oil and gas in primary energy, and electricity in secondary energy, all three of which are still significant pillar industries for economic growth.

For example, the oil and power industries that emerged in the second half of the 19th century still play an important role in driving economic growth in the USA. Measured by industry R\&D investment per capita and the proportion of employees with an education in the STEM disciplines (science, technology, engineering and

${ }^{3}$ Chris Freeman, and Luc Soete, The Economics of Industrial Innovation, Routledge, 1997. 
Table 1 Consecutive waves of technology change

\begin{tabular}{|c|c|c|c|c|c|}
\hline \multicolumn{2}{|l|}{ Long wave or period } & \multicolumn{4}{|c|}{ Major characteristics of the base structure } \\
\hline Period & Kondratiev wave & $\begin{array}{l}\text { Science, technology, } \\
\text { education and training }\end{array}$ & Transport & $\begin{array}{l}\text { Energy } \\
\text { system }\end{array}$ & $\begin{array}{l}\text { Common and } \\
\text { inexpensive } \\
\text { critical elements }\end{array}$ \\
\hline First, $1780-1840$ & $\begin{array}{l}\text { Industrial } \\
\text { revolution: } \\
\text { industrialised } \\
\text { production of } \\
\text { textiles }\end{array}$ & $\begin{array}{l}\text { Apprenticeship, } \\
\text { learning-by-doing, schools } \\
\text { and scientific associations } \\
\text { with different opinions }\end{array}$ & $\begin{array}{l}\text { Canals, } \\
\text { roads }\end{array}$ & $\begin{array}{l}\text { Hydraulic } \\
\text { power }\end{array}$ & Cotton \\
\hline Second, $1840-1890$ & $\begin{array}{l}\text { Steam power and } \\
\text { rail }\end{array}$ & $\begin{array}{l}\text { Professional mechanical and } \\
\text { civil engineers, technical } \\
\text { colleges and public } \\
\text { entry-level education }\end{array}$ & $\begin{array}{l}\text { Rail (iron), } \\
\text { telegraph }\end{array}$ & Steam & Coal and iron \\
\hline Third, 1890-1940 & $\begin{array}{l}\text { Electricity and } \\
\text { steel }\end{array}$ & $\begin{array}{l}\text { Industrial R\&D laboratories, } \\
\text { national chemical and } \\
\text { electrification laboratories, } \\
\text { and standard laboratories }\end{array}$ & $\begin{array}{l}\text { Rail (steel), } \\
\text { telephone }\end{array}$ & Electricity & Steel \\
\hline Fourth, 1940-1990 & $\begin{array}{l}\text { Mass production } \\
\text { of vehicles and } \\
\text { synthetic } \\
\text { materials } \\
\text { (Fordism) }\end{array}$ & $\begin{array}{l}\text { R\&D in mass production } \\
\text { industries and government } \\
\text { institutions, widespread } \\
\text { access to higher education }\end{array}$ & $\begin{array}{l}\text { Motorways, } \\
\text { radio and } \\
\text { television, } \\
\text { air routes }\end{array}$ & Oil & Oil and plastics \\
\hline Fifth, 1990-? & $\begin{array}{l}\text { Microelectronics } \\
\text { and computer } \\
\text { networks }\end{array}$ & $\begin{array}{l}\text { Data networks, global R\&D } \\
\text { networks, life-long } \\
\text { education and training }\end{array}$ & $\begin{array}{l}\text { Information } \\
\text { highway and } \\
\text { digital } \\
\text { networks }\end{array}$ & $\begin{array}{l}\text { Oil and } \\
\text { gas }\end{array}$ & Microelectronics \\
\hline
\end{tabular}

Source Freeman and Soete (1997)

mathematics), the USA currently has 50 industries that contribute nearly a quarter of its total employment opportunities (direct and indirect) and $17 \%$ of its GDP. They also account for $90 \%$ of R\&D investment in the private sector, $85 \%$ of US patents, and $60 \%$ of the country's exports. ${ }^{4}$ Among the 50 industries, power and oil and gas refining rank second and third respectively in terms of industry scale, with their combined gross added value (GVA) accounting for $16.1 \%$ of the total of all 50 industries. This shows that every energy technology revolution triggers the emergence of important energy sectors that hold long-term development potential.

Based on the above, this study argues that energy technology revolutions generally appear

\footnotetext{
${ }^{4}$ Mark Muro, Jonathan Rothwell, Scott Andes, Kenan Fikri and Siddharth Kulkarni, America's Advanced Industries: What They Are, Where They Are, and Why They Matter, Brookings Institution, 2015.
}

in a concentrated manner within a short timeframe. They generate long-term and significant impacts, including industrial revolution and important new energy sectors.

\section{Energy Technology Innovation and Development}

Technology readiness is a necessary but insufficient condition for an energy revolution. Technologies that achieve high levels of deployment benefit from a supporting set of factors, in addition to their technological development. These support factors consist of demand for the services the technology provides, such as clean or secure energy; supply of the input the technology requires, such as the components of the technology or primary fuels; and markets that incentivise the deployment of the new technology, such as a newly liberalised market that favours a new lower-cost technology. If the 
supply, demand and market factors are well-facilitated in the innovation ecosystem, the prospect of triggering an energy technology revolution becomes likelier, and thus the marginal impact of innovation is greater.

\subsection{Innovation Policy: Basic Findings}

It is hard to predict which technologies will win through, given that adoption is driven by a mix of demand, supply and market factors, in addition to the technology's characteristics. As a result, there is a tension between the need to fund a large pipeline of innovation, and the uncertainty about which technologies will be adopted. Innovation policy is ultimately about resolving this tension.

\subsubsection{Prioritise Financial Support}

Government funding of innovation should focus on the following three aspects.

First, on the early stages of research, development and deployment, rather than on the later stages of niche and wider market deployment. At these early stages the scale of financing is often relatively small, so limited government budgets can fund a broader range of innovations. The risk is high, but government can bear it and share losses across society, which is fair as gains will be shared by society if the innovation is successful.

Second, innovations that create new classes of technology, rather than innovations for specific technologies.

Third, technologies with high capital intensity, longevity and requiring new networks, but only if alternatives with lower capital intensity and transition costs have been explored first. Technologies with high capital intensity and longevity are riskier and require public support further into the deployment phase when they do not plug and play in the current energy system.

\subsubsection{Encourage and Coordinate Diversity}

Government institutional support for innovation should focus on the following three aspects.

First, it should support an ecosystem of innovators. Innovation has several development stages. Different skills, resources and types of organisation are needed at each stage- from universities for basic research, to entrepreneurs for entry into niche markets, and large companies for wide deployment of the technology. Government should acknowledge that this diversity is needed, rather than trying to deliver the entire innovation pathway through one organisation.

Second, it should create links between stages of innovation. Government can support collaboration by distributing information and by supporting networks of innovators. Government can also step in if part of the ecosystem is weak; for example, by running demonstration projects, as long as the findings are then passed on to organisations in the next stage of the innovation pathway.

Third, providing standards for and access to infrastructure.

\subsubsection{Continuously Evaluate and Adapt}

Innovation is an uncertain and dynamic process. So, the question of whether to fund an innovation should be regularly evaluated to take into account new findings and changes in circumstances. Government is not always best placed to evaluate the success or failure of an innovation. All decision makers have biases, but government can be too biased as its decision-making power is often concentrated. Also, a policymaker's view of a technology may differ from that of end users. Ultimately, a technology will need to succeed in a market. So, as innovations mature, they should be increasingly exposed to market competition.

\subsubsection{Be Able to Fail Fast}

Government can often face a tension in that while it is economically best placed to bear the 
losses from risky innovations, it can face greater institutional barriers to accepting failure than the private sector. However, as prolonging failure comes at an increasing economic cost, it is best to fail fast before rising costs make failure inevitable. This requires more than constant evaluation. It also requires a political understanding that innovation is a dynamic, uncertain process, where failure can be a good outcome, and it may be best to fail fast.

\subsection{Innovation Policy: Case Study}

Many of the technologies leading the low-carbon transition were initially developed more than 40 years ago and may still require years to change the energy system materially. For example, mentions of solar energy peaked in 1982, but solar energy provided only $1.1 \%$ of global electricity in 2015 (Fig. 1).

To better illustrate the process of innovation and the associated challenges, four case studies will be referred to throughout. These case studies cover a range of innovations, including synthetic fuels in the USA in 1979; the Human Genome Project (HGP) in the USA in the 1990s; early wind turbine development in Europe and the USA in the 1970s; and bioethanol fuel in Brazil in 1975 (Table 2).

\subsubsection{Innovation Rate}

Innovation is a process of experimentation, so the rate of innovation depends on the nature and number of experiments that can be undertaken within the research budget. In broad terms, four factors characterise the process of experimentation and, therefore, the rate of innovation. These can be divided into two categories: frictions and capital characteristics. Frictions include: (i) complex processes: progressing through the many stages of innovation and experimentation, from $\mathrm{R} \& \mathrm{D}$ to market deployment, is an uncertain and lengthy process; and (ii) collaboration: combining interrelated technologies (clustering) or adjacent technologies (spillovers) requires collaboration, which can be difficult to achieve. Second, capital characteristics include: (i) capital intensity: the high upfront costs of minimum viable units limit the number of experiments that can take place within a budget; and (ii) capital longevity: a technology with a long lifespan cannot be repeated as quickly as one with a short lifespan.

\section{(1) Frictions}

The process of innovation is complex and uncertain. The innovation process comprises several stages, each with different characteristics. The outcome of innovation is very rarely known at the start of the process, and surprise is a

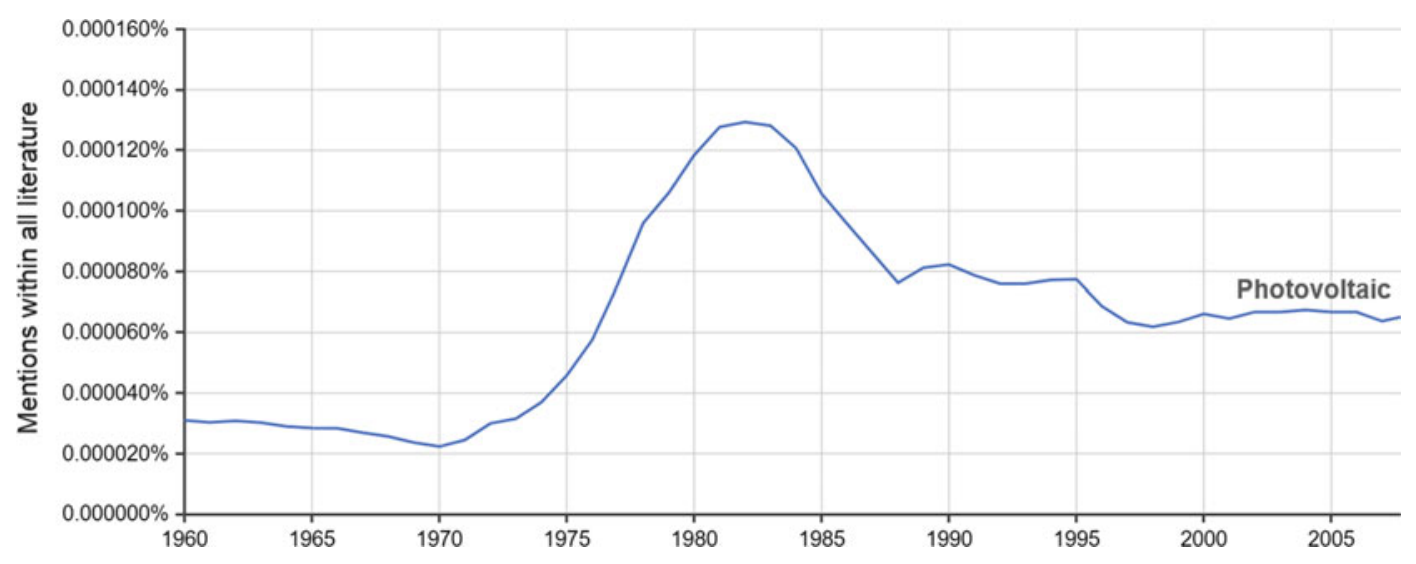

Fig. 1 Technology innovation can have long lead times. Source Google Ngram 
Table 2 The chosen case studies cover a range of interventions and learnings
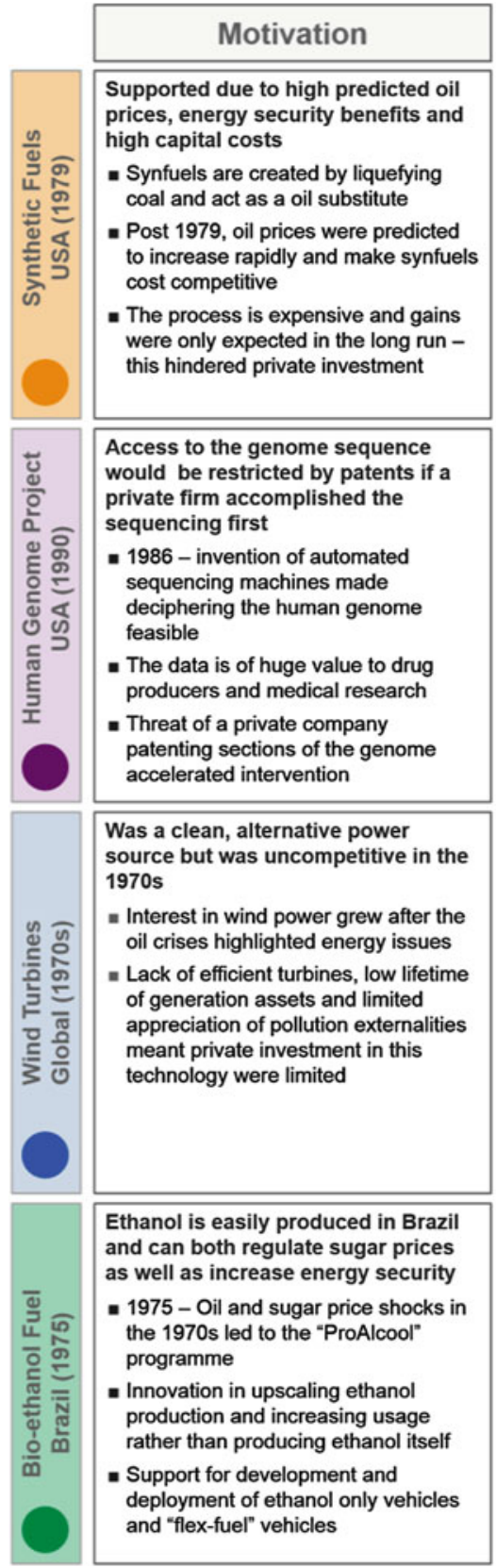

Access to the genome sequence would be restricted by patents if a private firm accomplished the sequencing first

- 1986 - invention of automated sequencing machines made deciphering the human genome feasible

- The data is of huge value to drug producers and medical research

- Threat of a private company patenting sections of the genome accelerated intervention

Was a clean, alternative power source but was uncompetitive in the 1970s

= Interest in wind power grew after the oil crises highlighted energy issues

- Lack of efficient turbines, low lifetime of generation assets and limited appreciation of pollution externalities meant private investment in this technology were limited

Source Vivid Economics

Ethanol is easily produced in Brazil and can both regulate sugar prices as well as increase energy security

- 1975 - Oil and sugar price shocks in the 1970 s led to the "ProAlcool" programme

- Innovation in upscaling ethanol production and increasing usage rather than producing ethanol itself

- Support for development and deployment of ethanol only vehicles and "flex-fuel" vehicles

\begin{tabular}{|l|}
\hline \multicolumn{1}{|c|}{ Intervention } \\
\hline R\&D support followed by large, \\
incentivised niche market \\
deployment \\
- Government provided research \\
funding in the 1950 s- 70 s, but low oil \\
prices limited development \\
- 1980-1986: large niche market \\
deployment supported by government \\
subsidies \\
- Goal of 0.5 million barrels by 1986 \\
and $\$ 12.2$ billion (1980 $\$$ ) initial \\
budget \\
\hline
\end{tabular}

\section{A government programme raced} against a private venture to complete the sequencing

- Government funding estimated at $\$ 5.6$ billion (2010\$)

- 1990 - Project officially begins with completion date of 2005

- 1998 - Celera Genomics begins sequencing, public effort intensified

- 2000 - Drafts announced, public programme is ahead by 3 days

- 2003 - Full release

\section{Different approaches by different} countries - Denmark regarded as the most successful

n US: large subsidy programme delivered capacity, but unreliable and led to market crash

- Denmark: focus on supporting small scale turbines, knowledge sharing and market support

- Germany: R\&D focus on large turbines, but no significant market support, hence little demand for unproven and unreliable technology

\section{Ethanol subsidies, agricultural R\&D} funds and support for ethanol vehicles at varying levels over time

- Mandatory fuel blending of ethanol with gasoline creates demand

- Incentivised supply with low interest loans and guaranteed prices

- Grants provided for agricultural research to increase crop yields

- 1986 - Guaranteed ethanol prices reduced below average cost of production due to oil price collapse

\begin{tabular}{|c|}
\hline Lessons \\
\hline $\begin{array}{l}\text { Shows the need for flexible goals } \\
\text { and policy in response to new } \\
\text { circumstances }\end{array}$ \\
\hline $\begin{array}{l}\text { - Oil prices already falling when niche } \\
\text { market deployment just begun }\end{array}$ \\
\hline $\begin{array}{l}\text { = } 1985 \text { - projects produce only } 2 \% \text { of } \\
1986 \text { targets }\end{array}$ \\
\hline $\begin{array}{l}=1986 \text { - Project cancelled, total cost of } \\
\$ 4.5 \text { billion }(2010 \$)\end{array}$ \\
\hline
\end{tabular}

There can be value in government replacing private sector funding, but the benefit to society must be clear

- The economic impact of the HGP to 2012 has been valued at $\$ 965$ billion

- For this style of intervention to be justifiable the project must have unequivocal benefits

- Argument that competition helped HGP come under budget and 2 years ahead of schedule

\section{There needs to be support across} stages and communication between agents for effective deployment

- Germany spent 5 times more on R\&D than Denmark up to 1990 but achieved no notable wind capacity.

- The Netherlands created a competitive market that discouraged knowledge sharing

- The US had a booming market driven by large subsidies, but a lack of standards hampered reliability and led a market crash

\section{Exposure to market forces drives} cost reductions and supporting technologies can be essential for success

- 1980 - beliefs of increasing oil prices meant no concentrated effort was made to improve efficiency

- Post 1986 - subsidies were rolled back, leading to cost reductions across the production chain

- Post 2004 - introduction of flex-fuel cars re-energises the programme fundamental characteristic of innovation. These are common issues that all technologies face, and there are various frictions. Misaligned economic incentives between investors and society give rise to additional issues. This occurs most prominently when externalities exist. Whenever an innovation has a positive externality that benefits a third party or creates a common good, it is unlikely that it will be fully appreciated by the private sector, as the social gains cannot be 
captured, leading to a suboptimal level of investment.

Governments have a key role in correcting these frictions and ensuring an optimal outcome is realised. The issues of misaligned incentives, the high risk of innovation, and changing parameters of investment along the innovation pathway are all frictions that can result in socially beneficial innovations not reaching market deployment. It is in governments' interests to help ease these frictions and help innovation deliver the best societal outcome possible.

\section{(2) Capital characteristics}

The capital intensity of an asset is the capital cost of developing a minimum viable commercial energy business. This will tend to be low for modular technologies, such as solar photovoltaic cells, and higher for technologies that need to be deployed at scale, such as nuclear power plants. High capital intensity leads to greater financial risk and a longer payback time. This can reduce demand; without sufficient demand an innovation will not be profitable, even if it is successfully developed. This in turn leads to less investment in innovation and slower innovation overall. Capital longevity is the useful lifetime of an asset - it can also reduce innovation by causing lower turnover rates, creating fewer opportunities to learn by doing, and generating less demand for new capital assets.

Power generation technologies generally have high capital intensity and long capital longevity, limiting the potential for experimentation and slowing deployment rates. Government can provide support to overcome these barriers. The case study of wind turbine development in the 1970s provides an example of this. In Germany, the emphasis was on developing very large turbines, which had a high capital intensity but strong economic potential. In Denmark, the government wanted to accelerate innovation in wind turbines and actively supported the development of smaller turbines. These smaller turbines were less complex than the large German turbines and the capital cost was lower. This lower complexity and greater number of opportunities to experiment reduced the risks that demonstration turbines would fail and accelerated the learning rate, which led to Denmark's faster deployment of wind power, establishing the industry rapidly with the minimum viable product.

Another key trend in energy is the transition towards decentralised energy, where technologies have smaller unit sizes. Since 2009, a period characterised by increased small-scale investment, even the major markets have generally seen increasing levels of investment. The lower capital intensity of decentralised energy is opening new demand avenues that increase adoption rates, creating the necessary signals for new innovation (Table 3 and Fig. 2).

\subsubsection{Innovation Pathway}

There are four stages that an innovation must pass through before it can be marketed: $R \& D$, demonstration, introduction into niche markets, and deployment. Different actors are present and the relevant types of support vary at each stage. In the early stages, funding and favourable loans are the most important factors. When a technology moves beyond demonstration, market creation policies, such as support infrastructure and public procurement, become the more common options for policy interventions (Fig. 3).

\section{(1) Challenges along the innovation pathway}

The changing characteristics of each of the four stages and fundamental market failures create challenges along the innovation process. The two main challenges that can hinder innovation are misaligned incentives between actors at each stage of innovation, and the increases in capital requirements and risk as projects advance along the innovation pathway.

First, misaligned incentives. Misaligned incentives can result in innovations with positive externalities being under-supported and socially inefficient technologies surviving. Misaligned incentives can lead to imitation, where near-identical products are deployed in the market, which is wasteful for society. Imitations arise when competing products are not interoperable because they follow different standards or formats. This can be less efficient than a common, 
Table 3 The example of renewable energy generation
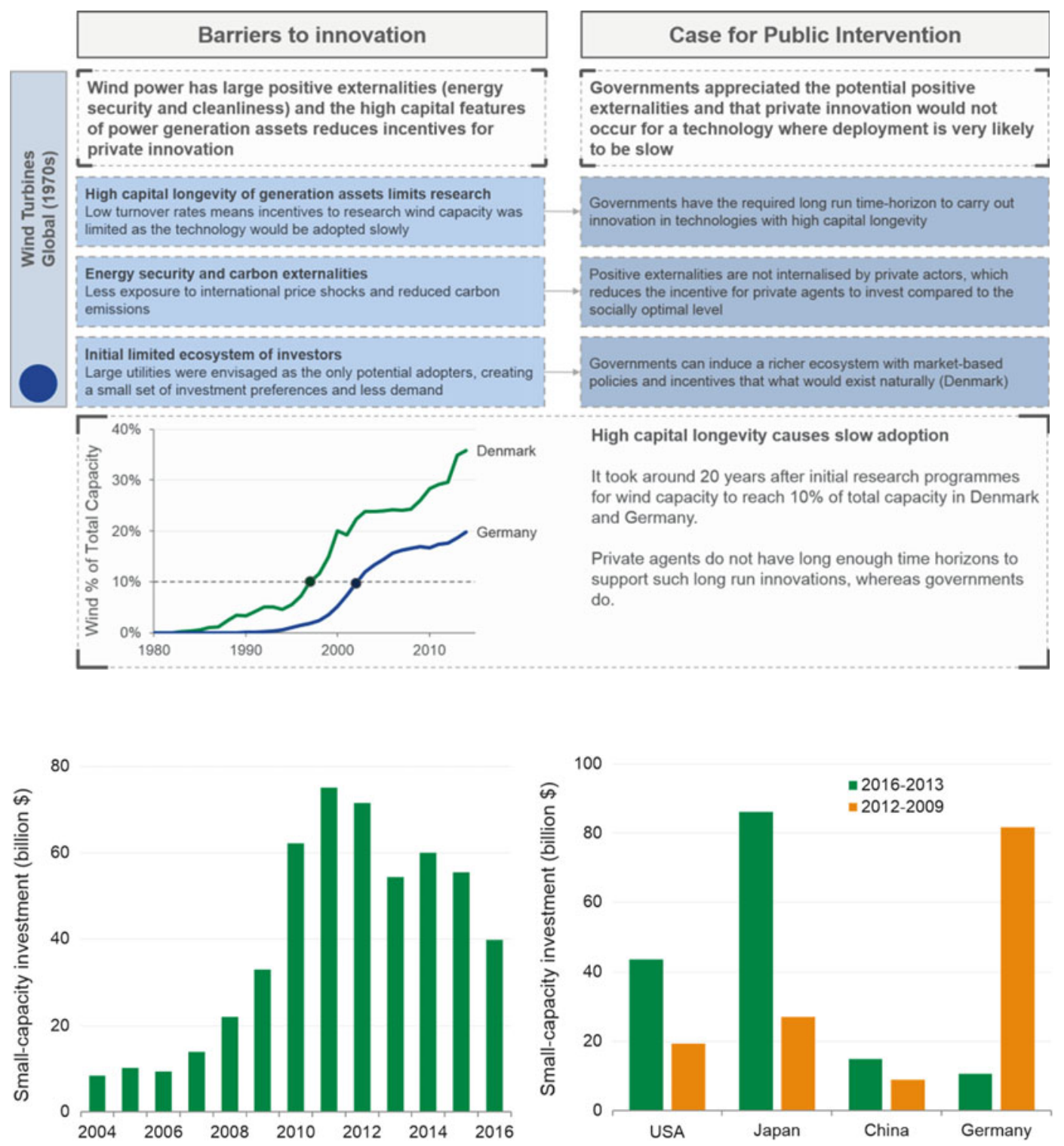

Fig. 2 Small-capacity investments. Note Small capacity is defined as roof-mounted solar PV cells with a total capacity of under $1 \mathrm{MW}$

interoperable system. The diversity of electric vehicle plug formats is an example.

However, active collaboration can arise should synergies exist. Ethanol fuel is a typical example. Ethanol fuel was heavily supported in Brazil, despite being more costly than imported oil due its positive externalities of better energy security and its potential to help regulate the domestic sugar market. This was achieved by creating demand through ethanol-petrol blending mandates, providing ethanol distribution infrastructure and supporting flexible fuel innovations (Table 4). 


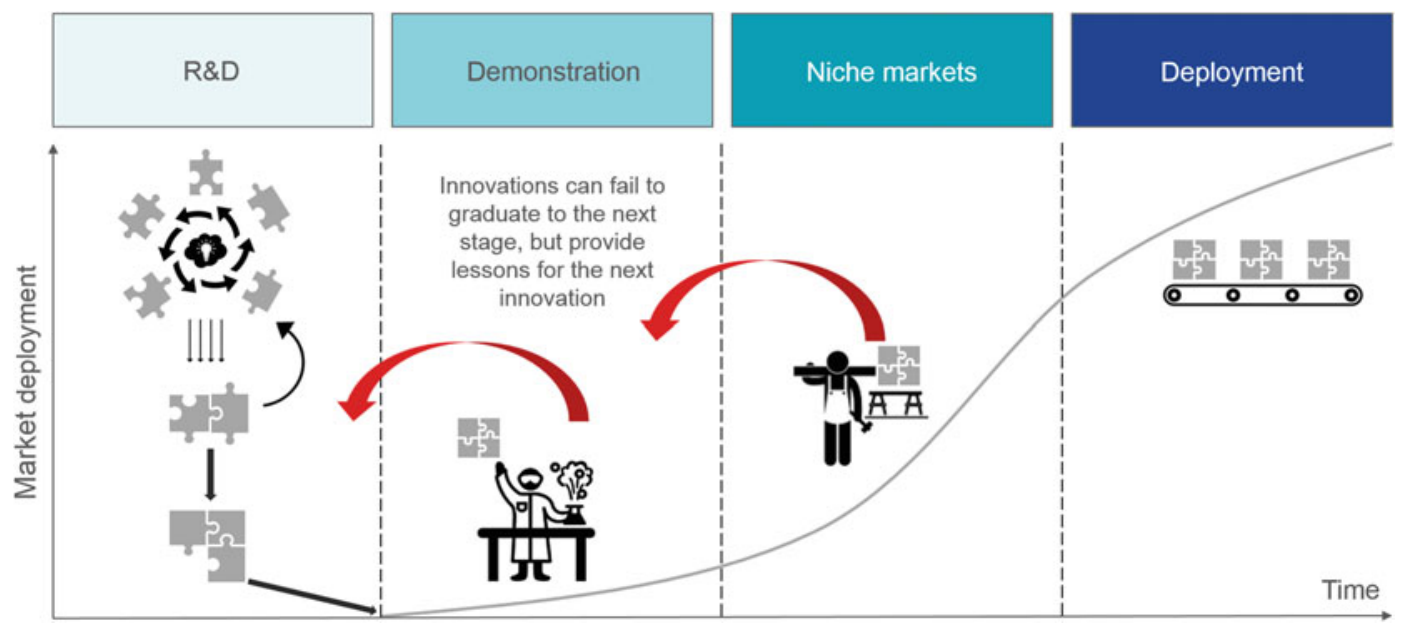

Fig. 3 Four stages of innovation pathway. Source Vivid Economics

Table 4 The example of ethanol fuel

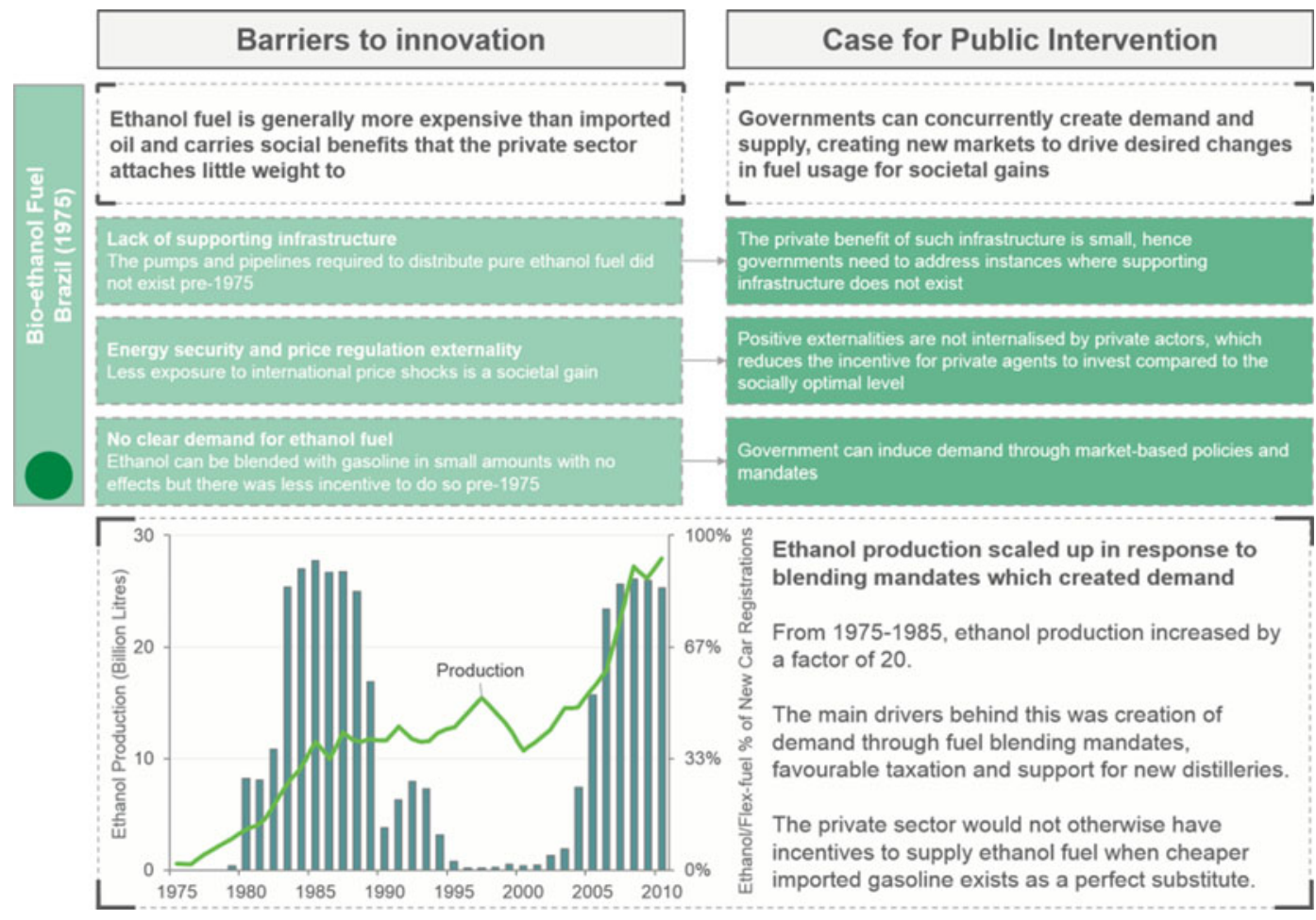

Second, changing capital requirements. Each stage of innovation is distinct and has its own level of risk and capital requirements. A broad range of investors, with different risk preferences and capital availability, will ensure there is adequate support at all stages of innovation. When there are no investors for all stages, innovations can fail to progress and be left stranded.

Take the Human Genome Project (HGP), for example. The level of funding increased over time as the project advanced. In 1988, \$54 million was provided, much of it from public funds, 
Table 5 The example of the Human Genome Project

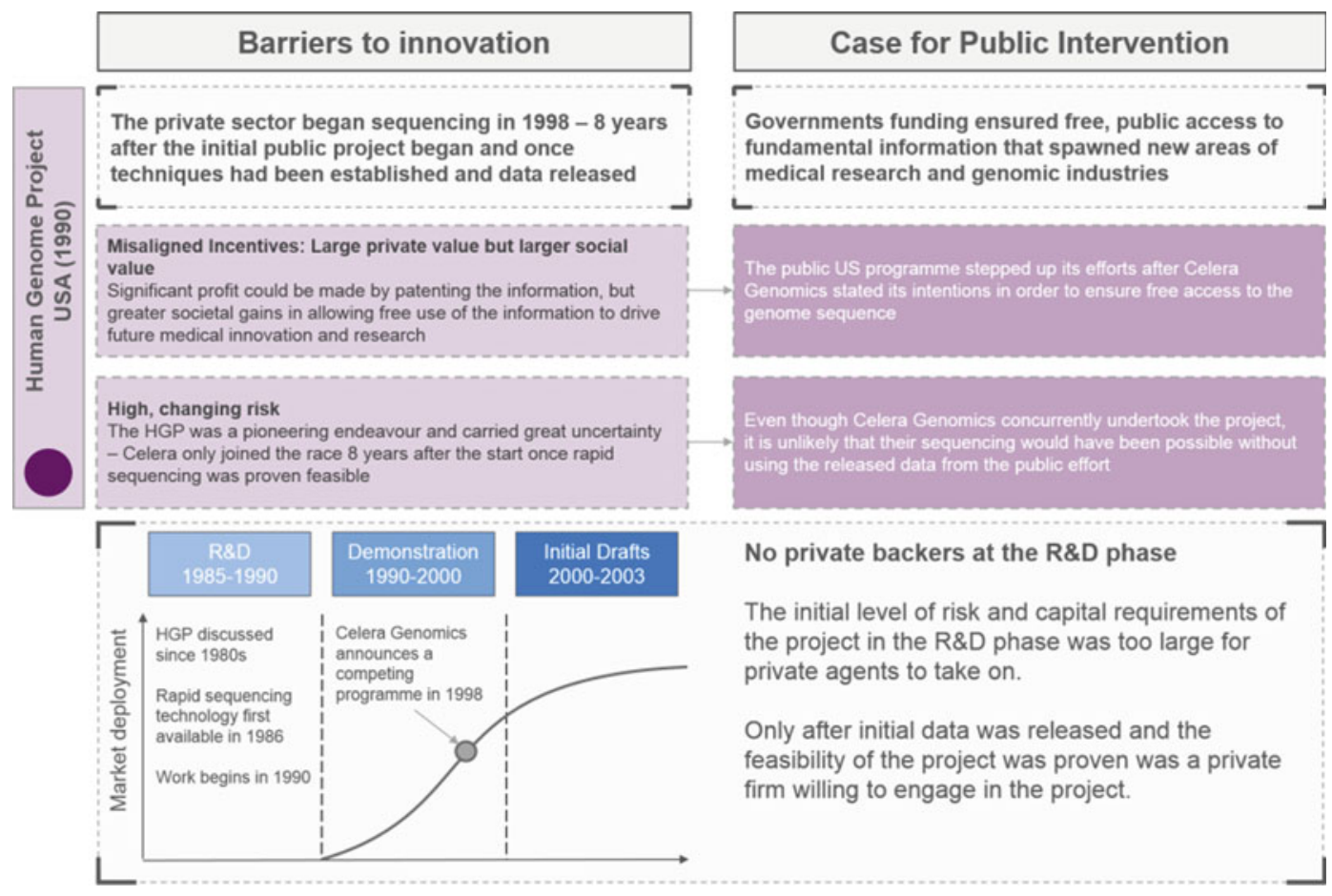

which rose to $\$ 290$ million in 1992 . In the final two years of the project (2002-03), average yearly funding stood at $\$ 550$ million, 10 times that of 1988. A private company, Celera Genomics, announced its intention to decode the genome in 1998. By that time data had already been released and the feasibility of the project proven. The lower risk attracted private investment that was not available during the initial, higher risk phase of the project (Table 5).

\section{(2) Risk and reward along the innovation pathway}

A project having high risk or requiring high capital is not immediately a sign of a bad investment if the expected return is high - the balance between risk, capital and return should be considered. Increasing capital requirements and increasing risk are both undesirable from the point of view of an investor. Hence, for a certain level of risk and capital investment, an appropriate level of return is expected.
Take synthetic fuels (synfuels) in the USA, for example. The expected private return of a synfuel plant is tied to the expected future oil price, as the two commodities are near-perfect substitutes. Given the volatility of oil prices and the generally poor accuracy of previous price forecasts, synfuels carry a degree of risk that, when coupled with the high level of capital at stake, is unattractive for private investors. Public agents have longer time horizons. This, and the desire to increase energy security played a large role in convincing the US government to support a large-scale synfuel project (Table 6).

\section{(3) Summary}

The role of a government or public body is to minimise these challenges of misaligned incentives and changing capital requirements via monetary and non-monetary interventions. Governments have a range of policy options available to them to address these challenges and improve the social outcomes of innovation. 
Table 6 The example of synfuels

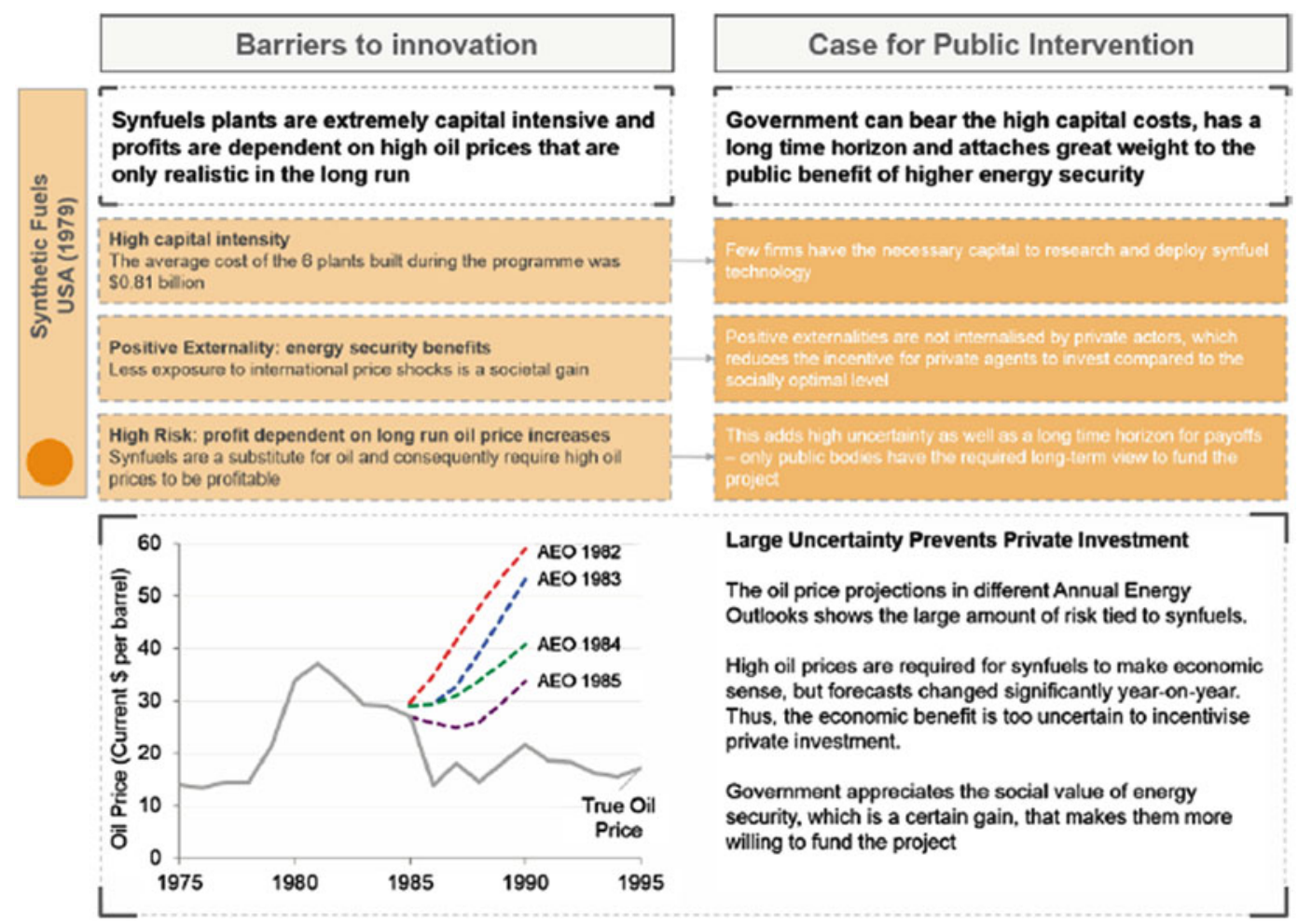

Note AEO = U.S. Energy Information Administration (EIA), Annual Energy Outlook.

These can range from acting directly as an investor with monetary interventions to compensate for: (i) a limited ecosystem of investors or; (ii) addressing misaligned incentives that prevent investment in socially beneficial projects. They can also include non-monetary interventions, such as fostering a culture of innovation investment, ensuring strong links exist between all relevant agents in the ecosystem, and providing market support via mid-stream investment choices and operating standards.

\subsubsection{Intervention Policy}

(1) Defining success and assessing policy interventions

It is clear that the inefficiencies within innovation create a role for public intervention. However, what defines the success or failure of such intervention is less clear. Innovation is an experimental process: while discovering viable technologies is one side of this, the unpredictability of the outcome means that it is not certain that the choice of support technologies is correct. There are also valuable spillovers and lessons learned, even when technologies do not reach the general market. Consequently, defining success purely on the final, direct output or widespread use of a new technology does not create the optimal environment for successful innovation. Hence, exploring both the dynamic pathway of innovation, as well as the final outcome, is the key to understanding and assessing public intervention.

First, assessing innovation with hindsight. Once an innovation project has been completed, its final outcome is defined by the realised social value of the innovation and whether the technology reached deployment. Hindsight removes uncertainty and reveals both the true social value of the innovation project and the extent to which it was supported. High social value innovations 


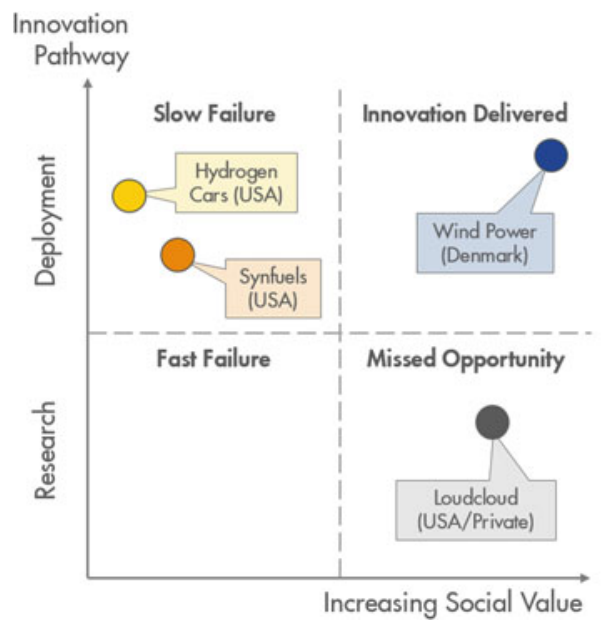

Hydrogen Cars (USA, 1990s-00s) - Back to Research Support programme first announced in 2003

Very limited take up or infrastructure development and programme was halted in 2009

Synfuels (USA, 1980s) - Programme Scrapped

Formal tender for synfuel projects in 1980

Funding halted in 1986 following oil price crash - $\$ 4.5$ billion was spent

Wind Power (Denmark, 1979-2015) - Innovation Delivered

Wind capacity represents $36 \%$ of total capacity and generates $41 \%$ of total power

LoudCloud (USA/Private, 1999-2001) - Missed Opportunity

Founded in 1999, it was one of the first firms to offer cloud computing as a service

Changed focus to data centre operations after the dot-com bubble due to security concerns around cloud systems

Fig. 4 Innovations can be assessed on their final outcome

generally create a new or improved service or have significant positive externalities (Fig. 4).

From this viewpoint, projects that ended with deployment of a high-value innovation or in fast failure should be seen as desirable. The complexities of the innovation system mean that it is not possible to identify high social value projects with certainty at the start of the innovation process. Once it is realised that a project will not be beneficial enough to justify further support, it should be stopped to minimise wasted resources. The final deployment of a technology is only one stage of what is often a lengthy process that is characterised by high uncertainty. Even if a particular innovation is eventually defined as a slow failure, the pathway that led to that outcome should be analysed to avoid unfairly characterising it as the result of poor public interventions, when it is possible that exogenous shocks rather than poor policy are to blame.

Second, the dynamic process of supporting innovation. Successful public policy is more than achieving a final result of fast failure or technology deployment - the actions taken throughout the whole innovation process should be evaluated. How governments support changes in response to unexpected circumstances is a key part of successful intervention and can easily be overlooked if the dynamic nature of intervention is not fully appreciated.
Sensible responses to shocks are requiredsupport should be withdrawn or further action taken whenever long-term changes in circumstances demand it. When analysing interventions dynamically, the actions taken in response to changing circumstances and shocks carry more weight than the final outcome. Hence, it needs to be understood that not only is failure a feature of innovation, but also that failure of advanced innovations is acceptable under certain circumstances. Wind power was developed in several countries during the 1970s and provides a comparison of how different types of policies at different stages result in diverging outcomes (Fig. 5).

Dynamic intervention along the innovation pathway should ensure that the appropriate market signals at each stage are not suppressed by excessively favourable policies. It is important that an appropriate level of exposure to competition is maintained at each stage of innovation to make full use of market signals in guiding intervention decisions. Providing overly generous budgets or limited exposure to competing technologies late on in the innovation pathway prevents the viability of a technology from being tested, making fair appraisal more difficult (Fig. 6).

It is also important that these signals are interpreted in the correct fashion and that 


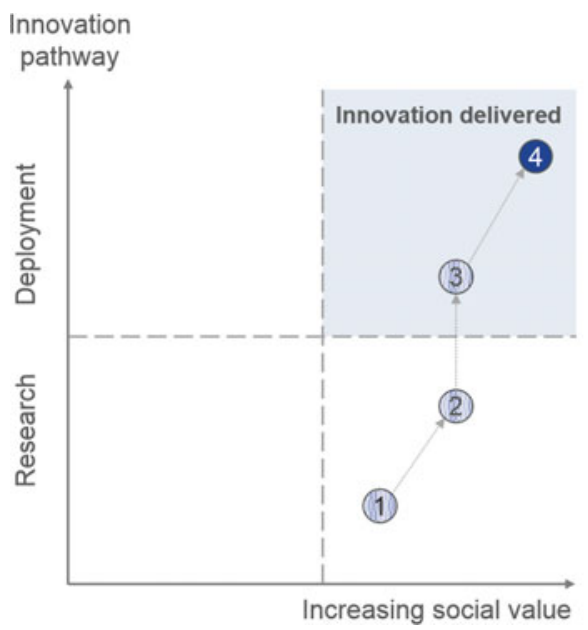

1) Wind generation has been researched since the 19th century

- Given greater importance following oil crises in 1970s.

2) 1970s: Establishment of research and formal standards

- Riso National Laboratory - researched and certified turbines.

- Allowed for effective knowledge-sharing between users, manufacturers and researchers.

- Focus on small, reliable designs with upscaling later.

3) 1980s: Niche market creation and support

- Subsidy system, favourable taxes and supporting policies (wind mapping, grid connection regulations etc.).

- "Wind cooperatives" encouraged where communities shared a wind turbine - increased dissemination.

4) 1990s-2000s: Scaling up

- Increase in wind's \% of total generation from $3 \%$ in 1995 to $18 \%$ in 2005 and then to $41 \%$ in 2014 .

- Consistent development of larger capacity turbines.

Fig. 5 Denmark successfully delivered innovation in wind power

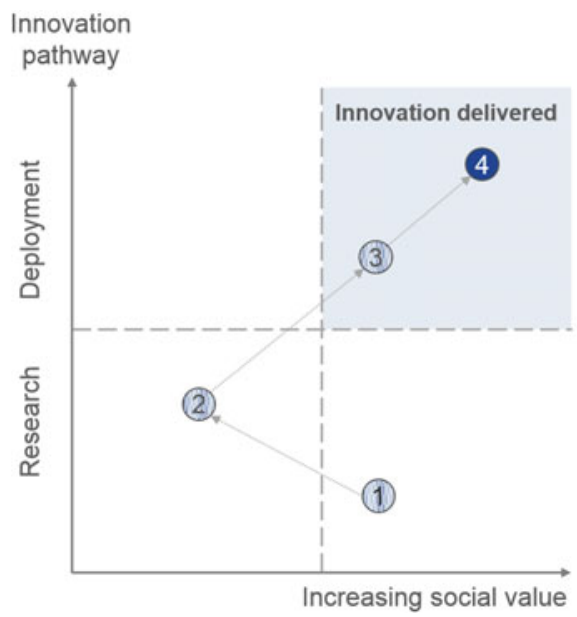

1) Wind generation has been researched since the 19th century

- Given greater importance following oil crises in 1970s.

2) 1970s-1980: Research and initial use of large-scale turbines

- R\&D focus on large turbines without strong market support.

- Low demand/incentives for unproven, unreliable technology.

- 1983 - Growian turbine: 3MW, largest in the world but only 420 hours operation over 5 years.

3) 1990s: Switch to Danish model

- Manufactured turbines based on the Danish designs - benefited from technology transfer and knowledge spill-overs.

- 1990 - feed-in tariffs and priority dispatch introduced for renewables.

4) 2000s: Renewable subsidy programme bolstered

- Adoption of more comprehensive subsidy programme - wind now accounts for $20 \%$ of total capacity.

- Gradual lowering of subsidies and switch to tender system for new installations.

Fig. 6 Germany eventually successfully deployed wind capacity

hypotheses are tested and updated rationally over time. Even when signals are obvious, biases or misaligned incentives can skew expectations and lead to irrational beliefs. A part of the solution is to ensure that successful innovation intervention is not defined solely by the output, such as delivering technologies to the deployment stage (Fig. 7).

The deployment of synfuel capacity in the USA illustrates the issues that can arise when targets are rigid and not updated with new information. The US synfuel project committed itself to developing capacity that would no longer be viable in the intended time frame, rather than shifting the focus to developing alternative technologies that would be more valuable in the new context (Table 7).

\section{(2) Monetary interventions}

One of the avenues of innovation policy is to provide direct monetary support. This action can be in the form of funding assistance, where the government enters the innovation market as a funder of primary $R \& D$, or as an investor; or it can be non-direct assistance to help improve the investment ecosystem, create long-term incentives for investment and develop mid-stream 


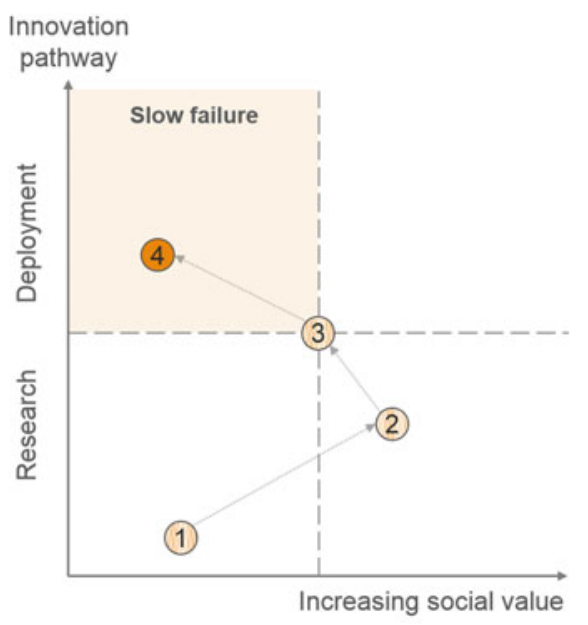

1) 1925-1956: Synfuel research first conducted

- Pilot plants shut down in 1950s due to high costs, but new research was carried out in the late 60 s.

2) 1970s: Oil crisis, research into synfuel production technologies

- Brent spot price rises from $\$ 14$ to $\$ 37$ from 1978-1981.

- ElA predicts trend to continue ( $\$ 60$ by 1990 s), making synfuels viable for the future.

3) 1980-1985: Synfuel production target set, 6 contracts awarded

- President Carter criticised for lack of response to oil crisis - potential nudge to implement large-scale project.

- 500,000 barrels per day target by 1987 - no consideration for oil prices in this target.

- Oil prices peaked in 1980, fell each year thereafter but tenders still consistently issued - lack of flexibility.

4) 1986: Oil price crash and termination of the project

- Oil fell to $\$ 14$ in 1986 .

- Less than $2 \%$ of 500,000 barrel target produced.

- Total expenditure of $\$ 4.5$ billion (2010\$).

Fig. 7 Synfuels in the USA ended as a slow failure. Note EIA = U.S. Energy Information Administration

Table 7 A different approach may have led to the programme being better received

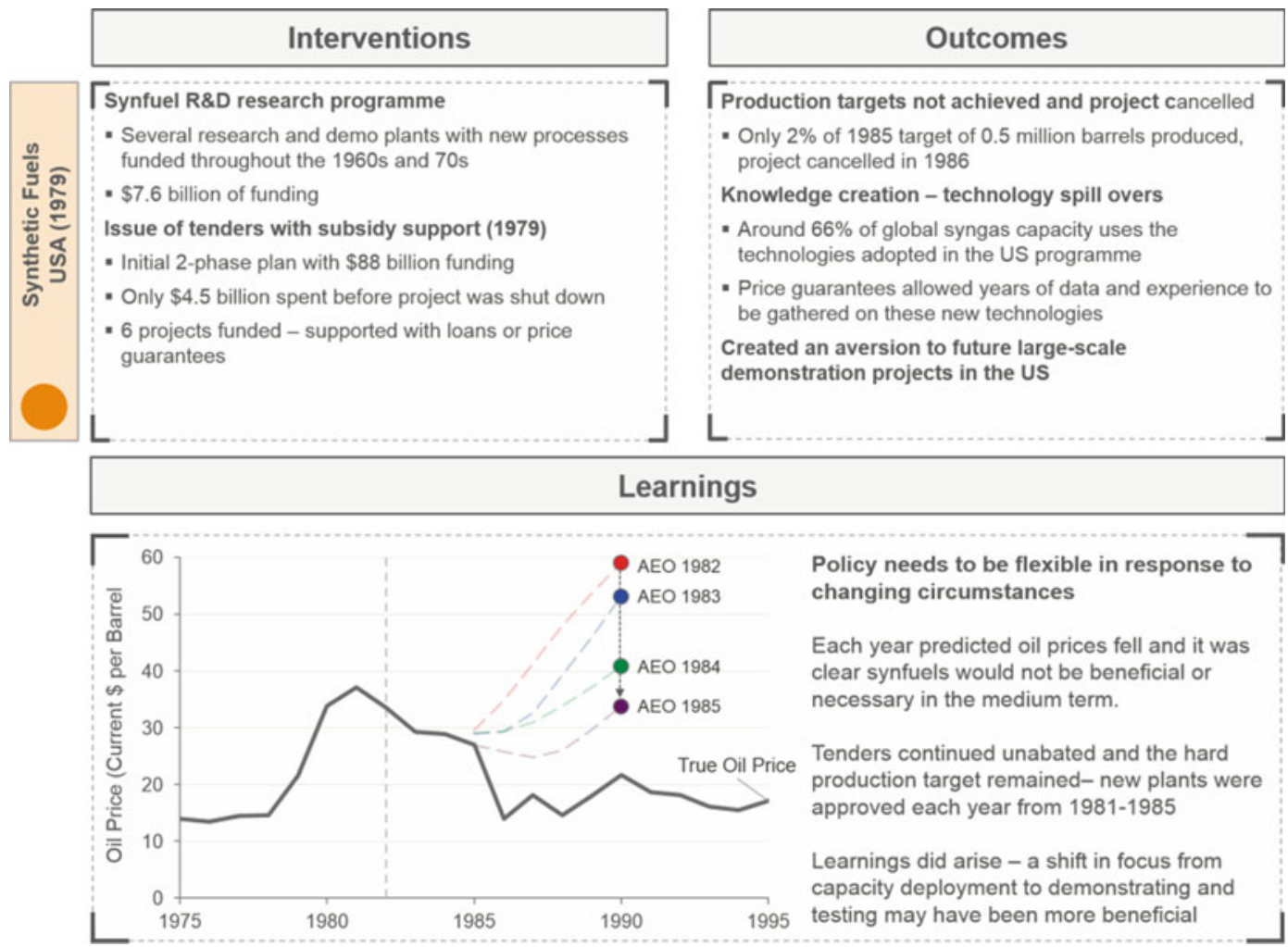

Note $\mathrm{AEO}=$ U.S. Energy Information Administration, Annual Energy Outlook.

areas. Doing so can ensure that socially beneficial innovations receive funding when externalities skew the incentives of investment.
Governments should use the fact that they have far longer time-horizons than any private investor, which makes them uniquely suited to support 
projects where success is highly uncertain, benefits will be widespread, adoption rates will be slow and the payback period long. Energy generation technologies generally fit into this category and can be an obvious area for government intervention to have a beneficial impact.

Government can grant private innovators exclusive access to revenue streams as an alternative to direct government financing. Private investment in innovation can be motivated if there is sufficient profit to be made. For example, patents grant a time-limited monopoly for an innovation, which has been used very effectively in pharmaceutical development. In sectors with regulated prices, such as electricity networks, price formulas can be adjusted to incentivise innovation. In highly competitive sectors, government can support innovation by offering to buy a new product at a higher than normal price if the new product meets innovative specifications. The use of public procurement to reward innovation has been effective in, for example, energy efficiency (Table 8).

The government should also intervene when ecosystems of investors are too limited to support good innovations through all stages. Governments can intervene and prevent a good innovation from entering the Valley of Death. However, innovations can also fail to be funded along the pathway because the innovation is simply not good. There is an asymmetric information issue facing governments, who should be pragmatic and not overestimate their ability to discern which innovations are valuable and which are not. However, trade-offs exist for government between picking winners and allowing market forces to determine innovation.

The efficiency of ethanol fuel production in Brazil increased sharply once subsidies were reduced, demonstrating the benefits of market forces and the potential consequences of picking winners. It was never intended to be a cheaper

Table 8 The Human Genome Project also has opportunities to succeed
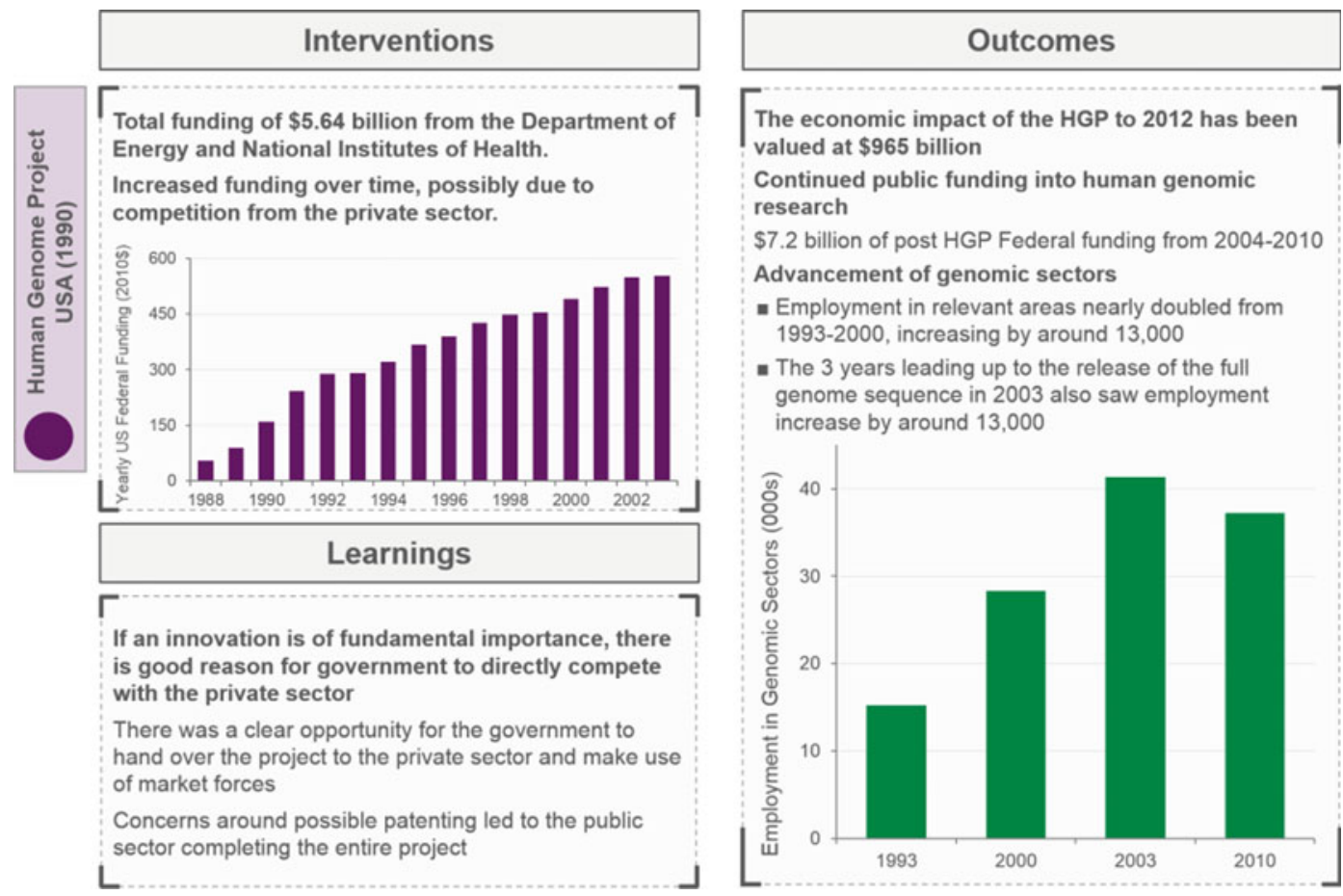
alternative to petrol when the project first started in 1975, but predictions of future high oil prices led to sustained generous subsidies and a belief that ethanol would become competitive over time. After economic difficulties in 1985 and the oil price crash in 1986 guaranteed prices for ethanol were reduced, causing ethanol production to fall for the first time since the programme began. It was only following this reduction in guaranteed prices that ethanol production efficiency began to increase rapidly and consistently. From 1985-95, production costs fell by $45 \%$, with average costs over that period nearly $40 \%$ lower than in 1975 85. Efficiency gains were obtained throughout the entire supply chain, from improving agricultural yields to using larger distilling units and turning waste by-products into heat and energy. This potential for improvement was likely present in the 1970s but did not arise due to overlyprotective government policies (Table 9).

\section{(3) Non-monetary interventions}

A more diverse range of private investors can mitigate the issues arising from a transition along the innovation pathway, as well as the inherent uncertainty of innovation. Cultivating a culture of innovation investment and encouraging more agents to participate facilitates the matching of projects with investors. This helps to resolve the

Table 9 A reduction in subsidies led to increases in the efficiency of ethanol production in Brazil

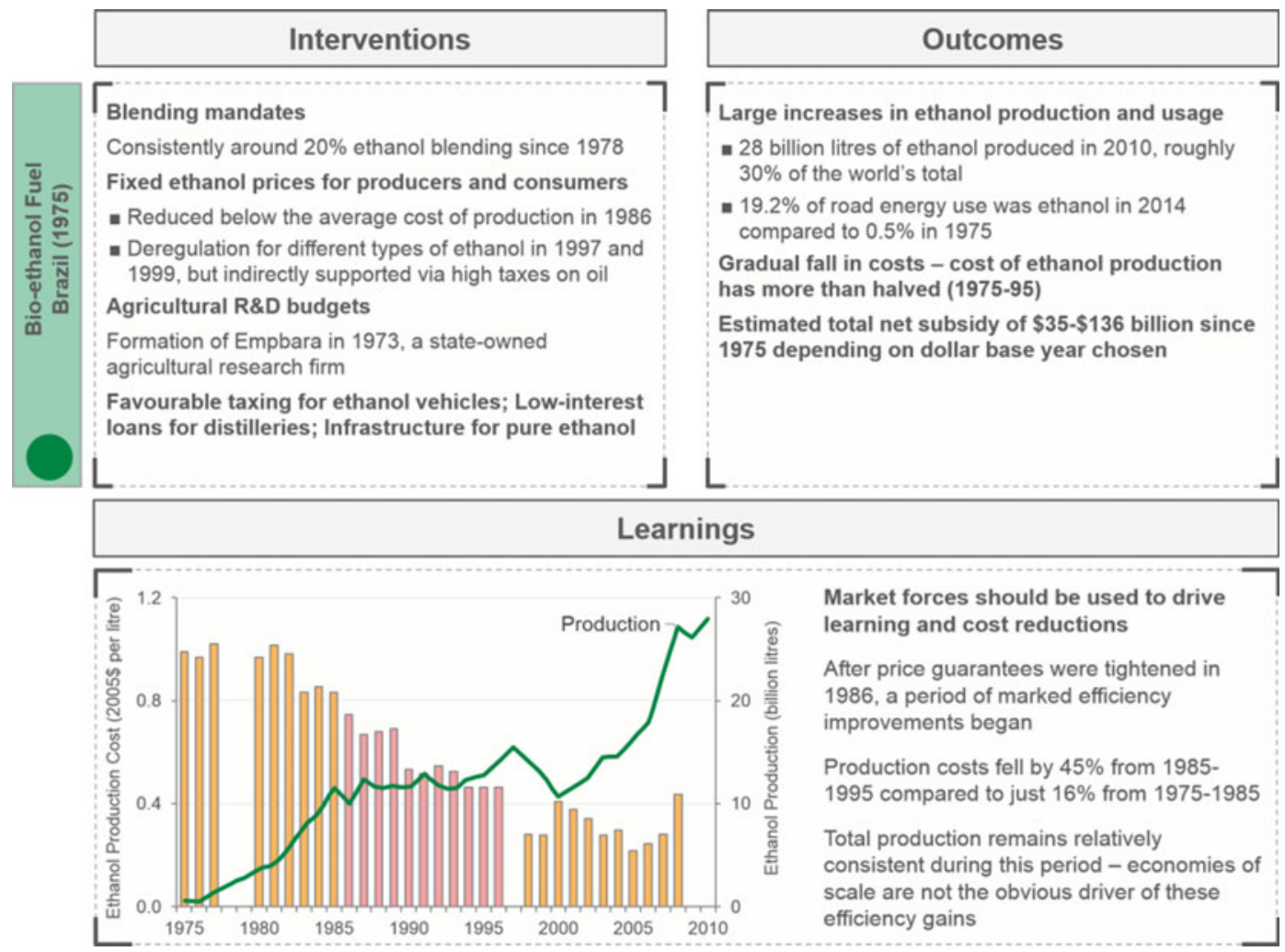


friction of changing capital requirements and risk across stages of the innovation pathway.

Ensuring strong links between different agents and investors eases the transfer of projects between stages and potentially generates benefits from technology clustering and spillovers. Better links between agents help mitigate issues of information asymmetry between investors and make it easier for an innovation to be passed to a more suitable party as it progresses along the pathway. Strong links between agents can also encourage collaboration across sectors, leading to spillovers where a technology is used for a role it was not originally intended for. Both clustering and spillovers have the potential to increase the avenues of use for an innovation, leading to larger impacts from the technology and increased incentives for innovation. A way in which this can be done is by designating institutions to set standards and collect research to encourage knowledge-sharing and collaboration between agents. Reliability is a vital factor for new technologies. Establishing non-profit institutions to develop standards would be a prudent step to avoid similar losses of confidence.

The contrast between the Danish and German experience with wind turbine research and deployment shows the importance of holistic support and the impact of non-monetary interventions. The Riso National Laboratory for Sustainable Energy in Denmark was tasked with developing a certification process for wind turbines and with providing large-scale turbine testing facilities and performing R\&D activities. Riso's role allowed it to coordinate interactions between agents in industry, policy and research and to provide technical assistance to manufacturers when required. Denmark also provided strong market support policies, encouraging the adoption of wind power by a wide range of agents. Germany had a heavy R\&D focus in the 1980s and a lack of proper consideration for reliability and other measures of support for the initial deployment phase of wind power. Finally, Denmark's adoption and use of wind power has far outpaced Germany's, despite a far smaller R\&D spend (Table 10).

\section{Major Factors Influencing Global Energy Technology Development and Their Trends}

History shows that there are many factors that can influence energy technology development. Some are constant throughout time, such as striving to raise the quality of life. Others are specific to a certain period, such as the discovery of new geological resources, awareness of the need to protect the environment, the spreading influence of other technologies, and accidental events.

\subsection{Major Factors Influencing Global Energy Technology Development}

The major factors that influence energy technology development in our time are:

\section{(1) Deep integration of digital and intelligent technologies in the energy sector}

The global financial crisis undoubtedly brought tremendous shocks to the international economy. As World Bank data indicates, global GDP in 2009 reported negative growth for the first time since the1960s. ${ }^{5}$ From a positive perspective, however, people realised that the development and wide deployment of digital and intelligent technologies are very likely to generate game-changing impacts on production and living.

In recent years, new concepts identifying a new industrial revolution have emerged. The most important include:

First, Industry 4.0. This concept explains that human society has passed through three industrial revolutions, characterised by the steam engine, electricity, and electronics and information technology (IT) respectively. The world is now entering the fourth industrial revolution,

\footnotetext{
${ }^{5}$ This impact remains. As the World Bank data indicates, from 2009 to 2015 , global GDP grew from $\$ 63.12$ trillion to $\$ 75.24$ trillion (calculated in $2010 \$$ ), up $2.97 \%$ annually. In comparison, from 2002-08, global GDP grew from $\$ 51.95$ trillion to $\$ 64.22$ trillion, up $3.6 \%$ annually.
} 
Table 10 Comparison between Demark and Germany on wind turbine development

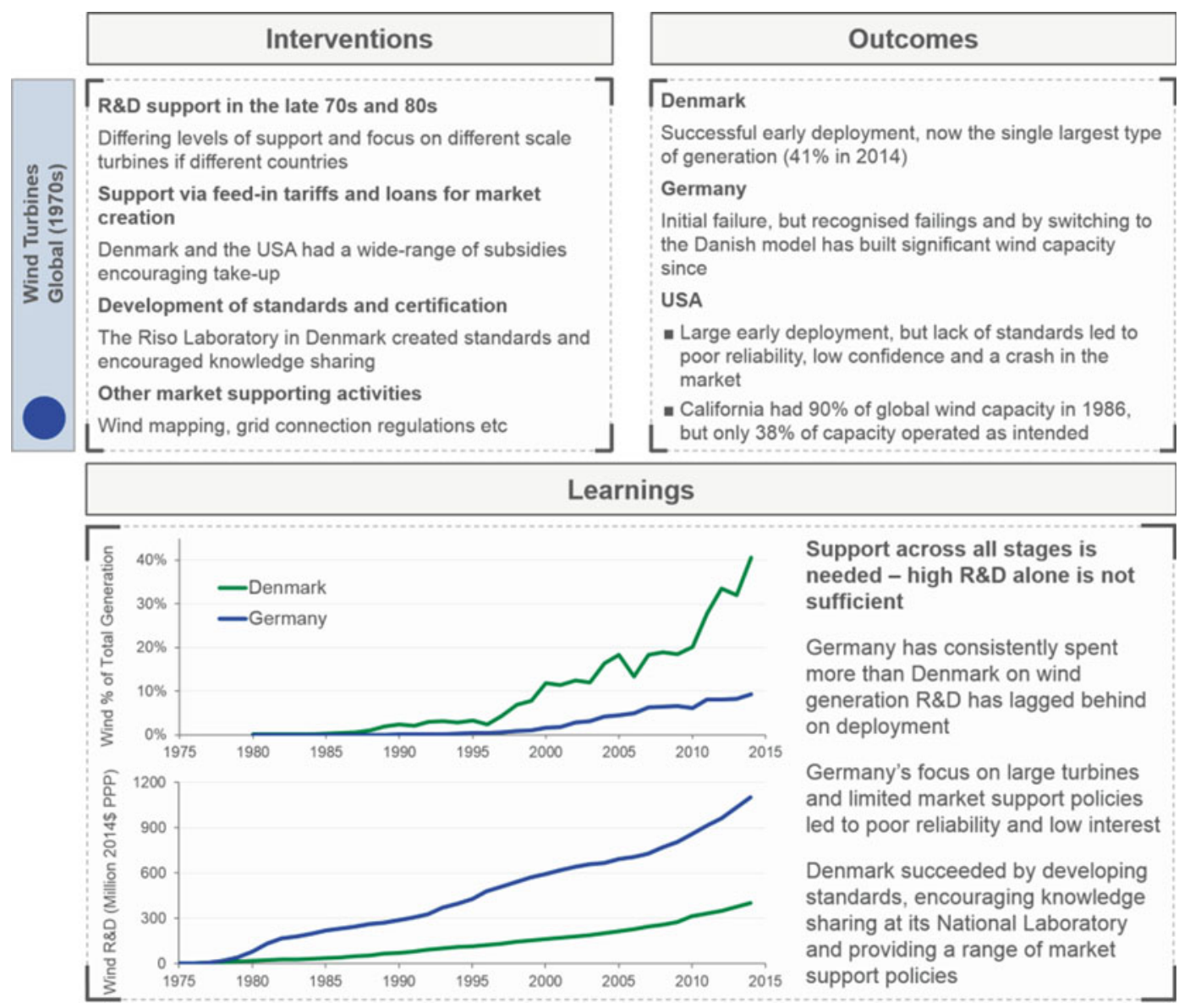

Note PPP $=$ purchasing power parity.

which comprises several components, including cyber-physical systems like smart grids and autonomous vehicles, the Internet of things and cloud computing. Industry 4.0 will have a huge impact on global manufacturing and society.

Second, the industrial Internet of things. In this concept, the countless machines, equipment, facilities and system networks in manufacturing and industry are integrated with computing, information and communications technologies to create a new industrial Internet revolution. The essence of the industrial Internet of things (IIoT) comprises three elements - intelligent machines, advanced analytics and people. The impacts of IIoT are not limited to industry, but also span transport, healthcare and government. It is projected that by 2025 , the IIoT can affect $50 \%$ of global economic volume, equivalent to about $\$ 82$ trillion. According to GE, the IIoT is a direct response to the scarcity of energy resources.

Third, the New Industrial Revolution (NIR). At the 2016 G20 Summit in Hangzhou, China, the G20 New Industrial Revolution Action Plan was released. It says, among other things, that "the ongoing industrial revolution characterised by the intelligent interconnectedness of people, machine and resources driven by the convergence of Next Generation Information Technology and advanced manufacturing, is increasingly blurring the boundary between the physical and 
the digital world and between industry and services, and presents countless opportunities to harness modern technologies for pursuing enhanced economic growth with the potential for more efficient and environmentally friendly processes". And, "The NIR has the potential to improve productivity and competitiveness, reduce energy and resource consumption, and hence to protect the environment and increase resource efficiency and effectiveness".

Deep integration of digital and intelligent technologies in the energy sector generates significant impacts on energy technology development. First, it drives the development and deployment of advanced technologies like energy efficiency management and smart grids. The International Telecommunication Union estimates that information and communications technology (ICT) could reduce global carbon emissions by $15-40 \%$ and cut energy use in industry to a fifth of what it is today. Second, it improves the life cycle efficiency of most existing energy technologies, making them greener. For instance, by using virtual drilling digital technology Shell reduced its drilling costs in Argentina from \$15 million to \$5.4 million.

\subsection{Global Energy Consumption Will Continue to Grow}

According to BP, during 1965-2016, global energy consumption grew by a factor of 2.56 , from 3,730 Mtoe to 13,276 Mtoe. However, this growth was quite unbalanced-the total energy consumption of OECD countries more than doubled from 2,641 Mtoe to 5,529 Mtoe, while that of non-OECD countries grew from 1,089 Mtoe to 7,747 Mtoe, increasing by a factor of 6.11. In 2007, the total energy consumption of non-OECD countries exceeded that of OECD countries for the first time, and the gap between them continued to widen. There are several reasons for this. For OECD countries, it is mainly due to their entering post-industrialism and achieving significant improvements in energy efficiency; for non-OECD countries, it mainly results from their rapid industrialisation (Fig. 8).
Given that many emerging countries will start to industrialise in the near future, and developing economies will intensify their industrialisation, global energy consumption is projected to continue to grow. According to the United Nations, there were 56 industrialised economies, ${ }^{6} 31$ emerging industrial economies and 78 developing economies in 2015. The industrialisation process in these emerging and developing countries is characterised by energy intensity.

As some research indicates, global energy consumption is projected to increase from 575 quadrillion Btu in 2015 to 663 quadrillion Btu in 2030 and 736 quadrillion Btu in 2040. Energy consumption in OECD countries will remain stable, but due to rapid economic growth, significant population increase and greater access to energy markets, non-OECD countries will contribute most of the growth in global energy consumption. This trend is relatively stable and consistent (Fig. 9).

By region, among non-OECD countries, Asia shows the most obvious energy consumption growth. During 2015-40, the energy consumption in non-OECD Asian countries will increase by $51 \%$. Driven by rapid population growth and abundant domestic energy resources, the African and Middle East countries will also see growth in energy consumption. In comparison, thanks to the improved energy efficiency of new technologies, OECD countries will see modest growth in total energy consumption (Fig. 10).

By industry, the total energy consumption in energy-intensive manufacturing and non-energyintensive manufacturing will maintain fairly fast growth.

\footnotetext{
${ }^{6}$ As defined by the United Nations Industrial Development Organization (UNIDO), economies can be divided into "industrialized economies", "emerging industrial economies" and "developing economies" by the adjusted manufacturing added value per capita. If an economy's adjusted manufacturing added value per capita is more than $\$ 2,500$ or GDP per capita more than $\$ 20,000$ (measured at purchasing power parity), it is an "industrialized economy". If an economy's adjusted manufacturing added value per capita is $\$ 1,000-2,500$ or its share in global manufacturing added value higher than $0.5 \%$, it is an "emerging industrial economy". The rest are considered "developing economies".
} 


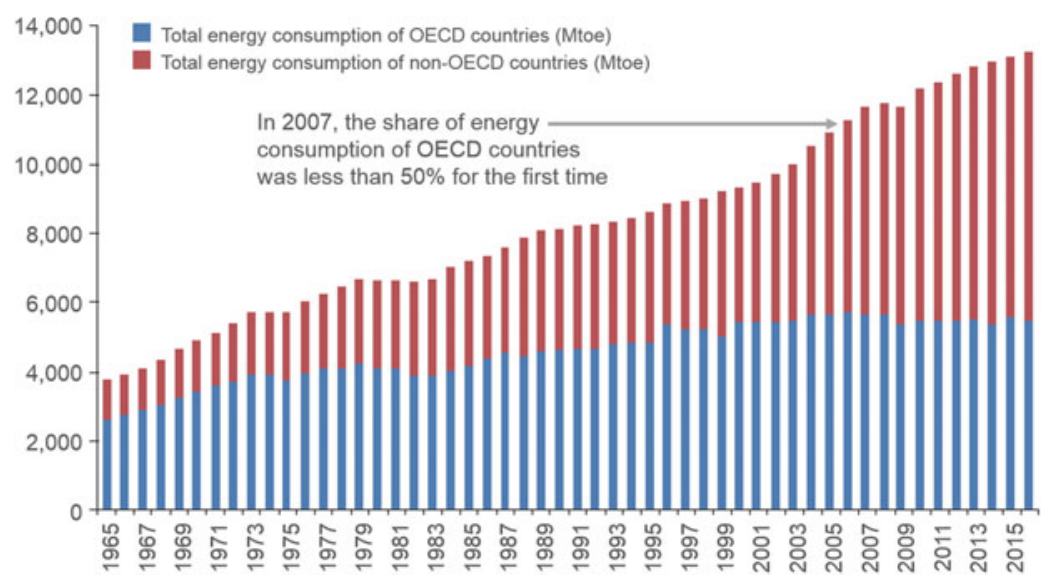

Fig. 8 Changes in total energy consumption of OECD and non-OECD countries (1965-2016). Source BP

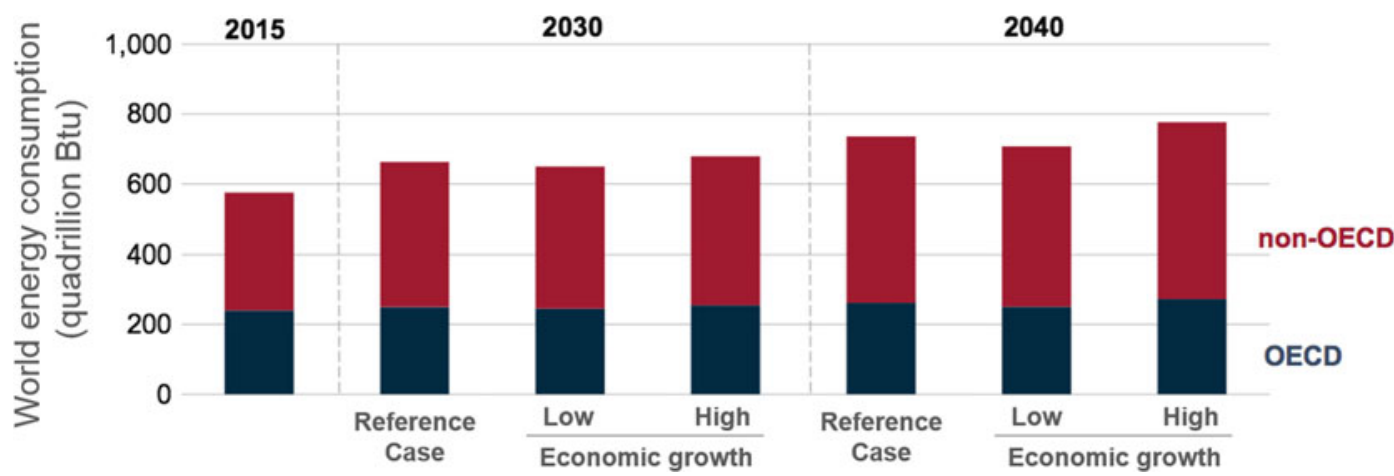

Fig. 9 World energy consumption in three economic growth cases (2015, 2030 and 2040). Source U.S. Energy Information Administration

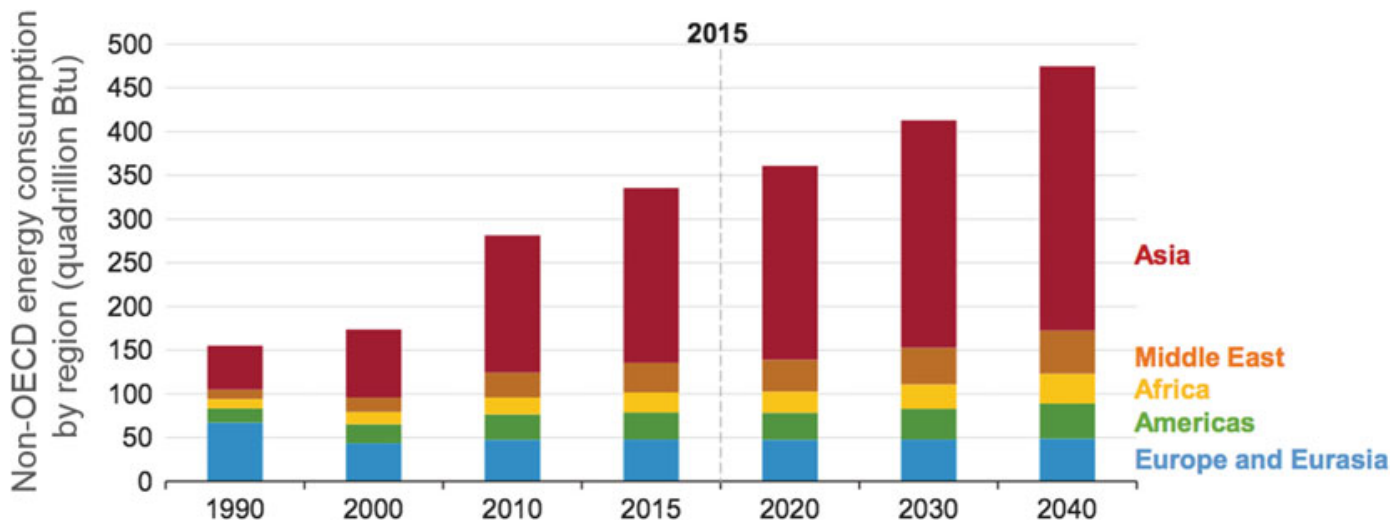

Fig. 10 Energy consumption by region. Source U.S. Energy Information Administration 


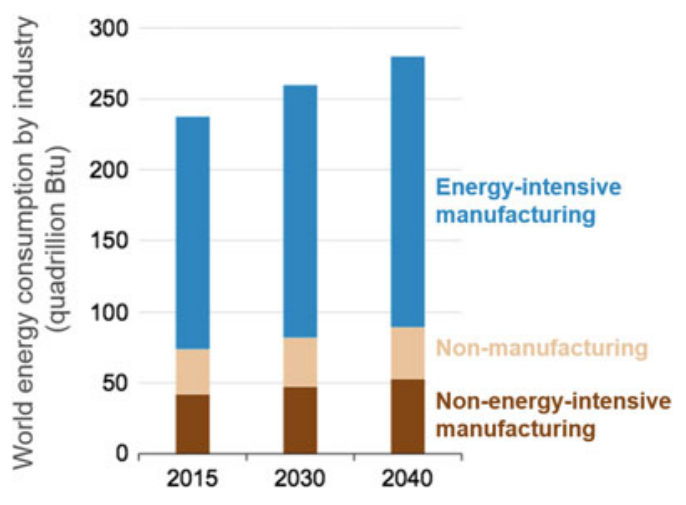

Fig. 11 World energy consumption by industry. Source U.S. Energy Information Administration

Such growth trends have varied impacts on global energy transition and technology development. On the one hand, this provides market space for development and deployment of many new energy technologies, and positively drives energy technology innovations. On the other hand, conventional energy forms like coal and oil will continue to play a significant role for a long time, so the energy transition cannot be achieved overnight and shifts between different energy forms will remain for a long time (Fig. 11).

\subsection{Great Uncertainty in Global Collaborations to Combat Climate Change}

Climate change represents a unique challenge in the present age. Currently, there is plenty of evidence that human activities have significant impacts on the climate; failure to make change may result in catastrophic consequences. As related data show, the number of published papers that reject the conclusion that climate change is caused by human factors is insignificant.

In recent years, major countries have taken action to combat climate change. In December 2015, nearly 200 ratifying parties of the United Nations Framework Convention on Climate Change (UNFCCC) agreed on the Paris Agreement at the 2015 Paris Climate Conference (COP $21)$. This was the second legally binding climate deal following the Kyoto Protocol of 1997. Taking effect in November 2016, the Paris Agreement is a milestone in the shared commitment to deliver the long-term goal of keeping the increase in global average temperature to well below $2^{\circ} \mathrm{C}$ above pre-industrial levels, and even limit the increase to $1.5^{\circ} \mathrm{C}$. The 2030 Agenda for Sustainable Development, effective as of January 2016, put forward 17 sustainable development goals (SDGs) and 169 targets. Several of the SDGs are closely connected with energy production, transmission and consumption, as well as with addressing climate change. They include "ensure access to affordable, reliable, sustainable and modern energy for all"; "build a resilient infrastructure, promote inclusive and sustainable industrialisation and foster innovation"; "make cities and human settlements inclusive, safe, resilient and sustainable"; "ensure sustainable consumption and production patterns"; and "take urgent action to combat climate change and its impacts". In addition, some countries are proactively promoting carbon taxes and carbon trading systems to help combat climate change at national level.

There are several misperceptions about climate change, as pointed out by the World Bank: (i) climate change is a slow process, but individuals' position on climate change is based on recent experience and observations; (ii) ideology and social loyalty affect how people accept information on climate change; (iii) people tend to ignore or fail to fully understand information expressed as a probability number; (iv) people focus more on current issues than on future ones, but the worst impacts of climate change may not be evident for years; (v) some risks (like climate change) are unclear, and people tend to avoid taking action when facing unknown situations; and (vi) when deciding how to share responsibilities to combat climate change, individuals and organisations tend to follow their own interests.

The intensity and pace of global actions to address climate change impact significantly the future direction of energy technology innovation. Many actions aiming to combat climate change will eventually result in the development and deployment of new and low-carbon energy 
technologies. Whether the world can reach a more binding and powerful action plan to address climate change will directly affect progress of the shift to new energy technologies.

\subsection{International Competition Based on Resource Endowments}

The energy technology revolution will eventually generate new and important sectors, which will impact international competition. As a result, all major countries value highly the energy technology revolution. In recent years, the major energy powers have introduced an array of regulations, policies and actions to accelerate energy technology innovation, striving to occupy a vantage point and sharpen national competitiveness. This competition between nations spurs innovation across a diverse range of energy technologies.

The USA under the Obama presidency introduced the All-of-the-Above Energy Strategy, which identified science and energy as a top priority. The strategy aimed to create a complete energy technology innovation value chain, from basic research to final market solutions. It focused on accelerating low-carbon and clean energy technology development-especially solar power and fourth generation and modular nuclear power - and energy efficiency. The USA has also established many new energy $R \& D$ and innovation platforms, including the Advanced Research Projects Agency-Energy (ARPA-E) and the Energy Innovation Center to support game-changing energy technology development and effectively integrate resources from companies, universities and research institutions.

Japan has unveiled strategic plans, including the Energy and Environment Innovation Strategy for 2030, which sets guidelines for the country's energy security, economic efficiency, environmental protection and safety. The strategy supports the development of nuclear energy, energy efficiency, renewables, new energy storage technologies, and advanced coal utilisation technologies like integrated gasification combined cycle (IGCC) and integrated gasification fuel cell cycle. After the Fukushima disaster in 2011, Japan updated its Basic Energy Plan and adjusted its priorities for energy technology development, including speeding up the development of renewables and reducing the share of nuclear energy. The Energy and Environment Technology Innovation Strategy targets for 2030 and 2050 include increased R\&D investment to ensure Japan's global leadership in new energy technologies and applications.

The EU has developed strategic plans, including the Energy Roadmap 2050, to highlight the principal role of renewable energy in energy supply and develop ideas for smart grids, carbon capture and storage (CCS), nuclear fusion and energy efficiency. In September 2015, the EU announced the Integrated Strategic Energy Technology Plan (ISET-Plan) to drive the transition to a low-carbon energy system. Similarly, after announcing its nuclear phase-out plan, Germany has prioritised renewable energy and energy efficiency improvement technologies, and generally adjusted its policies for energy technology development and deployment.

Competition between countries can also be reflected in many specific fields. For example, major car manufacturing countries are accelerating the development of new energy vehicles. The USA adopted the EV Everywhere Grand Challenge Blueprint and the Intelligent Transportation System Strategic Plan 2015-19 to promote the development of new energy vehicles and an intelligent transport system. The EU introduced the Strategic Innovation Plan 2020 and the Intelligent Transport System Development Plan to promote a low-carbon and intelligent transport system. Japan's Next-Generation Vehicle Strategy 2010 and Automobile Industry Strategy 2014 prioritise the development of new energy and fuel-efficient vehicles. In China, the Action Plan for Innovation in the Energy Technology Revolution (2016-30) prioritises electric vehicle energy storage and wireless charging technologies in the energy technology revolution. 


\subsection{Uncertainty Due to Accidents and Changes in Government}

Natural disasters and changes in government can have a significant impact on energy technology development.

A case in point was the release of radioactive materials at the Fukushima nuclear power plant in Japan, one of the world's largest nuclear power stations, after it was severely damaged by an earthquake and tsunami in 2011. This drew the world's attention to nuclear power generation, with some countries deciding to phase out nuclear power in favour of other energy technologies. Such policies directly affect the technology structure of the energy revolution.

A change of government can bring uncertainty to energy technology cooperation within and between countries. For instance, after taking office President Trump announced the "America First" Energy Plan, which promotes the development of domestic conventional energy resources-including shale gas, oil, natural gas and coal. He also withdrew the USA from the Paris Agreement. Such policies not only affect energy technology development domestically, they also bring uncertainty to global energy technology collaboration.

\subsection{The Potential of Promotional Regulation Cannot Be Ignored}

As understanding of people's thinking and behaviour deepens, governments and non-governmental organisations (NGOs) can play an important role in changing energy consumption patterns and driving business model innovation. This also impacts the direction in which energy technology innovation proceeds.

Take Opower, a US-based company, that was acquired by Oracle in 2016. The company sends a home energy report to its residential customers, showing the difference in energy consumption between their home and those of neighbours. This comparison reduces home energy consumption by
2 percentage points, a result equivalent to raising the electricity tariff by $11-20 \%$. The main reason for this success is that people value the constraint that social norms have on their behaviour. When energy saving is considered a social norm, people tend to follow the norm, once they understand the context (Fig. 12).

In addition to the effects of social norms, interventions like information disclosure and setting proper default options can deliver very good results.

\section{New Trends in Global Energy Technology}

There are two main trends in global energy technology development.

\subsection{Decoupling of Economic Growth from Energy Consumption}

Annual growth in global energy consumption has been lower than economic growth in recent decades. This is due to improvements in energy technologies and energy efficiency and the impact of digitalisation. During 1965-2015, the average growth rate of global GDP (in 2010 \$) was $3.33 \%$, while that of global primary energy use was $2.54 \%$. Some countries like Denmark and states like California achieved economic growth without increasing energy consumption (Fig. 13).

Looking at future trends, energy intensity in developed economies will continue to decline. Rapidly growing developing countries like the BRICS nations (Brazil, Russia, India, China and South Africa) will shift to less energy-intensive industrial structures, resulting in significant decreases in energy intensity. Although the Middle East and Africa will register population and economic growth, their declining energy intensity will help reduce their energy consumption intensity (energy use per square foot per year) (Fig. 14).

As future economic growth will be driven mainly by productivity increases rather than by energy investment, the decoupling of economic 


\section{UtilityCo}

BOB SMITH

$\triangle 14$ NIDOLET MAU GO 6

MINNEAPOLS, MN 55401

\section{Home Energy Report}

Account numbor. 1234567800

Roport pericd: 11/00/00 - 12/00/00

Wo aroploasod to provido this porsonalized roport to holp you savo oncrgy.

The purpose of the roport is to:

- Provido information

- Holp you track your progross

- Sharo onorgy officioncy tips

This information and more is available at UtilityCo.com/reports

Last Month Neighbor Comparison | You used 19\% MORE energy then your efficient neighbors.

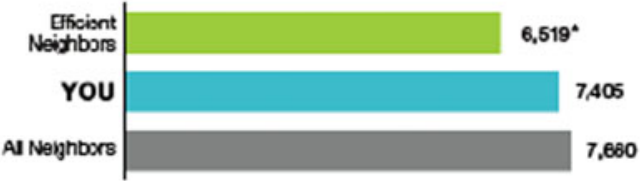

- This energy index 0 mbines ebcticity $(\mathrm{kWh})$ and notural g8s (therms) ints a single messuremert.

Who are your

Neighbors?

\section{all Neigtbors}

Aporoximately 100 cocupied neerby homes thet are sinils in siz to yours $(\mathrm{mg} 2,100 \mathrm{sq}$ in) and have bcth decricty and natural ges senvice
Eflicient Neighbors

Thy rrost efficiert 20 percert for the

"Al Neiggoors" grap

\section{Last Winter Heating Comparison}

Last whter, you used $37 \%$ more energy on heating than your neighbors.

2008

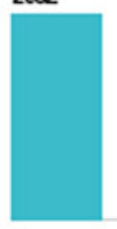

Your

Heating
Best ways to save this winter:

Loweryour thermostat before leaving home

Adjusting by $10^{\circ}$ can save $10 \%$ on heating costs.

Seal air leaks around windows and doors

Use caulk or weethersiripoing to eiminate cold drafts.

Let sunshine in for warmth

Open binds during the day to capture free heet.

For more spa, veit Utial tyco som/rep ort:

Fig. 12 UtilityCo's home energy report provides energy-efficiency comparisons between households

growth and energy consumption will become more evident. According to the International Energy Agency's World Energy Outlook 2017, in the next two decades the world economy will maintain an annual growth rate of $3.4 \%$, with $75 \%$ of that growth driven by productivity improvements, reducing energy intensity even more (Fig. 15). 


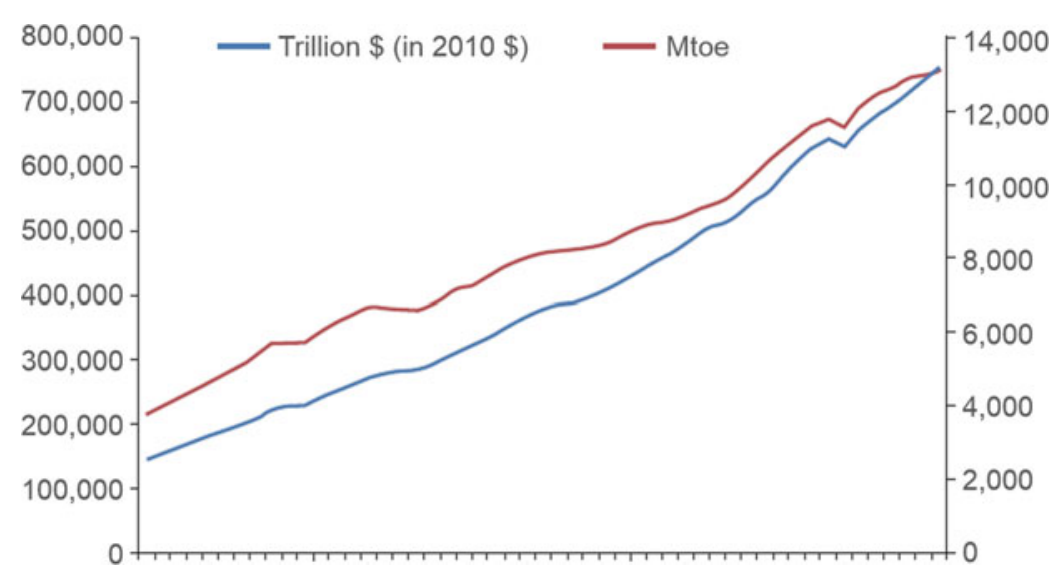

Fig. 13 Global economic growth versus energy consumption (1965-2015). Source BP and World Bank

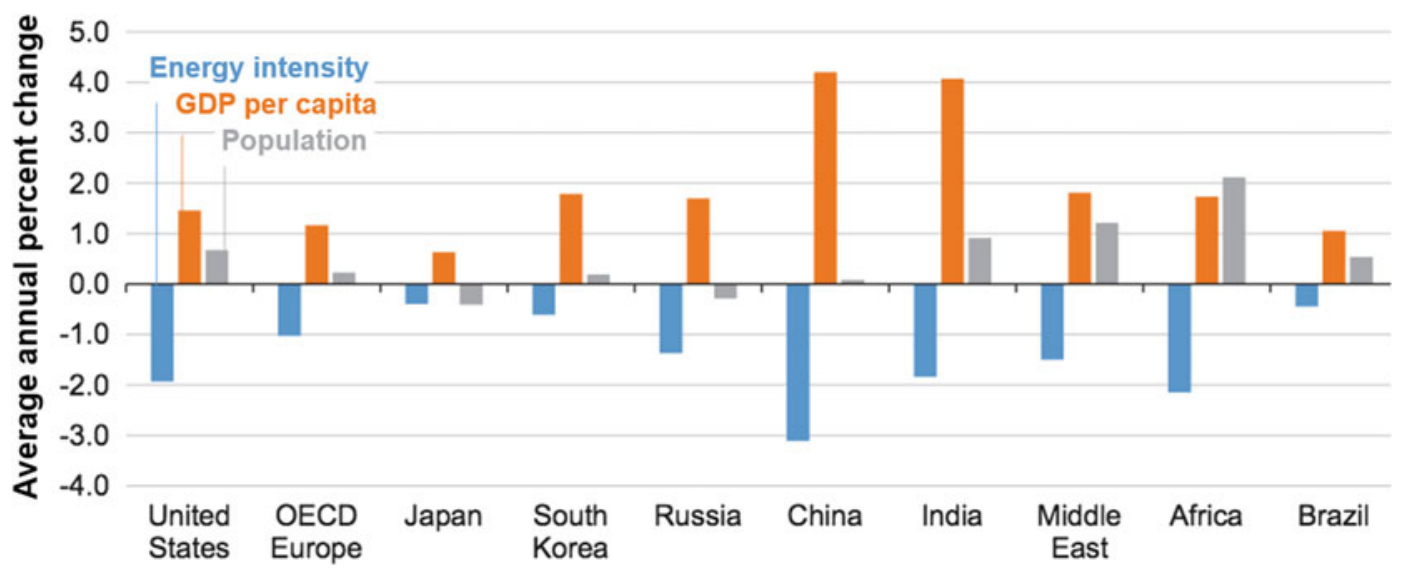

Fig. 14 Energy intensity, per capita GDP and population growth in selected regions (2015-40). Source U.S. Energy Information Administration

\subsection{Breakthroughs in Clean Energy Technologies}

Breakthroughs in energy technologies are an important part of the technology revolution and industrial change. Some clean energy technologies are already at the demonstration stage or in wide deployment and are gradually changing the global energy landscape. The International Energy Agency has projected that by 2030 renewable energy will exceed coal-fired power generation to become the largest power source globally; and by 2040, renewable power will account for more than half of all new generating capacity. In the fuel sector, biofuels and electricity have already replaced oil to some extent.

Clean and low-carbon energy technologies will make a big difference in driving the global energy transition. The $760^{\circ} \mathrm{C}$ ultra-supercritical power generation technology can improve the net energy efficiency of a coal-fired power plant by 14 percentage points and reduce $\mathrm{CO}_{2}$ emissions by $30 \%$. Technologies like integrated gasification combined cycle (IGCC), carbon capture and storage (CCS) and pressurised oxygen-enriched combustion are advancing rapidly. H-class heavy-duty gas turbines have been commercialised, and the net efficiency of combined cycle 


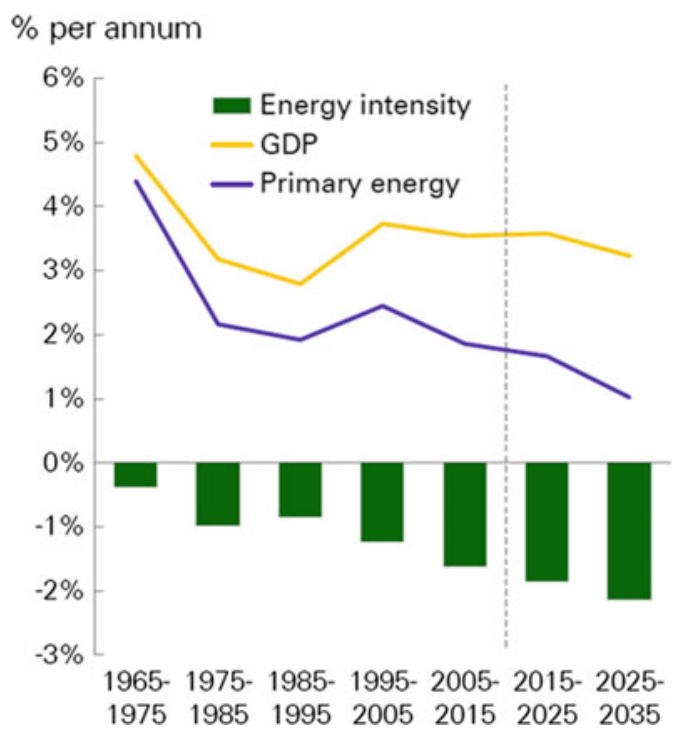

Fig. 15 Growth in GDP and primary energy (2015-35). Source BP

power plants improved. Breakthroughs in unconventional oil and gas exploration and development technologies have been made, primarily in North America. As a result, shale gas and tight oil have become new sources of growth in oil and gas. Offshore oil and gas exploration and development is continuously prospecting ever greater depths. China has made big breakthroughs in shale gas exploration and development and in coalbed methane exploration, capacity building and $\mathrm{R} \& \mathrm{D}$, which are reflected in the rapid growth of reserves and production.

Third-generation nuclear power technology has become mainstream in China's newly built generating units. Fourth-generation nuclear technology has reached the commercial-scale demonstration stage in a new plant featuring secure, modular high-temperature gas-cooled reactors. Renewable energy is gradually becoming an important source of newly added power capacity. The efficiency of solar photovoltaic (PV) systems continuously improves, and the average amortised cost of utility-scale and residential PV systems continues to fall. Concentrated solar power is under demonstration at scale. Wind power technology is maturing and the cost of producing biomass energy is falling.
Pumped storage power generation and lead-acid battery technologies have matured; and thermal storage, compressed-air energy storage (CAES), capacitor and super-capacitor technologies have either matured or are being commercialised. At the end of 2016, ownership of new energy vehicles exceeded 2 million units, and the demonstration of hydrogen-powered vehicles was progressing.

\section{International Experience}

The purpose of this section is to draw on international experience to identify the conditions for innovative technology to be successfully applied at a scale that revolutionises an energy system. Technologies that achieve high levels of deployment benefit from a supporting set of factors in addition to their technological development. We reviewed the different patterns of innovation and deployment across 12 technologies. This review suggests that four conditions are often collectively sufficient for successful deployment: technology innovation to a level such that deployment is feasible, supply of the inputs the technology requires, demand for the services the technology provides, and markets that incentivise deployment.

Most of the largest G20 energy revolutions were triggered by economic growth, energy security concerns, new market incentives or shocks, rather than by technology. Energy revolutions since the 1970s have been primarily triggered by the following factors. First, supply factors, including local energy resources (the greatest revolutions occur at the extremes, either when resources are abundant or when they are extremely scarce); and connectivity to energy trade (this is often a case of making the necessary investment in import or export capacity). Second, demand factors including rapid economic growth (this is a major driver of revolutions because investment is available and required during periods of growth, and energy networks are built, which, once built, lock-in energy choices), consumer demand for energy services and cleaner and more flexible fuels (this can trigger rapid 
change, especially when accompanied by new low-cost supplies of energy). Third, market factors including liberalised energy markets (this is especially important when the fundamental cost structures of new or incumbent energy sources change, but these changes cannot feed through to technology choices due to a regulated energy industry). In addition, energy systems are prone to shocks, and these can trigger energy revolutions.

The technologies involved in major energy revolutions can be considered on two dimensions. First, capital intensity. A technology with a high capital intensity, such as nuclear power, requires a large-scale player to deploy it, while a technology with low capital intensity, such as biofuels or compressed natural gas (CNG) vehicles, can be deployed by individuals. Second, network intensity. A technology with high network intensity, such as offshore oil and gas, requires significant investment in a network, which is often delivered by players other than the technology developer. A technology with low network intensity, again such as power generation technologies, can plug and play into an existing network, which means that the technology is not reliant on actions elsewhere in the energy system.

In international experience, high capital intensity and low network intensity technologies have played a major role in energy revolutions. These technologies are often deployed to meet rapid changes in energy demand, such as demand for more energy, secure energy or cleaner energy. This is because governments often have responsibility to meet these needs, and they have tended to favour deployment of large, established, single-fuel technologies - such as nuclear or coal - that can plug into existing networks.

\subsection{Basics}

History demonstrates that new technology can trigger revolutionary changes in energy systems. Over the timescale of centuries, technology has clearly transformed the energy system. The history of the UK, the first country to industrialise, shows this very clearly. The invention of the steam engine in 1763 started the Industrial Revolution, leading to increases in coal demand. The invention of the Ford Model T car in 1908 started a period of declining transport costs, leading to increases in oil demand. The opening in 1956 of Calder Hall, the world's first commercial nuclear power plant, led to increases in primary electricity supply. These examples show that the energy system is fundamentally based on technology, and so major changes in technology will be closely related to major changes in energy systems.

Recent decades have provided plenty of reasons for technological innovation in energy. Air pollution has become a major concern. In the 1950s countries such as the UK and the USA passed clean air laws, and by the late 1970s international agreements were formed, such as the Convention on Long-Range Transboundary Air Pollution. Energy security became a prominent concern with the oil crises of the 1970s. Climate change reached international levels of concern with the adoption of the Kyoto Protocol in 1997. These imperatives, coupled with the increasing technological sophistication of the wider global economy, have led to high levels of innovation activity. However, this has not resulted in significant change in the energy system. Since the 1980s, shares of primary energy have been relatively constant between biomass, coal, oil, and modern energy carriers (Fig. 16).

Other factors appear to have been the trigger for revolutionary change. These changes, while often using new technologies, were not always triggered by the development of these technologies. The UK provides examples of this. In 1967, demand for clean air and warmer homes led to a centralised decision to switch more than 40 million appliances from town gas to natural gas. In 1984, the miners' strike severely disrupted coal supply chains. In the 1990 s the power sector experienced a dash for gas as market liberalisation enabled recently invented combined-cycle gas turbine (CCGT) technology to compete for the first time. Each of these examples revolutionised the UK energy system, but technology had a supporting, rather than a leading, role. 


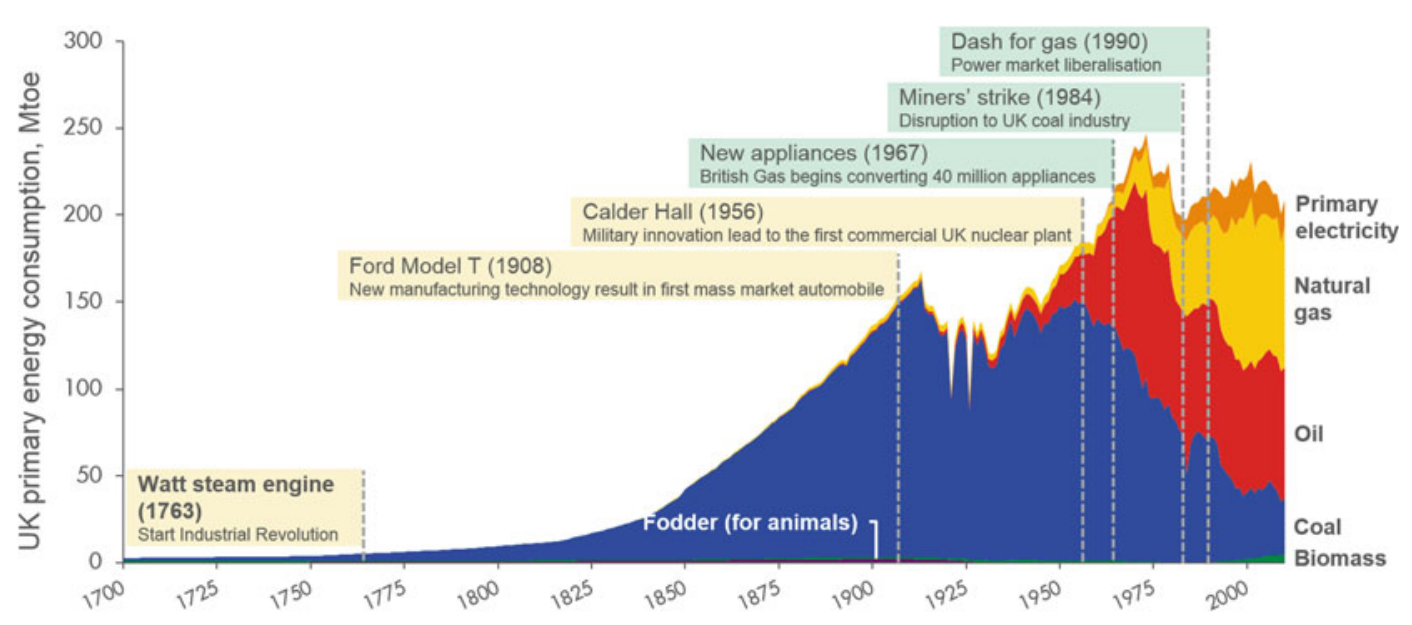

Fig. 16 UK history demonstrates that new technology can trigger revolutionary energy system change

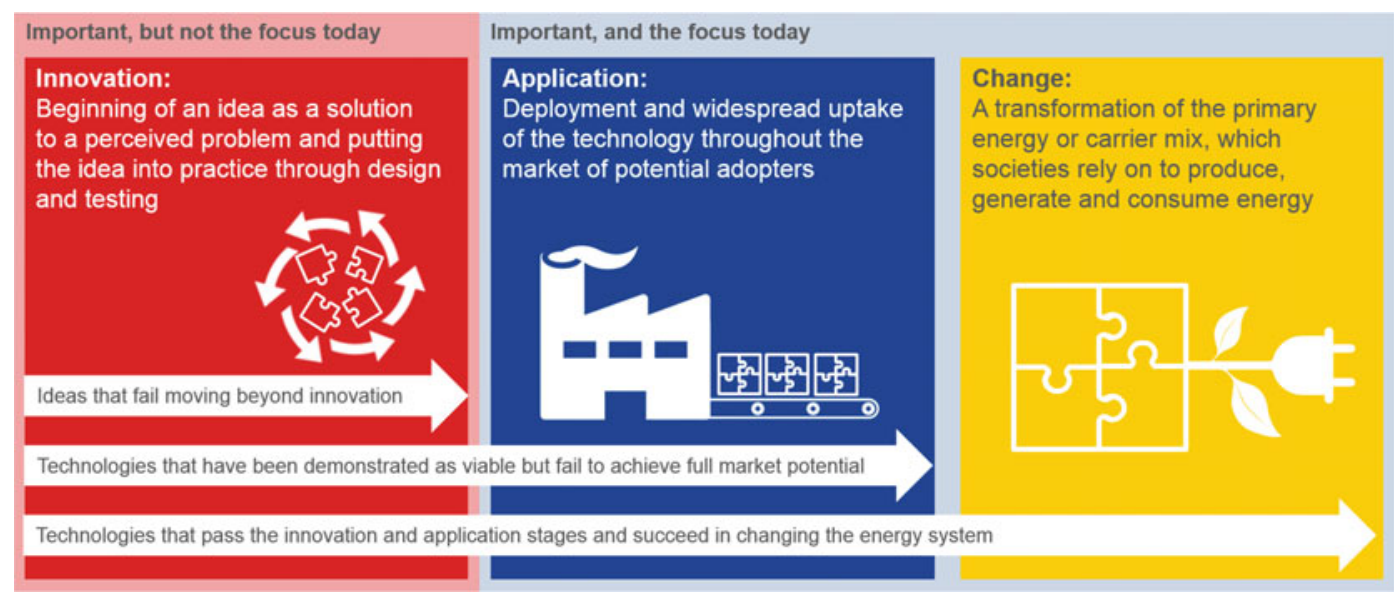

Fig. 17 Major energy technologies must develop through the three stages. Source Vivid Economics

The experience of recent decades shows that the contribution of technology to an energy revolution has different stages. First, innovation - the beginning of an idea as a solution to a perceived problem and putting the idea into practice through design and testing. Second, application - the deployment and widespread uptake of a technology throughout the market of potential adopters. Third, change-a transformation of the primary energy or secondary energy carrier mix, which societies rely on to produce, generate and consume energy. For a technology to contribute to an energy revolution it must develop through all three stages (Fig. 17).
An understanding of how innovative technologies can be successfully applied to generate revolutionary system change will be essential for China to deliver its energy revolution. Along with the rest of the world, China faces a major challenge to deliver low-carbon, low-pollution, affordable and secure energy. This challenge will be met by radically changing the energy mix, from fossil fuels to renewable energy. Technological innovation is often seen as the trigger for this change. The recent, rapid cost decreases in wind and solar photovoltaic (PV) technology support this view. However, the rapid improvements in technology have not yet changed the 
system and, in those countries where the most change has occurred, there has been significant effort to get the conditions right for large-scale application. This experience demonstrates that policymakers must consider factors other than technology that trigger revolutionary energy system change.

Successful innovation is the key first stage that benefits from policy support. Innovation is a complex process, and is undertaken by a network of stakeholders, with at least four distinct stages. First, research and development (R\&D) - where original ideas are developed and combined. Second, demonstration-where successful combinations of ideas are tested to see if they can deliver a viable product. Third, niche marketswhere technology is deployed at a small scale, often in areas where the performance of the new product is valued over the low costs of existing options, facilitating the route-to-market. Fourth, wide deployment-where technology is mass-produced and costs can compete with existing options. The risk of failure at each stage is high, and technology often falls back to an earlier stage, only to be combined with a new idea or champion that enables the technology to progress again.

International experience of best practice for accelerating innovation is a rich and important topic that may be worthy of specific focus for learnings, as China has significant innovation capabilities that should be put to best use. However, this study focuses on how technology can be successfully applied once innovation has occurred. This is because without the conditions for successful application, innovation efforts are wasted, and these conditions for successful application are interconnected with the goals of China's energy revolution.

\subsection{Drawing on International Experience}

This study uses quantitative analysis to evaluate the role of technology in delivering changes to the energy system and to summarise the related international experience and the implications for China.

\subsubsection{Quantitative Analysis}

\section{(1) Definition of revolutionary energy technology}

As technology and energy revolutions are complex, so too is the methodology for testing the role of technology in past energy revolutions. A revolutionary energy technology is the application of scientific knowledge that transforms the primary or secondary energy carrier mix relied on by societies to produce, generate and consume energy. The figure below shows how our work focuses on energy technologies, which are a subset of general technologies. Within energy technologies, our work focuses on revolutionary energy technologies that transform the fuel mix. This study does not consider energy technologies that increase the scale of energy production, generation or consumption. Such technologies are important, but the primary challenge for China and other countries in the coming decades is changing the fuel mix, rather than increasing scale. Therefore, our focus is on technologies that change the fuel mix (Fig. 18).

\section{(2) Innovation level}

We quantify innovation levels using metrics of hype and R\&D. On the one hand, we quantify hype using the frequency of citations of a technology in English language sources since 1970. These data are from Google Ngrams, a dataset of all words cited in written sources digitalised by the Google Books programme up to 2012. On the other hand, we quantify $R \& D$ activity using International Energy Agency (IEA) data on public R\&D expenditure in OECD countries since 1970. Innovation levels are quantified for hype and R\&D for 12 technologies: biofuels, carbon capture and storage (CCS), energy storage, fuel cells, geothermal power, hydropower, hydrogen, industrial energy efficiency, power from nuclear fission, power from nuclear fusion, 


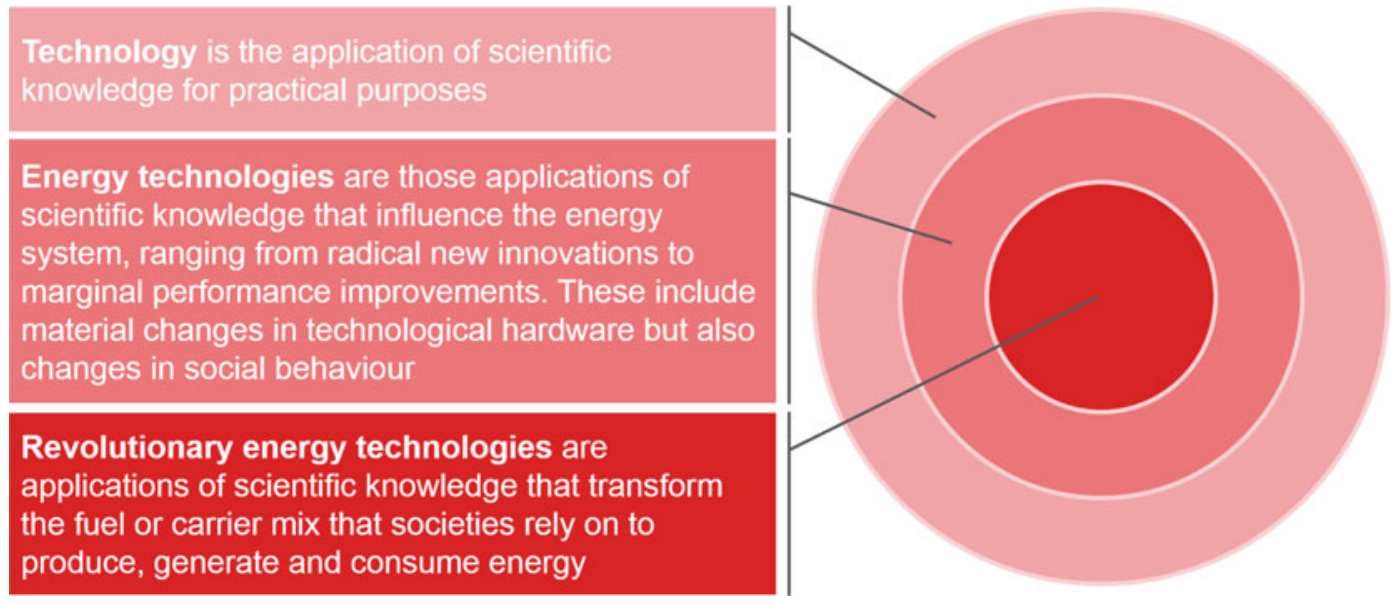

Fig. 18 Definition of revolutionary energy technology. Source Vivid Economics

renewable power, and transport energy efficiency. For each technology we analysed the profile of hype, R\&D spend and, where possible, deployment of the technology by country for G20 countries. There are lags between innovation levels and deployment across countries, and we analysed these lags to test when and where innovation was followed rapidly by application. Long lags suggest that other factors must be in place to trigger deployment of a technology.

It needs to be noted that not all technologies have suitable deployment data. For example, technologies such as nuclear fusion have been deployed only in small pilots. Other technologies, such as industrial energy efficiency, do not have comprehensive datasets for deployment. Some technologies are described as revolutionary by industry commentators even though deployment levels are too low to change the energy mix. For example, renewable power, such as wind and solar, is often described as driving a revolutionary change in the energy system, and high growth rates in capacity support this characterisation. However, the share of renewable power in the energy mix is very small, and changes in the mix towards renewable power are not yet on the same scale as the historical changes to gas or nuclear. Our view is that a revolution should be judged on its effect on the energy mix. This perspective is at the heart of our analysis, as we investigate which actions are needed to transform commentary and hype that a technology is revolutionary into a revolutionary change of the energy system (Fig. 19).

We analyse major groups of technology. A technology, such as nuclear, can include a family of technology subclasses and generations. For example, nuclear reactors can be Magnox reactors, pressurised water reactors (PWRs), boiling water reactors (BWRs), advanced gas-cooled reactors (AGRs) or fast breeder reactors (FBRs). Each of these reactor types is in turn composed of a family of technologies. Developments within major technology groups can have a significant effect on deployment. Figure 20 shows that deployment of nuclear power lagged between countries, which was in part due to the varying development paths of the different technologies they employed. The UK initially built its nuclear power plants with Magnox reactors, the Japanese with BWRs and PWRs, and the French with PWRs. So, the subclasses of technologies can be important to understanding deployment. However, this study focuses on aggregated technology groups for two reasons. First, from an energy revolution perspective, the technology subclass that succeeds is not important, only that some succeed rapidly and at scale. Second, while historical analysis can provide many lessons for innovation at this micro level, it adds greatly to complexity, and suffers from survivor bias. 


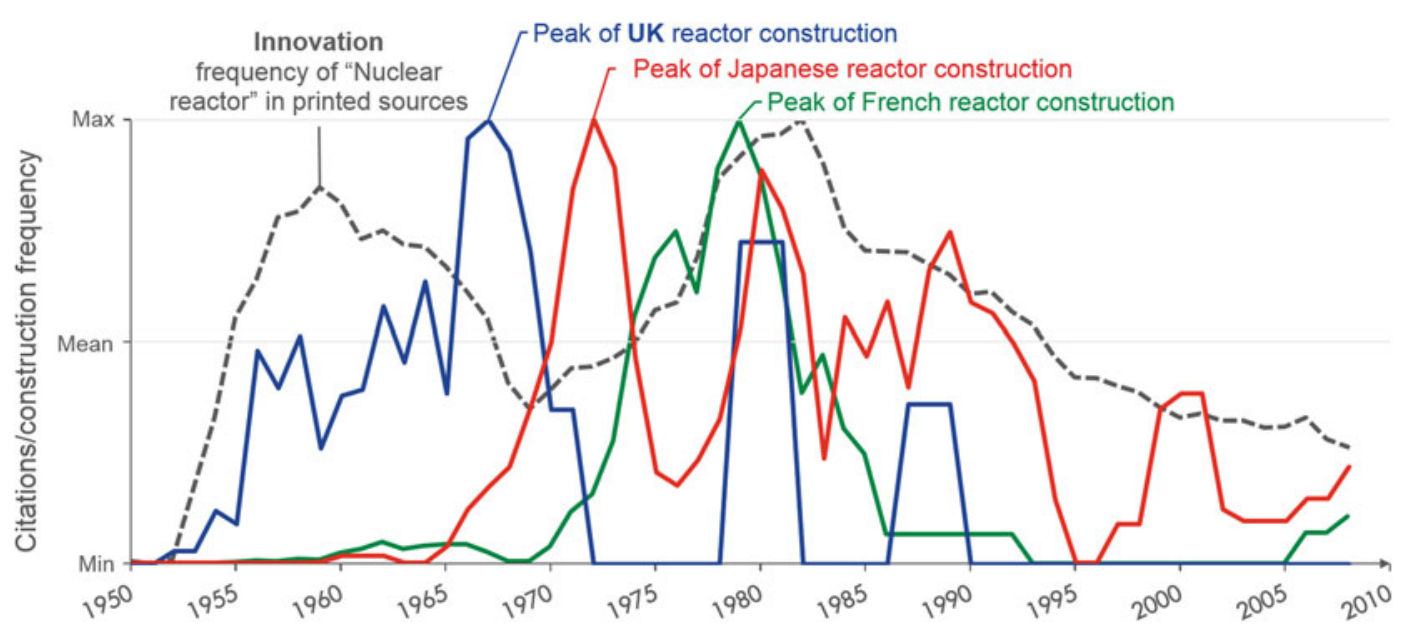

Fig. 19 The lag from citations to deployment of a technology. Source Vivid Economics

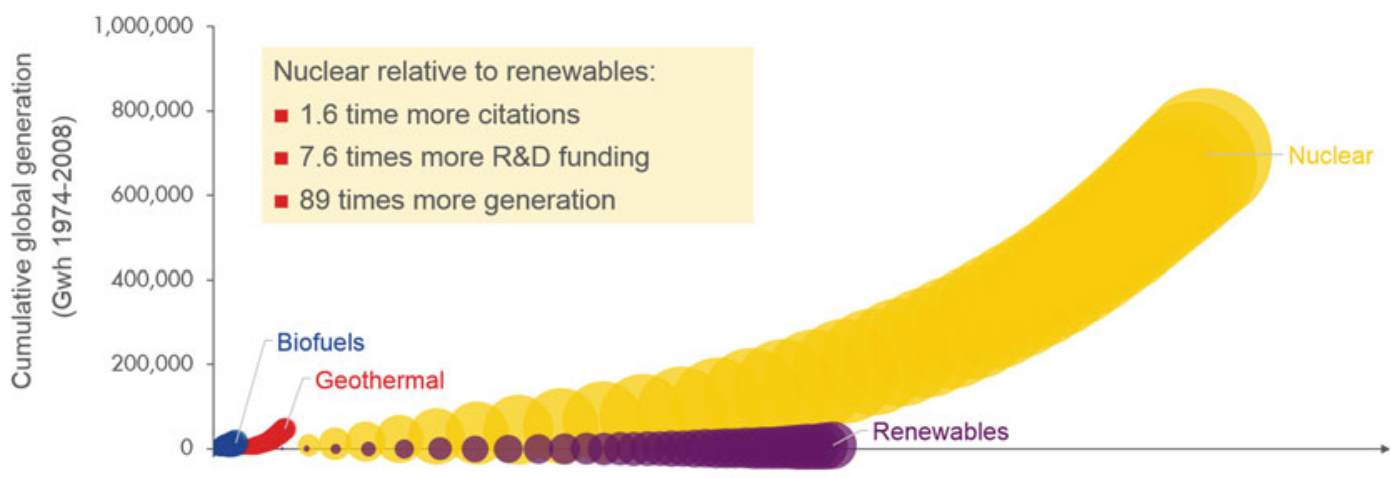

Cumulative citations (Google ngram 1974-2008)

Fig. 20 Hype does not translate into R\&D and deployment of new technologies. Note Bubble size represents cumulative R\&D expenditure. Source Vivid Economics

\section{(3) Definition of energy system change}

We developed a change metric to quantify energy system change. The energy system is the entire flow of energy from primary sources, through conversion to secondary fuel carriers (primarily power and refined oil products) to final consumption by end-use sectors (primarily buildings, industry and transport). Each component of this energy system, such as the flow of primary energy into power generation, has a particular fuel mix. We consider a revolutionary change to have occurred within a component of the energy system if the fuel mix has changed significantly within a decade. We calculate a single number (a change metric) to identify revolutionary changes in components of the energy system and the overall energy system, for all countries in the world. The change metric is calculated using annual data between 1971 and 2014 for most countries, and between 1960 and 2014 for a smaller set of countries where data are available. The data source is the International Energy Agency's World Energy Balances 2016. There are two crucial steps in calculating the change metric: first, significant changes in the fuel mix must be identified; and second, the magnitude of significant changes must be 
calculated in a single metric, comparable across countries.

We use a wild binary segmentation algorithm to identify significant changes in the fuel mix. This algorithm identifies out of the ordinary changes in the variance of the rate of change of the fuel mix. That is to say, the algorithm identifies when there is a statistically significant change in the rate at which the fuel mix changes relative to its normal rate of change. Such a test is necessary. The magnitude of significant change is identified by summation of the rates of change in fuels' share of the energy flow between the years identified as significant by the algorithm. For each fuel in a flow, such as primary energy to power, the absolute rate of change in its share of the fuel mix is calculated between the years identified as significant by the algorithm. The change metric for the flow is then the summation of these absolute rates of change. The change metric for the entire energy system is the sum of weighted change metrics for each component in the energy system, where weights are the ratio of absolute energy in that flow to the absolute energy in final consumption.

We identified the common characteristics of cases where technology played a major role in an energy system change by analysing the largest energy system changes in the G20 since 1970. We used the change metric dataset to identify the quantifiably largest energy system changes across countries and over time. We then investigated these periods of greatest change to understand which of the factors identified in our analysis of innovation and deployment (technology, demand, supply or markets) triggered the change. We then combined this analysis of trigger factors with an assessment of the characteristics of technology that played a major role in the set of greatest changes, even when technology was not a trigger factor. Our findings from this assessment were developed into a framework that describes the conditions that, in international experience, have enabled innovative technology to be successfully applied at a scale that revolutionises an energy system.

\subsubsection{Findings from International Experience}

We analysed the changes in G20 countries across five components of the energy system-primary energy, power, industry, transport and refining, and buildings to determine patterns of change. Additional results for the G7 subset are presented to demonstrate how patterns of change have altered as industrial economies mature into service-led economies over this time period.

\section{(1) Factors driving the successful application of energy technology}

The gap between hype, research effort and deployment varies by technology, which suggests that some technologies have supporting factors that others do not. First, hype tends to peak before R\&D spending, which peaks before deployment. This suggests that technology eventually has its impact on the energy system many years after its potential is perceived, and that changes flowing from actual deployment do not gather as much notice as the initial innovation. Second, there is significant variation in the gaps between hype, R\&D and deployment across technologies. Renewable power is often perceived as driving an energy revolution. However, since 1974, nuclear power has received 1.6 times more citations, 7.6 times more $R \& D$ funding and generated 89 times more power.

Technologies that achieve high levels of deployment benefit from a supporting set of factors in addition to their technological development. These include technology innovation to a level such that deployment is feasible, supply of the inputs the technology requires, demand for the services the technology provides, and markets that incentivise deployment. All the factors must be present and aligned if a technology is to move from innovation, through application to changing the energy system.

The case of US tight gas illustrates how the sequencing of supply, demand, market and technology factors can determine when revolutionary change is triggered. US tight gas 
revolutionised US and, to an extent, global gas markets. This occurred with apparent speed: the first large-scale application of hydraulic fracturing technology was in 2000 , with production increasing rapidly from 2006. However, this rapid revolution was supported by factors that had long been in place. The supply of tight gas below ground has been present for millions of years, while above ground the exploration and production industry was mature, and the demand for gas in the USA had been established for decades, with an extensive pipeline network serving the widest possible set of consumers. The USA also has a mature liberalised gas market that provides incentives to any technology that can supply demand. It can be argued that it is this market factor that triggered the shale gas revolution, because it is when gas prices increased due to the prospect of a shortage that hydraulic fracturing technology was applied at a large enough scale to change the energy system. The change metric shows that the fuel mix of US energy production has changed significantly in the 1970s-1980s. It was only when gas prices increased that the change metric rose above historic highs (Figs. 21 and 22).

It is important to note that to reduce technology deployment to four factors is a useful simplification of a complex process. Energy systems are complex systems. This means that there is a large number of factors that induce change to the system, and there are few direct, clear relationships. The simplification is a useful one as differences in the factors of technology, supply, demand and markets describe many of the differences between outcomes for technologies.

\section{(2) The role of technological development in driving energy revolution}

From 1960 to 1985 energy systems underwent significant change in the fuel mix, the change metric and to the scale of energy consumption. However, since 1985 fuel mixes in G7 countries have been relatively stable, as has energy demand. This is despite increased energy R\&D in the 1970s and accelerating rates of innovation in the broader economy (Fig. 23).

The stability of energy systems over the past 30 years is in stark contrast to the revolutionary changes required in the next 30 years due to decarbonisation. Countries tend to change their energy system most when energy demand is increasing, because this is when new energy transmission networks are created, which, once built, lock in fuel choices. Recent energy revolutions have mainly occurred in the upstream and midstream sectors, with the fuel mix that supplies energy use remaining relatively constant after significant change before 1985 . In the period
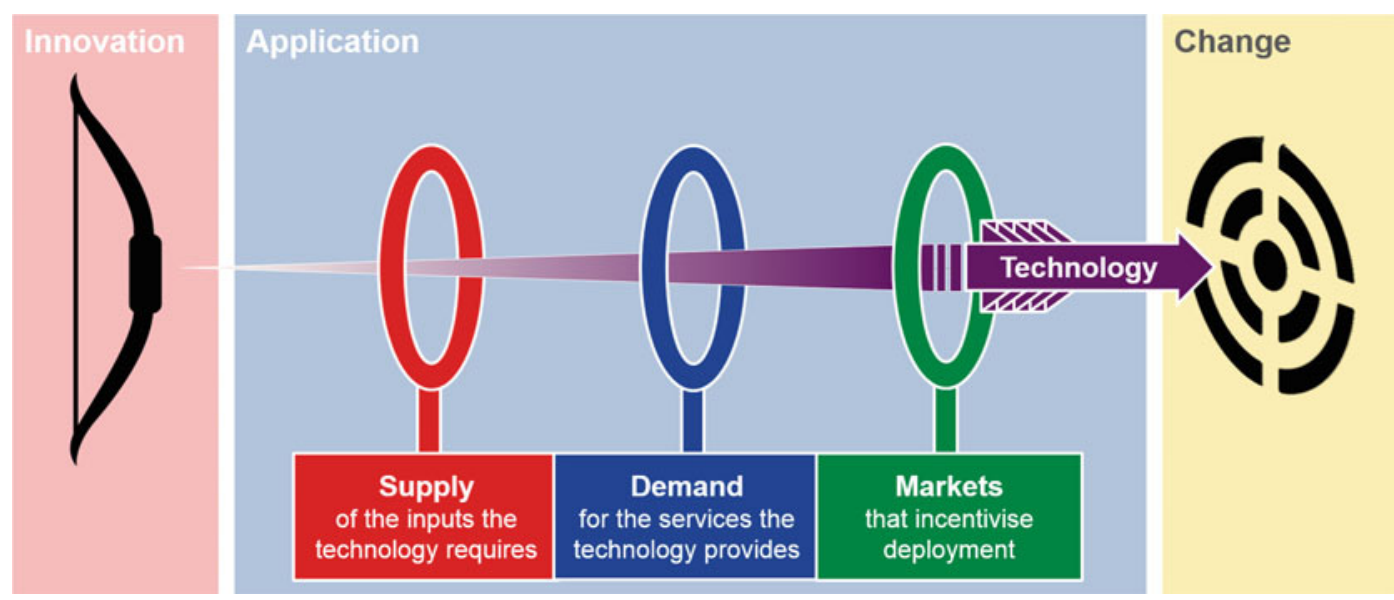

Fig. 21 Technology requires alignment of supply, demand and markets if it is to change energy systems. Source Vivid Economics 


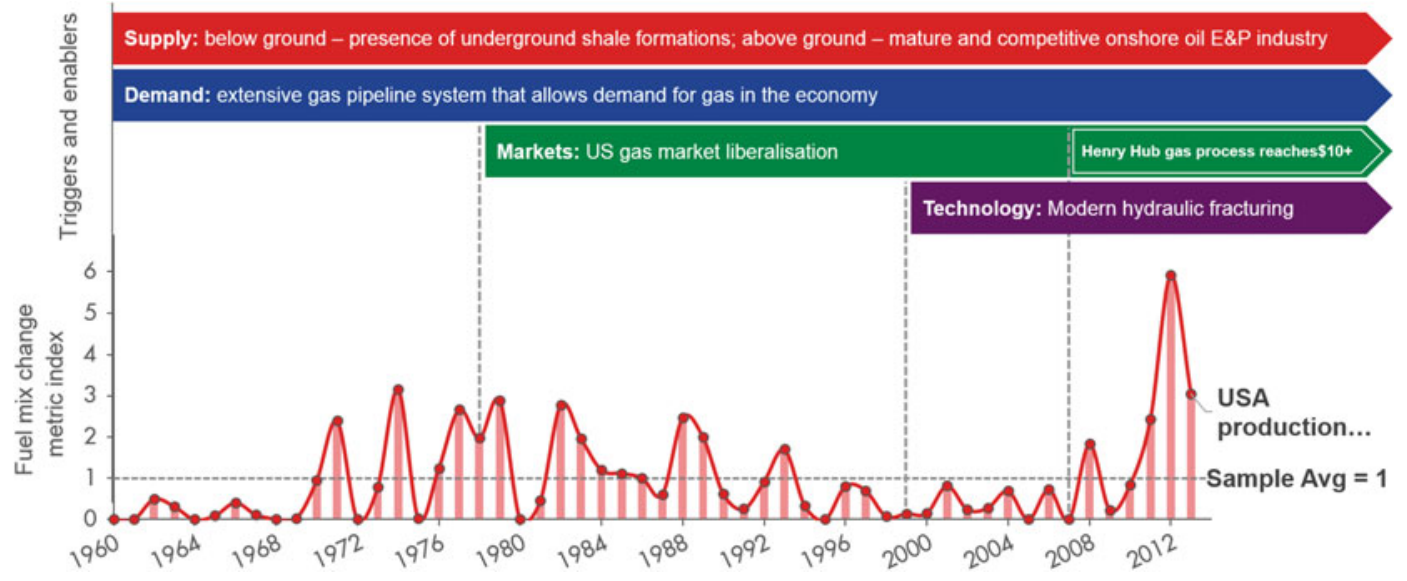

Fig. 22 US tight gas illustrates how the sequencing of supply, demand, markets and technology determines when revolutionary change is triggered. Source Vivid Economics

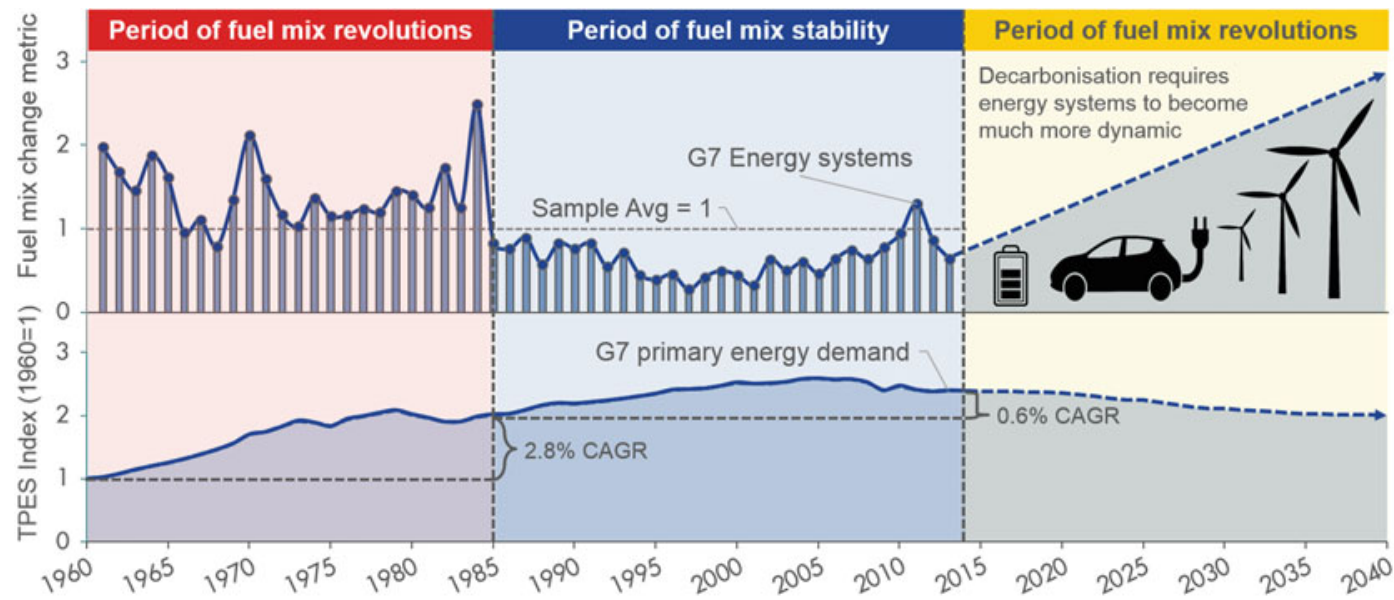

Fig. 23 G7 energy systems have been stable in the past four decades. Note TPES = total primary energy supply; $\mathrm{CAGR}=$ compound annual growth rate. Source Vivid Economics

before 1985, changes in fuel mix for buildings and industry contributed to a significant proportion of the overall change metric. However, in the decades since 1985, change has largely been driven by shifts in production and imports. Transport has remained oil-dominated throughout the period. This suggests that downstream fuel mixes are locked in by their distribution networks, which is a challenge for the future, given that fuels currently used in energy use- such as oil for transport, coal in industrial processes and gas for heating-will have to change if climate mitigation targets are to be met (Fig. 24).

Across the largest G20 energy revolutions, most are triggered by economic growth, energy security concerns, new market incentives or shocks, rather than by technology. Revolutions are colour-coded: red for a supply-triggered revolution; blue for a demand-triggered revolution; green for a market-triggered revolution; and purple for a technology-triggered revolution, of which there are none (Fig. 25). 


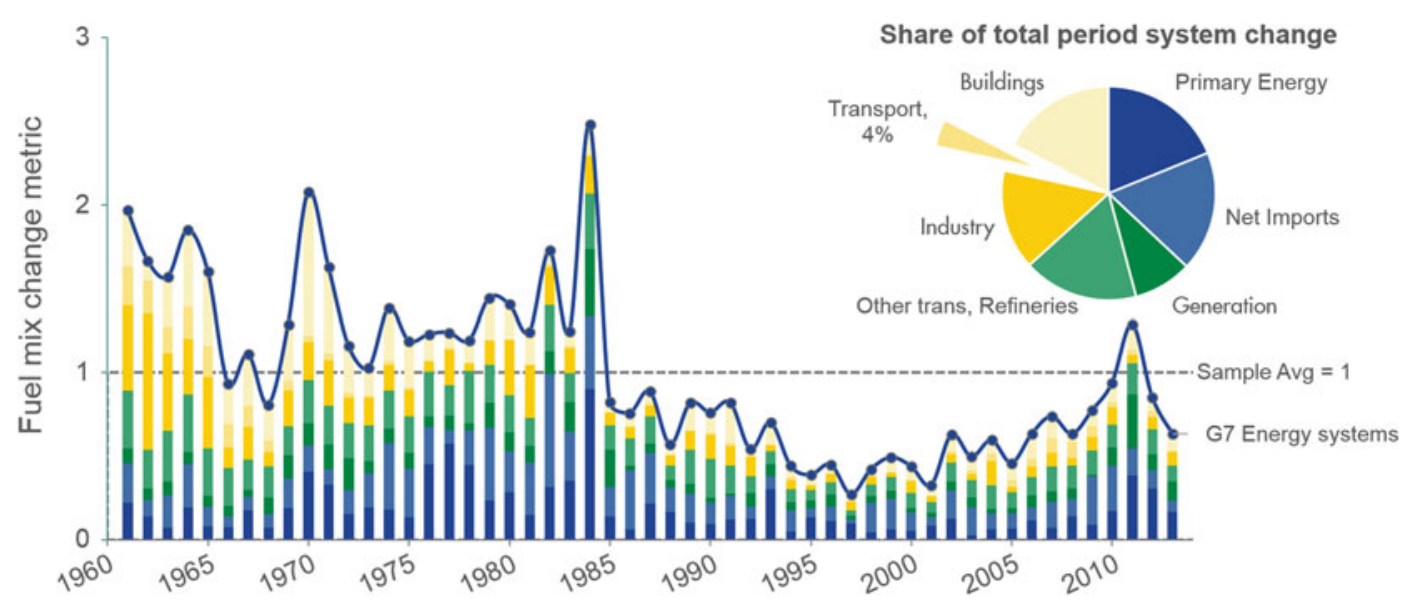

Fig. 24 Recent G7 energy revolutions have mainly occurred upstream. Source Vivid Economics

\begin{tabular}{|c|c|c|c|c|c|}
\hline Rank & Primary energy & Power & Industry & Transport/Refining & Buildings \\
\hline $1^{\text {st }}$ & $\begin{array}{l}\text { UK, } 1970-1980 \\
\uparrow \text { Oil and Gas } \\
\text { (North Sea) }\end{array}$ & $\begin{array}{l}\text { IDN, 1999-2010, } \\
\uparrow \text { Coal and Geothermal } \\
\text { (Economic growth) }\end{array}$ & $\begin{array}{c}\text { IDN, 1999-2010, } \\
\uparrow \text { Coal and gas } \\
\text { (Economic growth) }\end{array}$ & $\begin{array}{c}\text { ZAF, 1980-1982 } \\
\uparrow \text { Coal } \\
\text { (CTL Apartheid) }\end{array}$ & $\begin{array}{c}\text { KOR, 1990-1994 } \\
\uparrow \text { Oil } \\
\text { (Economic growth and } \\
\text { strong currency) }\end{array}$ \\
\hline $2^{\text {nd }}$ & $\begin{array}{c}\text { KOR, 1981-1991 } \\
\quad \uparrow \text { Nuclear } \\
\text { (Energy security) }\end{array}$ & $\begin{array}{c}\text { KOR, 1981-1991 } \\
\quad \uparrow \text { Nuclear } \\
\text { (Energy security) }\end{array}$ & $\begin{array}{l}\text { TUR, 2000-2010, } \\
\uparrow \text { Gas } \\
\text { (Pipeline and LNG) }\end{array}$ & $\begin{array}{c}\text { IND, } 1970-1988 \\
\uparrow \text { Oil } \\
\text { (Shift from rail to road) }\end{array}$ & $\begin{array}{c}\text { DEU, } 1990-1991 \\
\downarrow \text { Coal } \\
\text { (Collapse of East German } \\
\text { coal mining) }\end{array}$ \\
\hline $3^{\text {rd }}$ & $\begin{array}{c}\text { FRA, 1974-1991 } \\
\quad \uparrow \text { Nuclear } \\
\text { (Energy security) }\end{array}$ & $\begin{array}{c}\text { FRA, 1974-1991 } \\
\quad \uparrow \text { Nuclear } \\
\text { (Energy security) }\end{array}$ & $\begin{array}{l}\text { MEX, 1994-2010 } \\
\uparrow \text { Electricity and Coal } \\
\text { (NAFTA) }\end{array}$ & $\begin{array}{l}\text { CHN, 2008-present } \\
\uparrow \text { Gas and Electricity } \\
\text { (Market making) }\end{array}$ & $\begin{array}{l}\text { TUR, 2000-2010, } \\
\uparrow \text { Coal and Electricity } \\
\text { (Low cost alternatives } \\
\text { to biofuels and oil) }\end{array}$ \\
\hline $4^{\text {th }}$ & $\begin{array}{l}\text { ITA, 2000-2010 } \\
\uparrow \text { Biofuels and } \\
\text { Renewables } \\
\text { (Decarbonisation) }\end{array}$ & $\begin{array}{l}\text { GBR, 1990-1998 } \\
\uparrow \text { Gas and Nuclear } \\
\text { (Dash for gas) }\end{array}$ & $\begin{array}{c}\text { UK, } 1970-1976 \\
\uparrow \text { Gas } \\
\text { (North Sea) }\end{array}$ & $\begin{array}{c}\text { BRA, } 1982-1986 \\
\uparrow \text { Biofuels } \\
\text { (Energy security) }\end{array}$ & $\begin{array}{c}\text { UK, } 1970-1976 \\
\uparrow \text { Gas } \\
\text { (North Sea) }\end{array}$ \\
\hline $5^{\text {th }}$ & $\begin{array}{c}\text { IDN, } 1999-2010 \\
\uparrow \text { Coal } \\
\text { (Economic growth) }\end{array}$ & $\begin{array}{c}\text { JPN, 2011-2014 } \\
\downarrow \text { Nuclear } \\
\text { (Fukushima) }\end{array}$ & $\begin{array}{c}\text { FRA, } 1980-1984 \\
\downarrow \text { Oil } \\
\text { (Oil shock) }\end{array}$ & $\begin{array}{c}\text { ARG, } 1992-1995 \\
\uparrow \text { Gas } \\
\text { (CNG market making) }\end{array}$ & $\begin{array}{c}\text { FRA, 1980-1984 } \\
\uparrow \text { Electricity } \\
\text { (Nuclear programme) }\end{array}$ \\
\hline
\end{tabular}

Fig. 25 Most G20 energy revolutions are not driven by technology. Source Vivid Economics

\section{(3) Characteristics of revolutionary energy technologies}

Analysis suggests that, in addition to a technology having supporting supply, demand and market factors, the following characteristics of a technology can influence its successful application. First, capital intensity. A technology with high capital intensity, such as nuclear power, requires a large-scale player to deploy it, whereas a technology with low capital intensity, such as biofuels or compressed natural gas (CNG) vehicles, can be deployed by individuals. Second, network intensity. A technology with high network intensity, such as offshore oil and gas, requires significant investment in a network, in addition to the capital of the initial technology, which is often delivered by players other than the technology developer. A technology with low network intensity, such as power generation technologies, can plug and play into an existing network.

In international experience, technologies with high capital intensity and low network intensity, have played a major role in energy revolutions. These technologies are often deployed to meet 


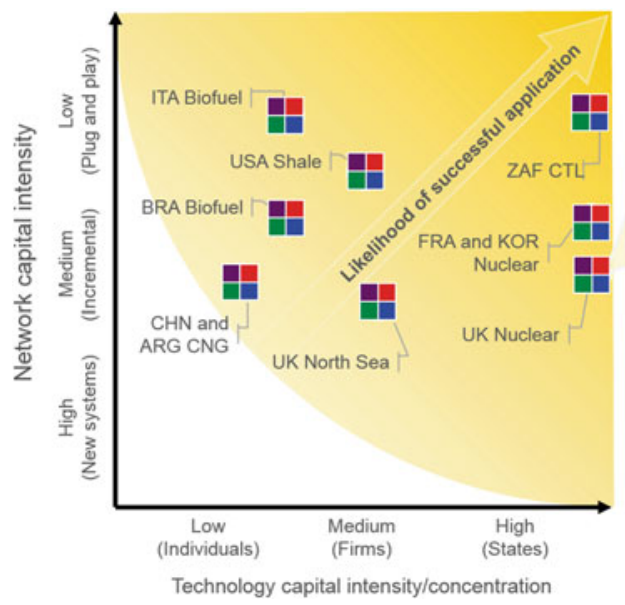

\section{UK nuclear, 1956:}

Calder Hall (180 MW of heat and $40 \mathrm{MW}$ of electricity) initiated the world's first civil nuclear programme.

- Technology capital intensity/concentration: $\underline{\text { High }}$ $£ 35 \mathrm{~m}$ in 1956 - approx. £830m today (Agent: State - UKAEA)

network capital intensity: Medium Limited system integration costs but significant waste management

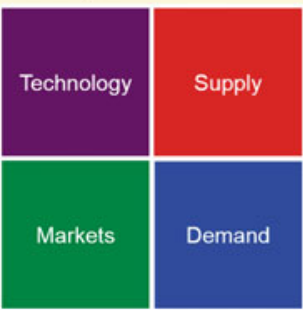

Two types of demand:

- Primary: Production of weapons-grade plutonium

- Secondary: Electricity for commercial purposes

Fig. 26 Revolutionary technologies tend to rely on large state investments and/or require incremental network investments

rapid changes in energy demand, such as demand for more energy, secure energy or cleaner energy. This is because governments often have responsibility to meet these needs, and they have tended to favour deployment of large, established, single-fuel technologies - such as nuclear or coal - that can plug into existing networks (Fig. 26).

\section{Current Developments and Potential Impacts of Some Major Energy Technologies}

This section analyses the development trends of some energy technologies of significance to China, and their implications for China to deliver energy technology revolution.

\subsection{Smart Grids}

\subsubsection{Current Status of, and Outlook for, Smart Grids}

A new round of energy revolution is around the corner. Large-scale use of clean and renewable energy to build a green, smart and sustainable energy system has become an unstoppable trend. The smart grid-integrating the new generation of energy, IT, control and materials technologies - is the key to green, smart and sustainable development of the energy system. Its significance has been widely recognised.

\section{(1) China}

To accelerate the development of the smart grid, the Chinese government has introduced incentive policies and included smart grids in its strategic plans. In November 2014, the State Council issued the Strategic Action Plan for Energy Development (2014-20), ${ }^{7}$ which defines the smart grid as a priority area in energy technology innovation. In July 2015, the National Development and Reform Commission (NDRC) and the National Energy Administration (NEA) released their Guiding Opinions on Boosting Smart Grid Development. ${ }^{8}$ This states that the smart grid is an important means to realise the energy production, consumption, technology and system revolutions and the Energy Internet (Internet+). In February 2016, the NDRC, the NEA and the Ministry of Industry and Information Technology published their Guiding Opinions on Promoting the Development of Internet + Smart

${ }^{7}$ General Office of the State Council, Strategic Action Plan for Energy Development (2014-20), 2014, pp. 1617.

${ }^{8}$ National Development and Reform Commission and National Energy Administration, Guiding Opinions on Boosting Smart Grid Development, 2015, p. 1. 
Energy, ${ }^{9}$ according to which an integrated energy network based on the smart grid will be developed. In April 2016, the NDRC and the NEA released the Action Plan for Innovation in the Energy Technology Revolution (2016-30) ${ }^{10}$ and the Roadmap for Major Innovation Activities in Energy Technology Revolution, ${ }^{11}$ which describe the plan to develop smart grid power transmission and transform end-user equipment.

China's smart grid focuses on the integrated and coordinated development of power generation, transmission, conversion, distribution, consumption and scheduling. State Grid Corporation of China proposed in 2009 to develop a smart grid based on robust grid architecture, supported by a communications and information platform and incorporating intelligent control, all voltage levels and all parts of the power system, including "power, information and business flows." 12 China Southern Power Grid researches such fields as new energy, flexible DC power transmission, intelligent substations, power distribution systems, integration of distributed energy resources, microgrids, and power use and information and communications technologies. The company is also developing green, reliable, smart and efficient 3C (computer, communications, control) power grids to make them efficient, resource-saving and environmentally friendly. ${ }^{13}$

\footnotetext{
${ }^{9}$ National Development and Reform Commission, National Energy Administration, and Ministry of Industry and Information Technology, Guiding Opinions on Promoting the Development of Internet + Smart Energy, 2016, pp. 5-7.

${ }^{10}$ National Development and Reform Commission and National Energy Administration, Action Plan for Innovation in the Energy Technology Revolution (2016-30), 2016, p. 6.

${ }^{11}$ National Development and Reform Commission and National Energy Administration, Roadmap for Major Innovation Activities in Energy Technology Revolution, 2016, pp. 67-69.

${ }^{12}$ Strong Smart Grid https://baike.baidu.com/item/\%E5\% 9D\%9A\%Е5\%BC\%BA\%Е6\%99\%BA\%E8\%83\%BD\% E7\%94\%B5\%E7\%BD\%91/9399809?fr=aladdin.

${ }^{13}$ China Southern Power Grid, Corporate Social Responsibility Report 2016, pp. 19-27.
}

\section{(2) USA}

The US government designed a strategic framework for smart grid development in the Energy Independence and Security Act of 2007. ${ }^{14}$ The U.S. Department of Energy issued the Smart Grid System Report ${ }^{15}$ in July 2009, which defines the scope, characteristics and indicators of smart grids. The new version of the Estimating the Costs and Benefits of the Smart Grid, ${ }^{16}$ published by the Electric Power Research Institute in April 2011, devised a method to calculate the cost and benefits of smart grids. The All-of-the-Above Energy Strategy as a Path to Sustainable Economic Growth, ${ }^{17}$ issued by the Obama administration in May 2014, proposed developing solar, wind, geothermal and other renewable types of energy to bolster economic growth and protect the environment. In January 2016, the U.S. Department of Energy made public its new blueprint for the modern power grid, which aims to integrate conventional energy, renewable energy, energy storage and energy efficiency to ensure grid reliability and protect it from cyberattack and climate change. ${ }^{18}$ Smart grids will, therefore, play a significant role in driving the transition to low-carbon energy.

The USA's smart grid underscores resilience, reliability, affordability, flexibility and sustainability. Currently, the grid transmits electricity from large remote power plants via high-voltage transmission lines to local distribution networks, which deliver the power to industrial, commercial and residential users, primarily with one-way electricity flow. In the future, the smart grid will still need large power plants for energy, but it

\footnotetext{
${ }^{14}$ U.S. Congress, Energy Independence and Security Act of 2007, pp. 293-304.

${ }^{15}$ DOE, Smart Grid System Report, 2009.

${ }^{16}$ EPRI, Estimating the Costs and Benefits of the Smart Grid, 2011.

${ }^{17}$ Executive Office of the President of the United States, The All-of-the-Above Energy Strategy as a Path to Sustainable Economic Growth, 2014, pp. 31-39.

${ }^{18}$ State Grid Energy Research Institute Co., Ltd., Analysis Report on Grid Development and Application of New Technologies in and outside China, Beijing: China Electric Power Press, 2016, pp. 22-23.
} 


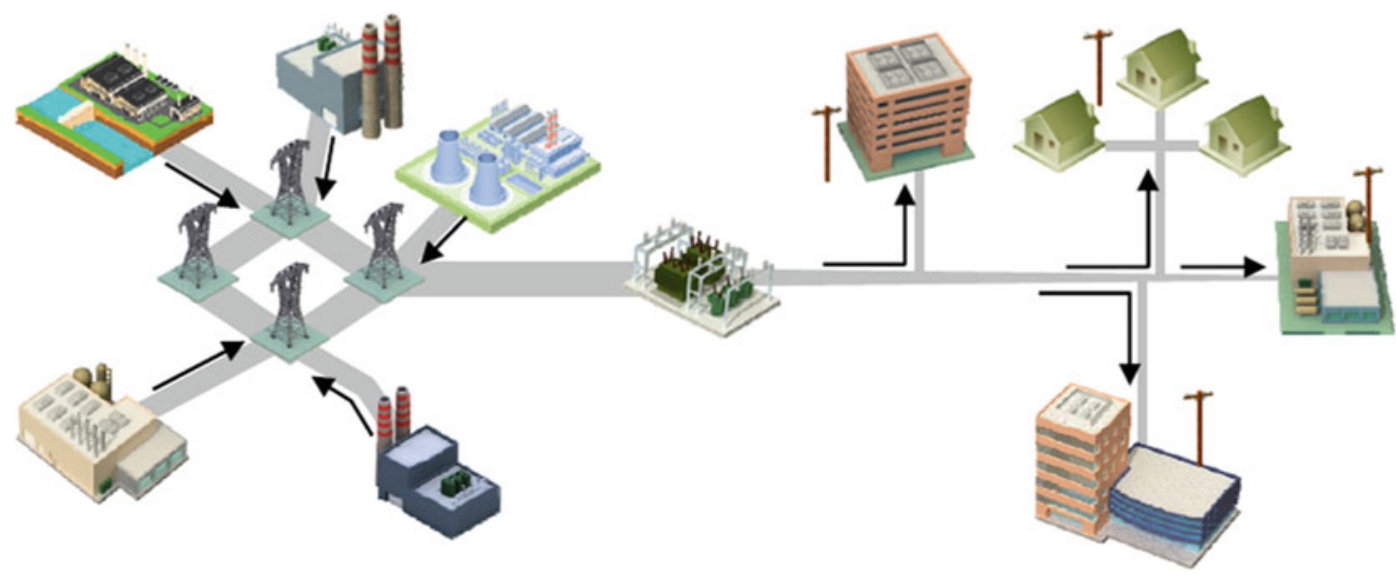

Fig. 27 Conventional power grid

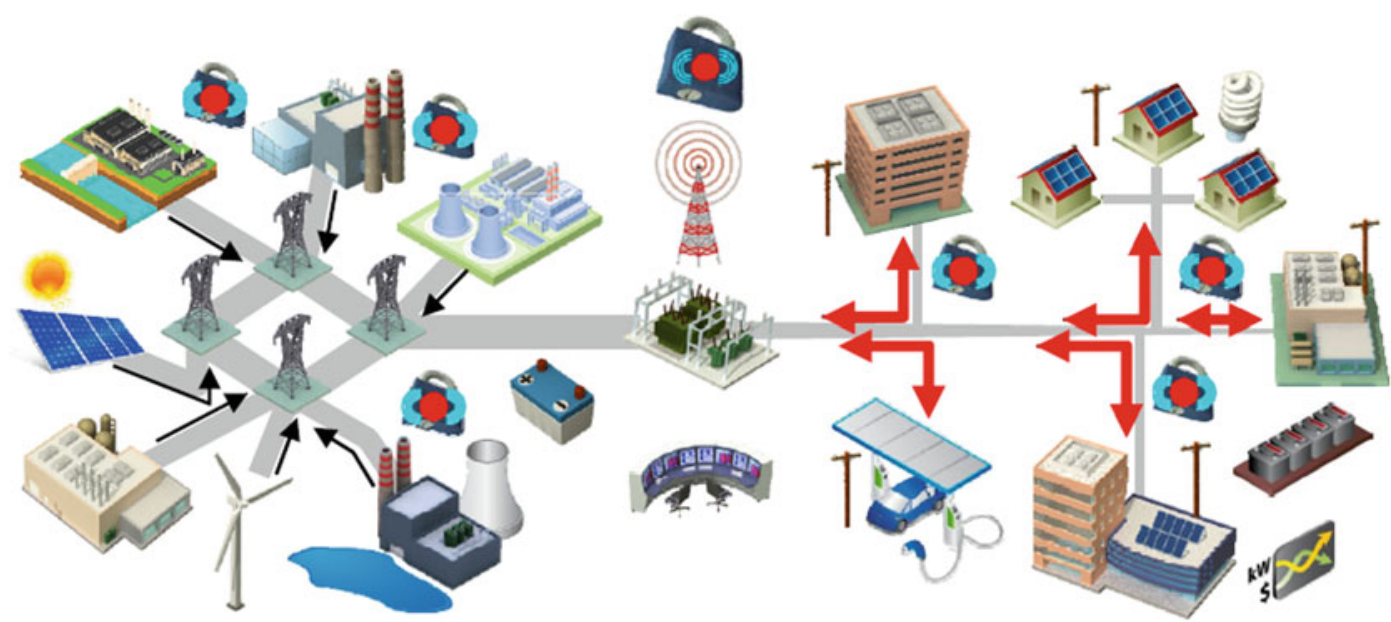

Fig. 28 Future smart grid

will integrate and coordinate different types of load, including distributed power, electric vehicles and smart homes through a communications and control platform. One-way electricity flow will no longer be predominant (Fig. 27 and 28).

\section{(3) Europe}

Development of the smart grid became an important driver for the $\mathrm{EU}$ to deliver its 20-20-20 climate and energy targets for $2020 .{ }^{19}$

\footnotetext{
${ }^{19}$ European Commission, Energy 2020: A strategy for Competitive, Sustainable and Secure energy, 2010, pp. 18-20.
}

The European Commission published Smart Grids: From Innovation to Deployment ${ }^{20}$ in 2011, in which it sets out its policy for the future development of the European grid. The Pan-European Ten-Year Network Development Plan, ${ }^{21}$ released in July 2014, defines 2030 as an important milestone and describes the overall development path for the European grid. The European Network of Transmission System Operators for Electricity (ENTSO-E) released the

\footnotetext{
${ }^{20}$ European Commission, Smart Grids: From Innovation to Deployment, 2011.

${ }^{21}$ ENTSO-E, Ten-Year Network Development Plan 2014, 2014.
} 
fourth version of its 10-year network development plan $^{22}$ in 2016, committing to continue developing the European smart grid.

The Roadmap to Implement the EU's Power Grid Vision, ${ }^{23}$ initiated by the European Commission and developed by two major grid operators in Europe, outlines the future European power system. On the one hand, the European smart grid would comprise interconnections to enable power transfer across borders and grid integration of large volumes of renewable energy. On the other hand, it highlights the importance of distributed energy resources and the combination of advanced measurement and control with effective market mechanisms, thus ensuring real-time balance and redundancy in the grid (Fig. 29).

\section{(4) Japan}

For the Japanese government, the smart grid is a critical tool to develop renewable energy, improve power infrastructure, boost economic growth and hedge against various risks. The Energy Innovation Strategies ${ }^{24}$ unveiled by the Ministry of Economy, Trade and Industry in 2016, target complete energy mix optimisation by 2030 by expanding energy investment, improving energy efficiency, increasing the share of renewable energy and reducing greenhouse gas emissions. This would help deliver the national GDP target of JPY 600 trillion for 2030.

Japan holds the view that the smart grid should make power supply efficient, high quality and reliable by integrating large-scale distributed power systems, high-speed communications technologies, distributed energy resources, energy storage devices and other demand-side resources. Japan's smart grids are divided into national, regional and household (building)

\footnotetext{
${ }^{22}$ State Grid Energy Research Institute Co. Ltd., Analysis Report on Development of Smart Grid in and outside China, Beijing: China Electric Power Press, 2015.

${ }^{23}$ State Grid Energy Research Institute Co. Ltd., Analysis Report on Development of Smart Grid in and outside China, Beijing: China Electric Power Press, 2013, p. 39.

${ }^{24}$ Ministry of Economy, Trade and Industry, Energy Innovation Strategies, 2016, pp. 1-2.
}

levels. Their characteristics differ from level to level. The national level comprises the transmission and distribution networks. Regions include renewable power generation and, given the reliance of renewables on weather conditions, regional demand-supply balance through an energy management system is essential (Fig. 30). Households and buildings focus on the collection of energy consumption data and the optimal control of electric power. ${ }^{25}$

\subsubsection{Generic Technologies in the Smart Grid}

Smart grid technologies are an important driver for the development of the smart grid. Power distribution and retail are the priority fields for innovation in smart grid technologies. Advanced metering infrastructure, advanced distribution automation, microgrids and the intelligent use of electricity are often seen in the smart grid development roadmaps of major countries.

\section{(1) Overview}

First, advanced metering infrastructure (AMI). AMI integrates smart meters, communications networks and data management. It allows two-way communication between the grid and end users. It also provides users with time-of-use or real-time measurement data-such as power consumption, voltage, current and electricity prices - to facilitate efficient power consumption by users and support coordinated grid operation. ${ }^{26}$ A typical AMI architecture is shown in Fig. 31.

AMI could provide power utilities with a communications network that connects with end-user terminals and improves grid control and visibility with the data uploaded by AMI. It is a very important foundation for the smart grid.

\footnotetext{
${ }^{25}$ State Grid Energy Research Institute Co. Ltd., Analysis Report on the Development of Smart Grids in and outside China. Beijing: China Electric Power Press, 2012, pp. 4046.

${ }^{26}$ Advanced Metering Infrastructure and Customer Systems, https://www.smartgrid.gov/recovery_act/ deployment_status/ami_and_customer_systems.html (2015).
} 


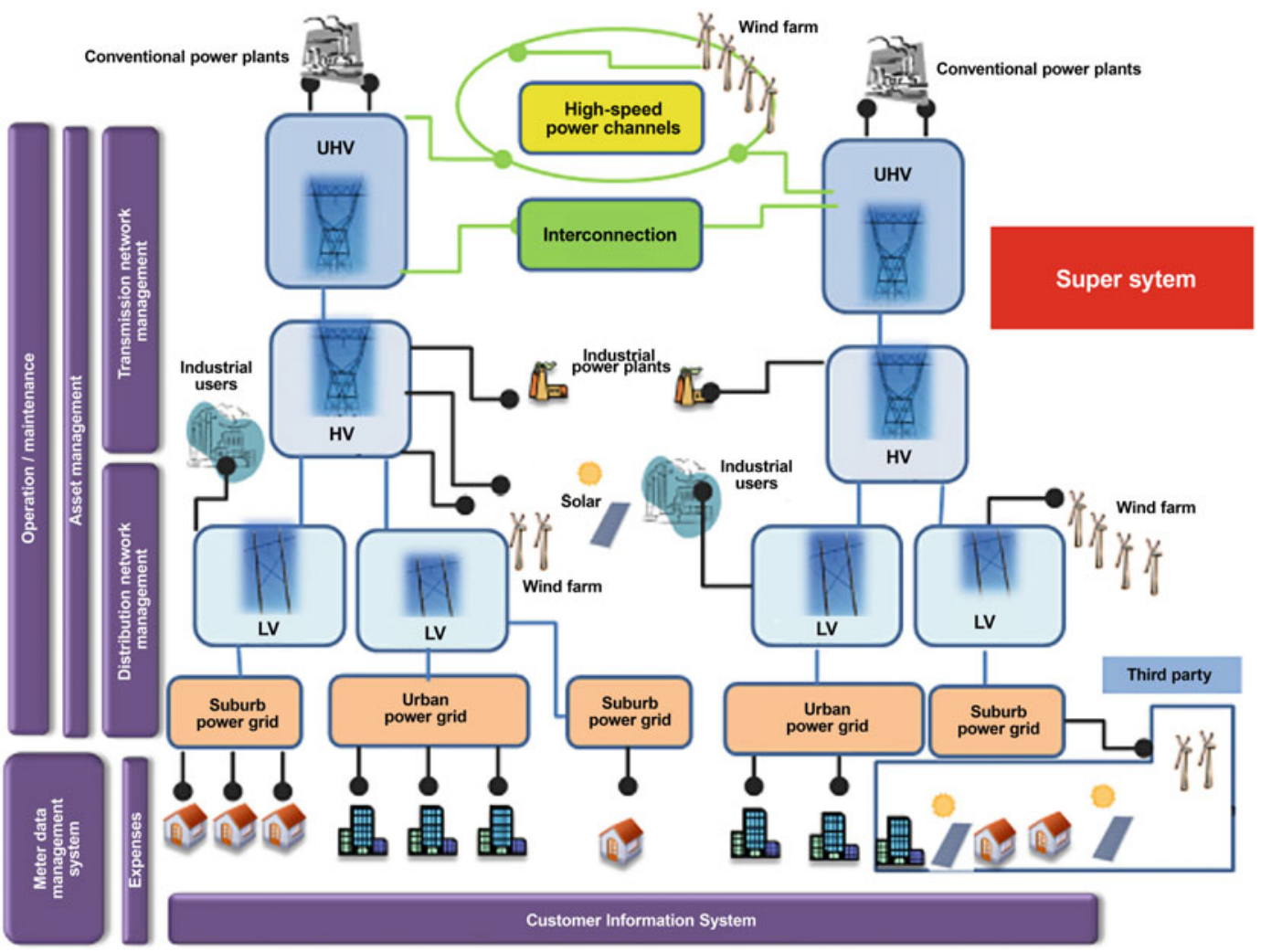

Fig. 29 Pan-European power system 2050. Source State Grid Energy Research Institute Co. Ltd., Analysis Report on Development of Smart Grid in and outside China, Beijing: China Electric Power Press, 2013, p. 39

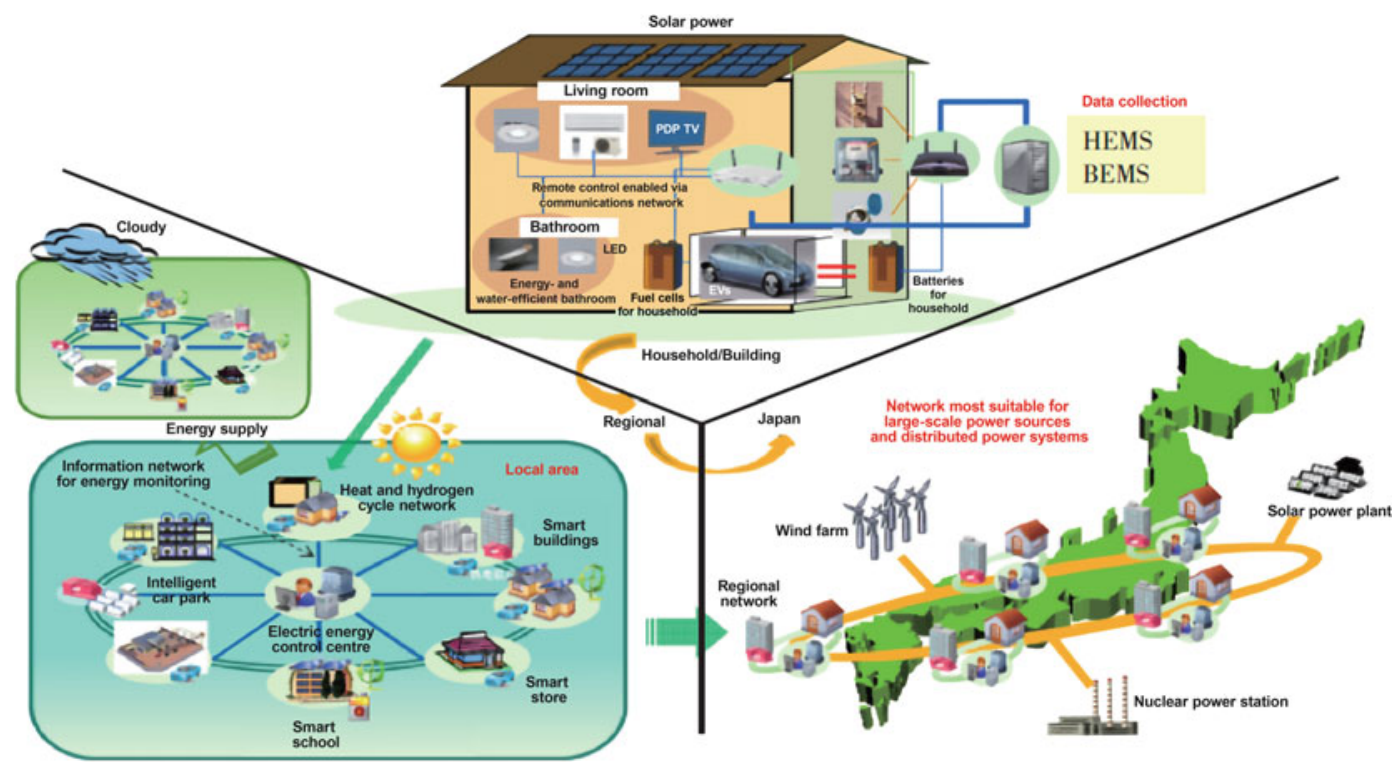

Fig. 30 Japan's smart grid. Source State Grid Energy Research Institute Co. Ltd., Analysis Report on Development of Smart Grid in and outside China. Beijing: China Electric Power Press, 2012, pp. 40-46 
AMI could provide several crucial measurements -including voltage, current and power-to address user requirements and support remote connection or disconnection, two-way metering, and regular or random reading of measurement data. AMI can also act as a gateway to the user's indoor network, providing them with real-time electricity prices and power consumption data, control over the indoor power load, and laying the foundation for demand response.

AMI provides significant benefits in energy use reduction, peak shaving and blackout recovery. Prior to the installation of AMI, US utility PG\&E made 48,000 repair sessions for outage calls each year, which was reduced substantially after AMI was deployed, saving \$43 million annually.

Developed countries conduct extensive R\&D of AMI in areas like automatic collection of power consumption data, measurement abnormity monitoring, power quality monitoring, and electricity consumption analysis and management. In 2009, China started to develop power consumption data collection systems and deploy smart meters. It introduced 24 technical standards on power consumption data collection and 12 technical standards on smart metering. By the end of 2015, State Grid Corporation of China had installed more than 300 million $^{27}$ smart meters.

Second, advanced distribution automation (ADA) uses power electronics, communications and network technologies to integrate topology information, operational and historical data, geographic information and user data with monitoring, protection, control and management of the power distribution network. The configuration and functions of a typical ADA are shown in Fig. 32.

ADA is an integral part of the smart power distribution network. It provides intelligent control of distributed power and energy storage systems, electric vehicle charging and discharging facilities and demand response. It improves power supply reliability, shortens outage

\footnotetext{
${ }^{27}$ Analysis on the Development and Market Prospects of China's Smart Meter Industry, 2016, http://www.chyxx. com/industry/201606/426731.html (2016).
}

recovery times and reduces power cuts and demand rationing. When integrated with other parts of the smart grid, ADA can enhance system monitoring, improve reactive power and voltage management, reduce transmission losses, improve asset utilisation, and optimise operation, scheduling and maintenance activities. ${ }^{28}$ According to American Electric Power (AEP), which owns the largest power transmission system in the USA and is one of the country's biggest power generators, ADA reduced the number and duration of outages by $45 \%$ and $51 \%$ respectively. ${ }^{29}$ By minimising use of line patrol vehicles after power failures, ADA can reduce greenhouse gas emissions.

ADA is being developed in countries like the USA, UK, France, Singapore and Japan. Japan stands at the forefront of ADA. In 1999, ADA helped reduce the average outage in Japan to 3 min per household per year. ${ }^{30}$ China is vigorously promoting ADA across the country. State Grid Corporation of China had deployed ADA across a third of its operating area in 2016. ${ }^{31}$

Third, microgrids. A microgrid is a small, self-contained power generation and distribution system that can operate independently or be integrated into a larger grid. Microgrids can supply one user, like a campus or military base, or multiple users across an island or geographic area.

The main functions of a microgrid are: first, autonomous operation. A microgrid operates autonomously and stably and meets the demand for power by itself. Second, it reduces power supply volatility by stabilising fluctuations in generation and consumption and by maintaining power and voltage stability at the point of connection with other grids. Third, it provides

\footnotetext{
${ }^{28} \mathrm{Yu}$ Yixin and Luan Wenpeng, Smart Grid, Power System and Clean Energy, vol. 25, 2009, pp. 10-11.

${ }^{29}$ AEP Ohio, Final Technical Report, 2014, pp. 169-216.

${ }^{30}$ Liu Yong and Han Wen, Development of China's Power Distribution Network vs. Construction of Japan's Power Distribution Network, https://wenku.baidu.com/ view/e6b524cbfc4ffe473268abb6.html (2016).

${ }^{31}$ State Grid Corporation of China, Social Responsibility Report, 2016, pp. 36-37.
} 


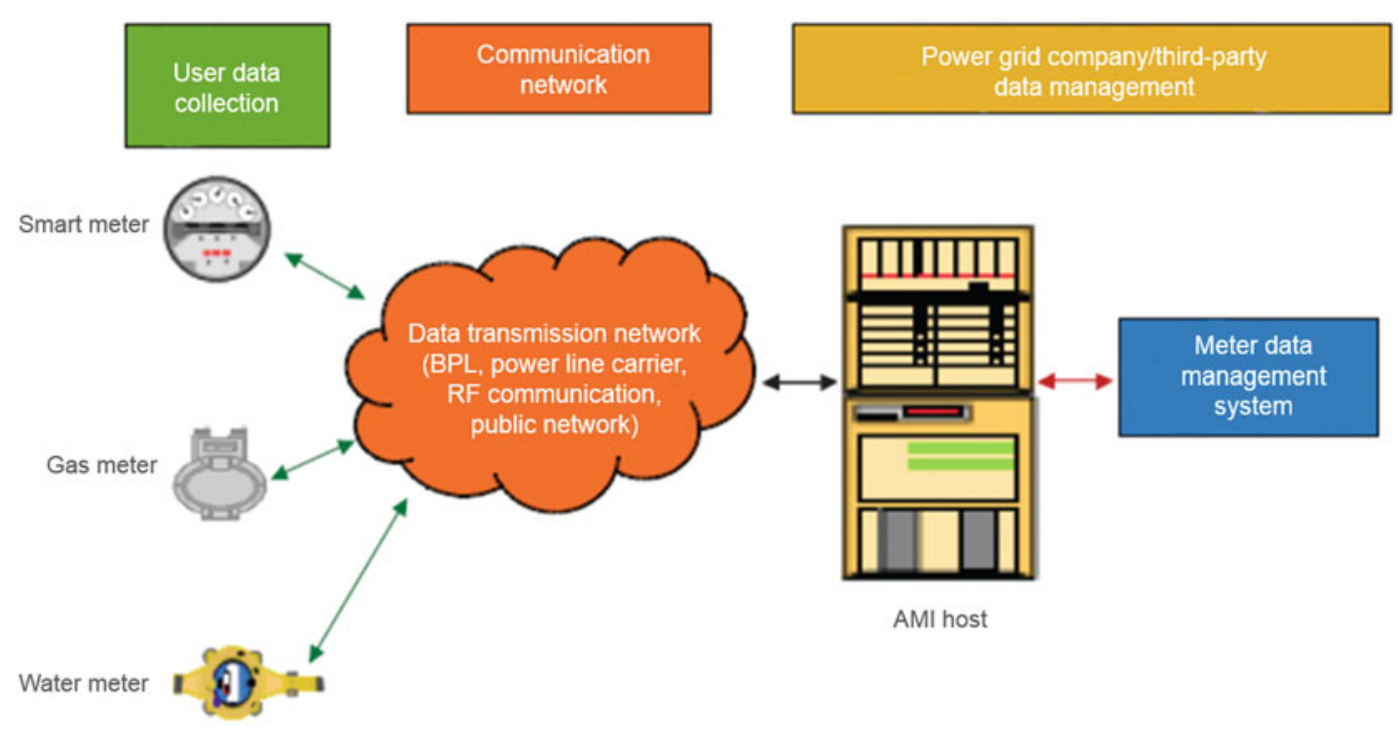

Fig. 31 Typical AMI architecture. Source EPRI, Advanced Metering Infrastructure, 2007, p. 1

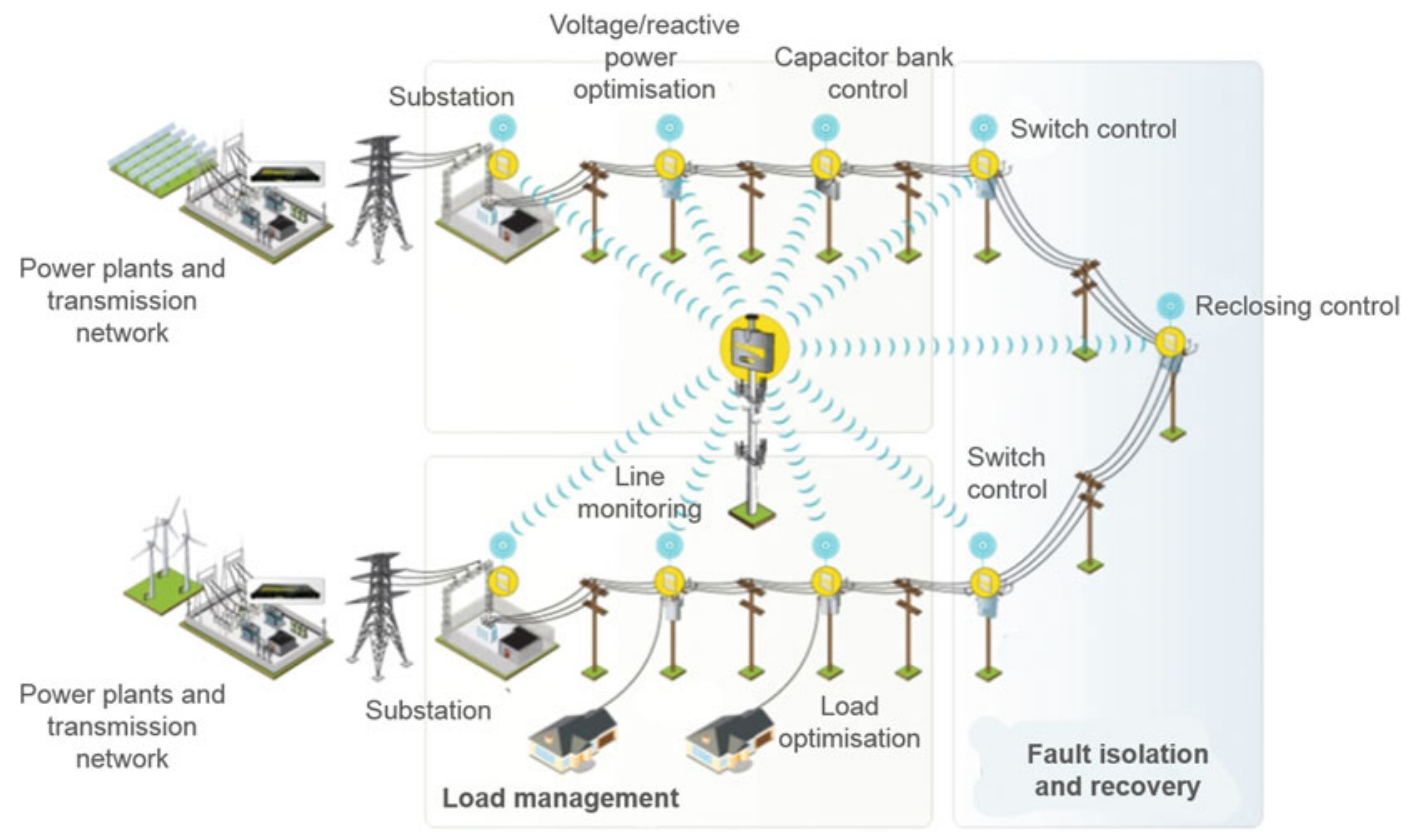

Fig. 32 Configuration and functions of advanced distribution automation. Source Distribution Automation, http://ruggedcom.net.ua/applications/electric-utilities/da.html

ancillary services by increasing power output or reducing power loads.

Increasingly mature microgrid technologies enable the integration of renewable energy, which reduces the use of fossil fuel generation and lowers greenhouse gas emissions. Flexible and parallel operation of the microgrid with the public grid enables peak shaving and better use of grid equipment. Developed countries have carried out in-depth research on microgrid 


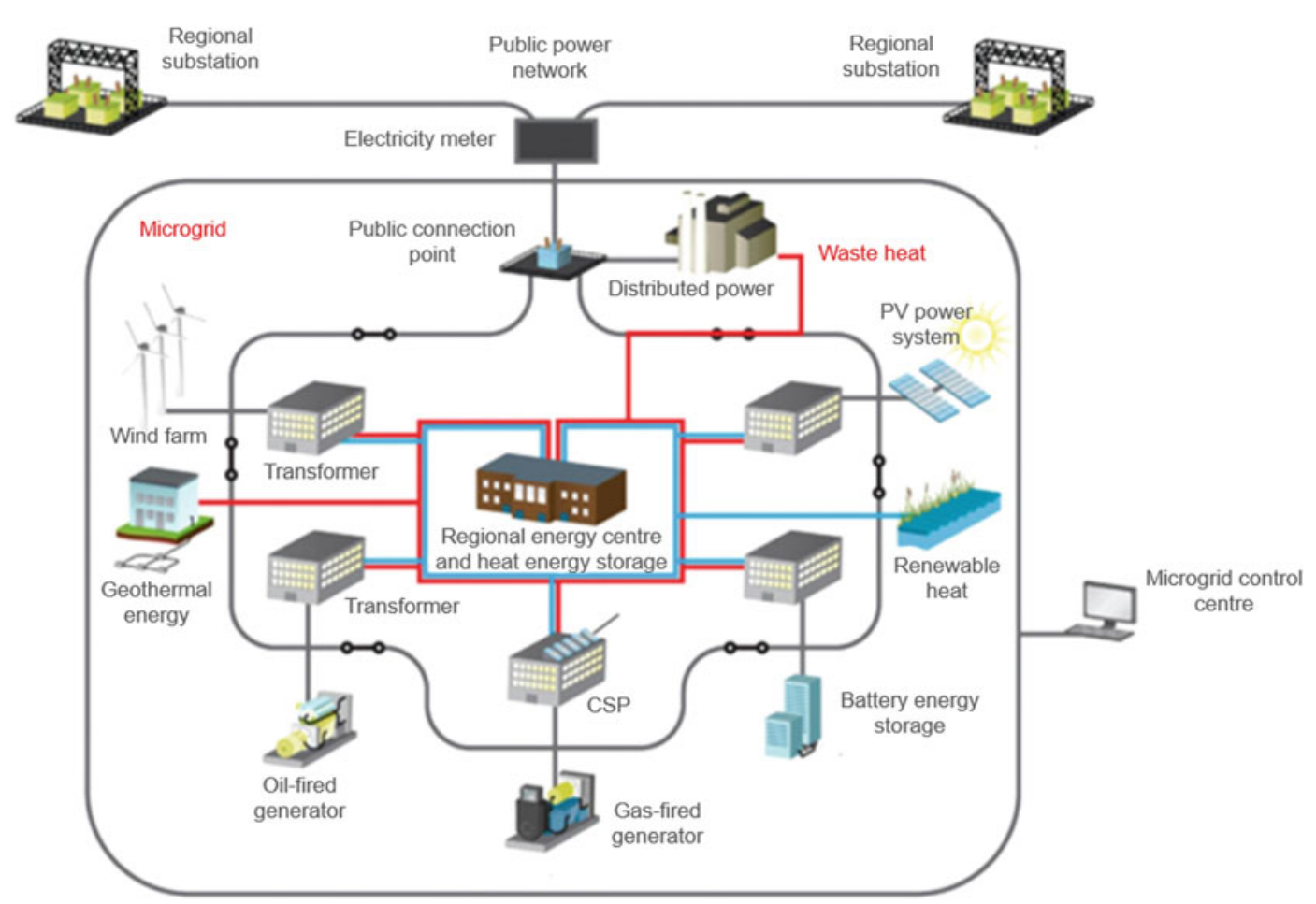

Fig. 33 Microgrid. Source NYPrize: Building Community Microgrids in New York. http://earthdesk.blogs.pace.edu/ 2014/02/03/nyprize-building-community-microgrids-in-new-york/, (2014)

technologies and constructed several pilot projects, such as Continuon's (now Liander) facility in the Netherlands, EDP's microgeneration facility in Portugal, the Mad River Park microgrid in Vermont, USA, and the Aichi microgrid in Japan. China also has several pilot microgrid projects, including those at Sino-Singapore Tianjin Eco-City; Henan University of Economics and Law; the Guangdong Foshan combined cooling, heat and power (CCHP) microgrid system; and the integrated solar, wind, diesel, energy storage and seawater desalination system on Zhejiang Dongfushan Island (Fig. 33).

Fourth, the intelligent use of electricity is an important area that demonstrates the advantages of the smart grid. It optimises resource allocation, enables peak shaving and reduces the cost of electricity by guiding users to manage their power consumption efficiently. As smart homes, electric vehicles and other power-driven devices evolve and become more flexible, technologies related to demand response, battery charging and discharging will make two-way intelligent electricity use services possible.

Demand response enables end users to change their power consumption behaviour in response to market price signals or incentive mechanisms. Demand response is mainly incentive- or time-based electricity pricing. Incentive-based demand response rewards users who consume less electricity during peak periods, thus lowering power loads. Time-based pricing strategies guide users to change their power demand by providing them with electricity pricing data (Fig. 34).

The rapid development of electric vehicles (EV) could have a major impact on the future power distribution system. EV-related technologies are divided into vehicle technologies (including battery management, engine, power 
control, safety, etc.) and charging/discharging technologies (such as battery swapping, two-way grid interaction and battery cascading).

The development of intelligent electricity use technologies improves equipment utilisation, reduces the cost of operation and maintenance and lowers energy consumption. Demand response can smooth out the load curve and reduce power supply costs in short-term power markets. If there is a power shortage or wholesale prices are high, demand response can adjust prices to level out price fluctuations. In long-term power markets, demand response reduces peak power demand to avoid or slow down the need for new investment; and it improves safety and power system stability by taking advantage of users' response to electricity prices. ${ }^{32}$ The USA has abundant experience of demand response and has standards and an industry alliance for automated demand response known as OpenADR. China started to research demand response and launch pilot projects in 1998, making great progress. In 2016, the Action Plan for Innovation in the Energy Technology Revolution (2016-30) ${ }^{33}$ proposed research on demand response-based technologies to make China's power consumption more intelligent.

Electric vehicles and hybrid electric vehicles (HEVs) have a significant impact on power distribution and use. As EV ownership increases and battery performance improves, EV batteries can be used as mobile energy storage units, charging during non-peak hours and supplying electricity to the grid during peak hours, thereby reducing valley-peak fluctuations in demand and improving grid efficiency. In microgrids with a high proportion of renewable power, electric vehicles can be used to store energy during periods of high renewable output and low load, and discharge the energy into the grid when

\footnotetext{
${ }^{32}$ Zhao Xin and Gao Shan, Demand Response and Advanced Metering in the US Electricity Market, in Power Demand Side Management, vol. 9, 2007, pp. 6869.

${ }^{33}$ National Development and Reform Commission and National Energy Administration, The Action Plan for Innovation in the Energy Technology Revolution (201630), 2016, pp. 8-10.
}

renewable power output is low and demand high (vehicle-to-grid, V2G), which strengthens the grid's capacity to absorb renewable power (Fig. 35).

EVs and HEVs are more energy efficient than fossil fuel vehicles. In the USA, ${ }^{34}$ the deployment of smart charging facilities could increase the share of EV mileage by light vehicles by 9 percentage points (from $64 \%$ to $73 \%$ of the total). Compared with fossil fuel vehicles, EV and HEV light vehicles use 2-5\% less energy. Currently, China has built a proprietary standard system of EV charging/battery swap facilities and is constructing a network of rapid-charging stations along urban roads and motorways. A rapid charging network has been built from Beijing-Harbin, Beijing-Hong Kong-Macao, Beijing-Shanghai, ShanghaiChengdu, Shanghai-Chongqing, on Beijing ring roads and the Hangzhou Bay ring expressway, covering 95 cities and 14,000 km of expressway.

\section{(2) Demonstration projects}

\section{AEP GridSMART Demonstration Project, USA}

The AEP GridSMART Demonstration Project comprises nine technical demonstration domains, including advanced metering, home area networks and redistribution management. Its advanced metering infrastructure (AMI) and demand response capability have made remarkable achievements in reducing carbon and PM2.5 emissions and improving grid efficiency (Table 11).

After the deployment of AMI, the average $\mathrm{CO}_{2}$ reduction was 16.91 tonnes per month, amounting to 406 tonnes per year. AMI saved AEP from reading meters on-site, avoiding 5,694 miles $(9,163 \mathrm{~km})$ of travel per month, and about 68,326 miles $(109,960 \mathrm{~km})$ per year. Assuming that driving one mile generates $423 \mathrm{~g}$ of $\mathrm{CO}_{2}$ on average, this amounts to reductions in $\mathrm{CO}_{2}$

\footnotetext{
${ }^{34}$ DOE, The Smart Grid: An Estimation of the Energy and CO2 Benefits, 2010, pp. 3.25-3.27.
} 


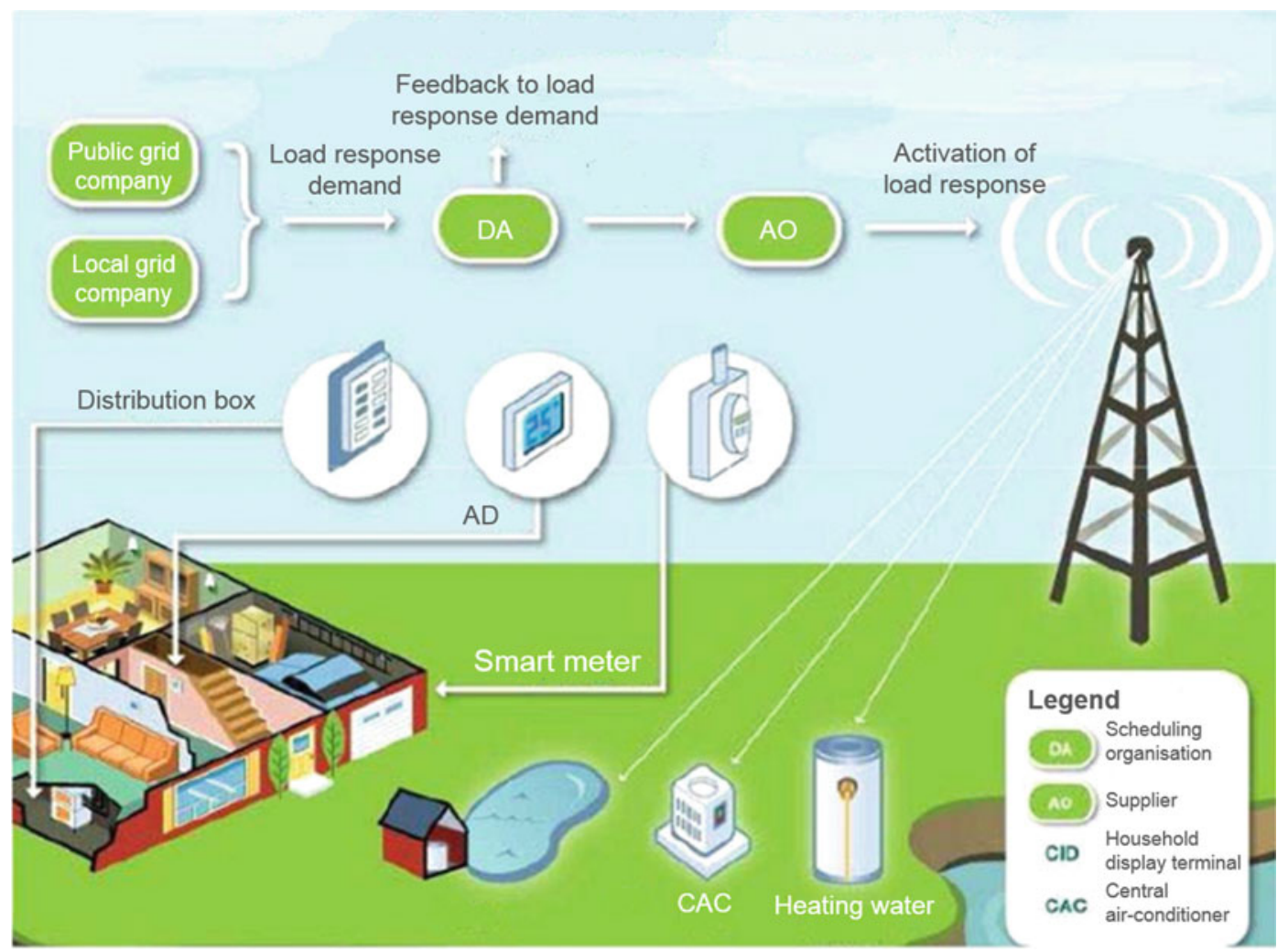

Fig. 34 Demand response. Source Rodan Energy, Demand Response and the Smart Grid in Ontario, 2012, p. 11

emissions from driving of 2,408 tonnes per month or 28,903 tonnes per year (Figs. 36, 37).

Moreover, the project saved $0.956 \mathrm{~kg}$ of $\mathrm{NO}_{\mathrm{x}}$ on average per month, amounting to $22.9 \mathrm{~kg}$ over the two years of its duration, as well as $0.220 \mathrm{~kg}$ of $\mathrm{SO}_{\mathrm{x}}$ per month on average $(5.3 \mathrm{~kg}$ over the two years) and $0.191 \mathrm{~kg}$ of PM2.5 per month on average ( $4.6 \mathrm{~kg}$ over the two years).

The project's demand response products include SMART Shift, SMART Shift Plus and SMART Choice. SMART Shift and SMART Shift Plus provide users with electricity price information for different time periods in power supply contracts. SMART Choice provides users with quasi real-time electricity price information that is updated every 5 min to guide users' power consumption behaviour. Demand response plays an active role in reducing energy consumption and fossil fuel emissions and in peak load shaving.
As shown in Fig. 38, SMART Shift and SMART Shift Plus users consume less power and emit less $\mathrm{CO}_{2}$. Calculation ${ }^{35}$ results show that under these three modes, nearly 196 tonnes of $\mathrm{CO}_{2}$ could be reduced.

Figure 39 shows that SMART Shift and SMART Shift Plus users consume less power and reduce their emissions of $\mathrm{SO}_{\mathrm{x}}, \mathrm{NO}_{\mathrm{x}}$ and PM2.5 by about $749 \mathrm{~kg}, 335 \mathrm{~kg}$ and $284 \mathrm{~kg}$ respectively.

\section{Sino-Singapore Tianjin Eco-City Smart Grid demonstration project}

The project comprises distributed power generation, microgrids and energy storage systems, intelligent substations, power distribution automation, equipment status and power quality monitoring systems, visualisation platform, power

\footnotetext{
${ }^{35}$ AEP Ohio, Final Technical Report, 2014, pp. 115-116.
} 


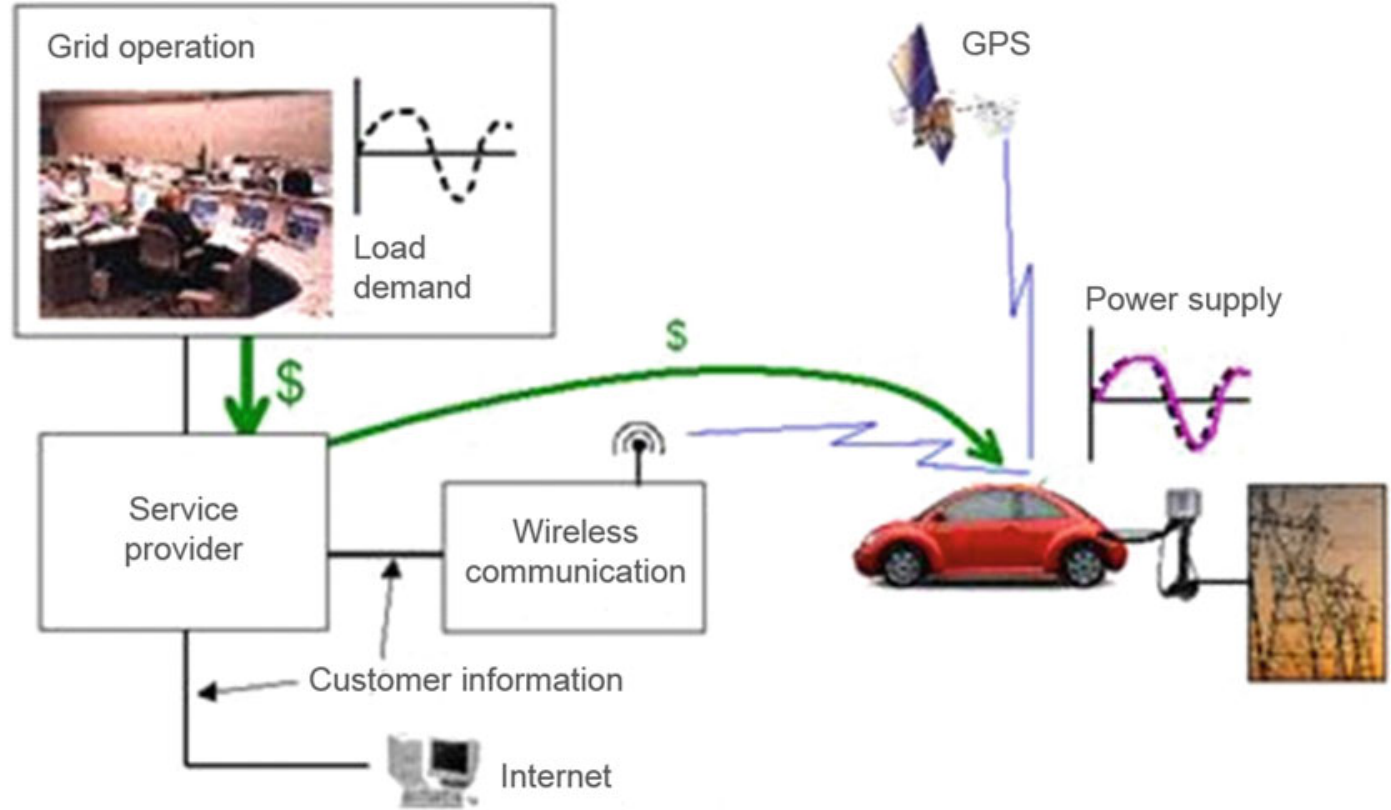

Fig. 35 Vehicle-to-grid. Source A market study on hybrid vehicles and the concept of V2G. https://www.dolcera.com/ wiki/index.php?title=A_market_study_on_Hybrid_vehicles_and_the_concept_of_V2G

Table 11 Profile of the AEP GridSMART Demonstration Project

\section{Item}

Residents

Employees in commercial and industrial fields

Peak load:

Summer

\section{Winter}

Total electricity sold:

To residential users

To industrial and commercial users

Total number of substations

Total number of power distribution lines

Total length of power distribution lines

Total length of power transmission lines

Number
100,000
10,000
$800 \mathrm{MW}$
$650 \mathrm{MW}$
3.5 million MWh
1.2 million MWh
1 million MWh
16
80
3,000 miles
0

AEP Ohio, Final Technical Report, 2014, p. 6

consumption data acquisition system, intelligent community/building, EV charging facilities, intelligent service, and a communications and information network (Fig. 40).
Different types of distributed energy are connected to the grid, including $40 \mathrm{MW}$ of solar power, $10 \mathrm{MW}$ of biomass power, $125 \mathrm{MW}$ of wind power and 1.5 MW of gas-fired combined 


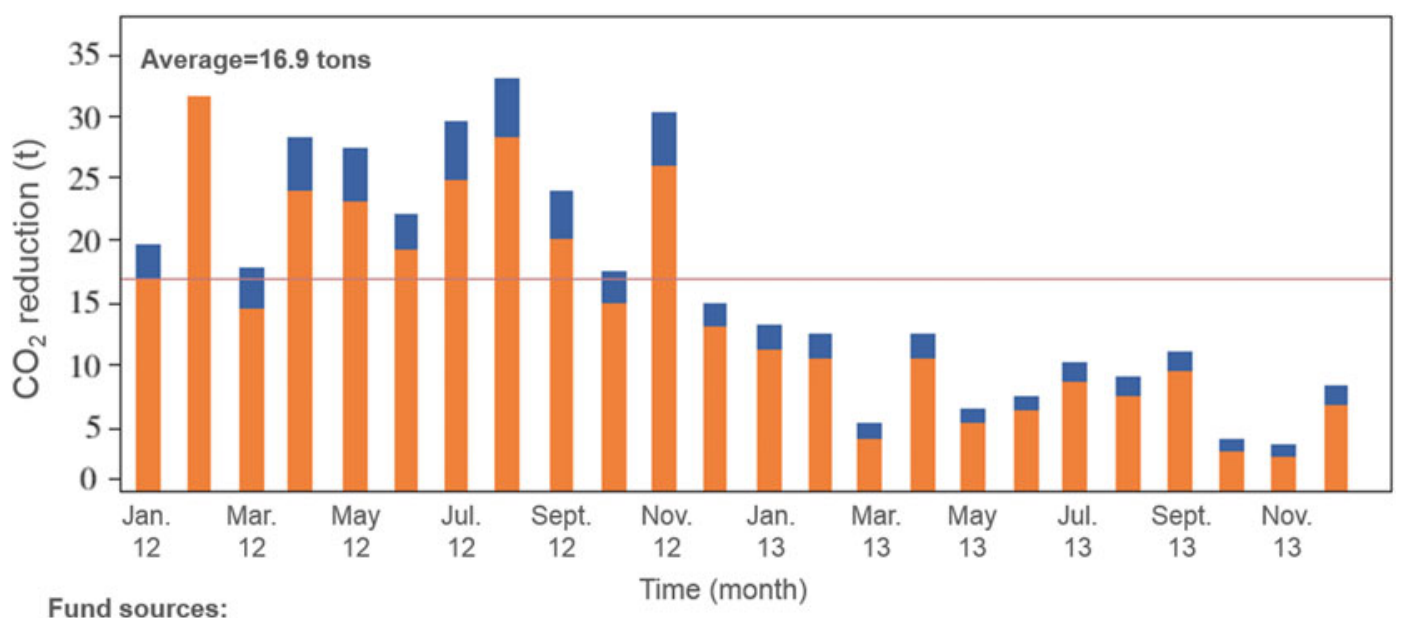

Fund sources:

Time (month)

AEP Ohio — The US Department of Energy

Fig. $36 \mathrm{CO}_{2}$ reduction after deployment of AMI. Source AEP Ohio, Final Technical Report, 2014, p. 35

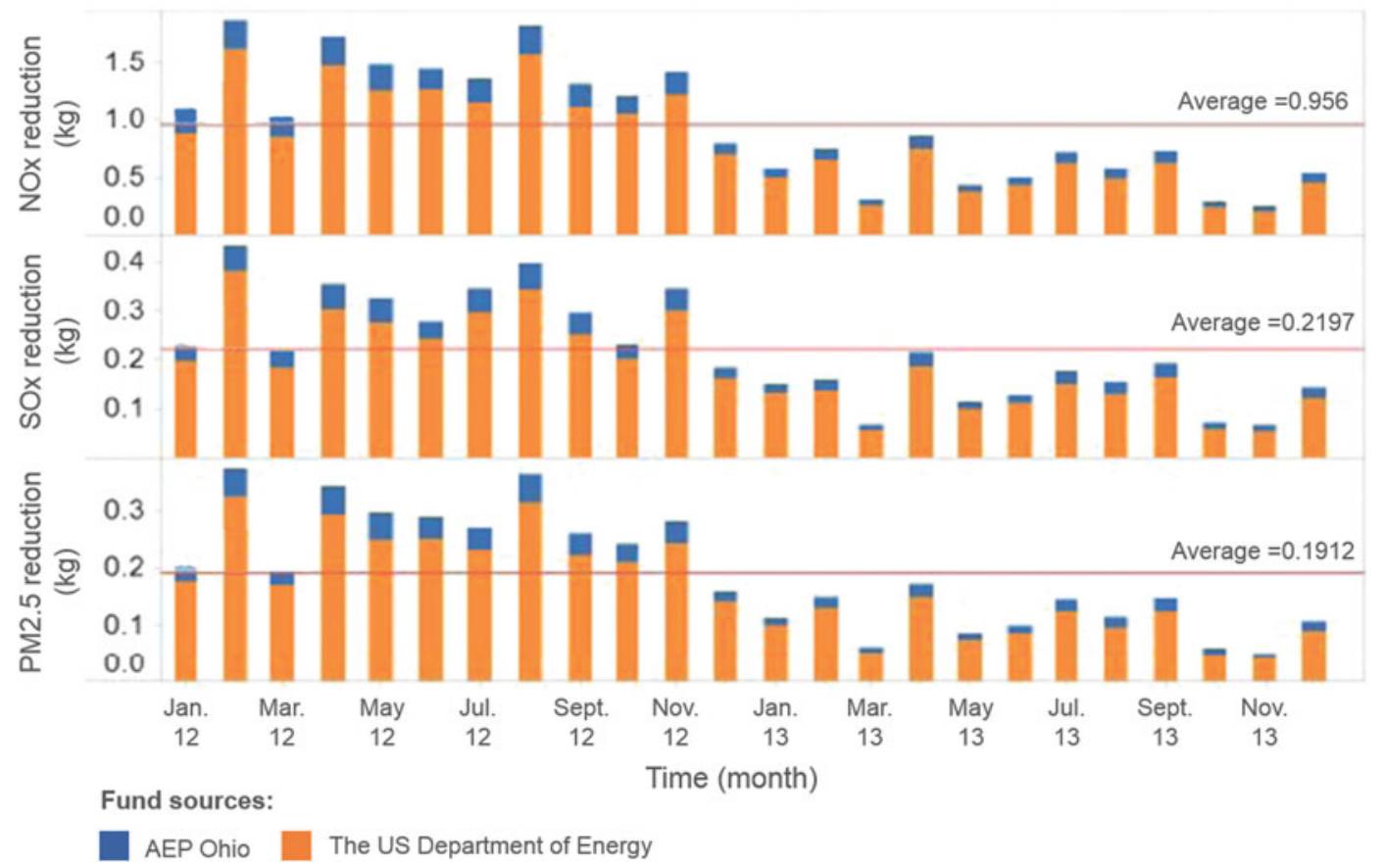

Fig. 37 Reduction of air pollutants after deployment of AMI. Source AEP Ohio, Final Technical Report, 2014, p. 39

cooling, heat and power. The microgrid is supplied by distributed power from a $30 \mathrm{kWp}$ solar power system and $6 \mathrm{~kW}$ wind turbines. The energy storage system is a $15 \mathrm{~kW} \times 4 \mathrm{~h}$ lithium-ion battery. Microgrid loads include $10 \mathrm{~kW}$ of lighting and
$5 \mathrm{~kW}$ of EV charging piles. Intelligent control of the grid is realised through a microgrid energy management system. Thanks to the deployment of technologies like power distribution automation, equipment monitoring system, intelligent 


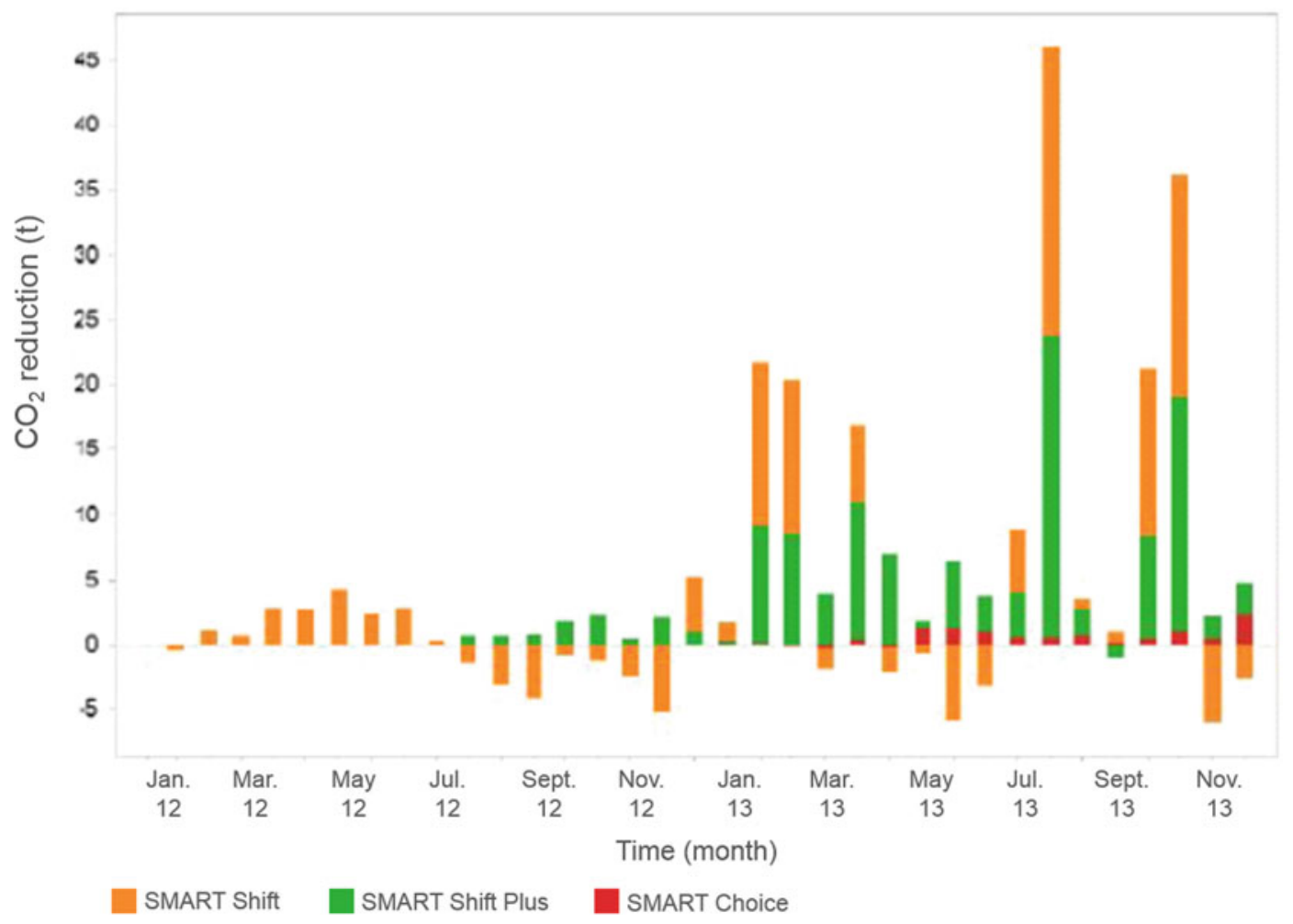

Fig. 38 Monthly increase/reduction of $\mathrm{CO}_{2}$ emissions with SMART Shift, SMART Shift Plus and SMART Choice. Source AEP Ohio, "Final Technical Report, 2014, p. 115

scheduling and smart substations, the eco-city's power supply reliability, voltage qualified rate and $\mathrm{N}-1$ pass rate stand at $99.999 \%, 100 \%$ and $100 \%$ respectively, and the overall line loss is reduced by $1.18 \%$, improving energy supply reliability. ${ }^{36}$

The Sino-Singapore Tianjin Eco-City Smart Grid demonstration project aims to verify new smart grid technologies, specifications, equipment performance and to test smart grid technologies in a comprehensive way. Its economic benefits include lower investment costs, reduced line losses, improved power supply reliability, lower operation and maintenance costs and enhanced operating efficiency (Fig. 41). The project saves 1,074 tonnes of fuel oil and 5,929 tonnes of standard coal equivalent (SCE) per

\footnotetext{
${ }^{36}$ Full Record of Smart Eco-city Part of deployment: Overview of the Sino-Singapore Tianjin Eco-City Smart Grid Demonstration Project. http://www.sgcc.com.cn/ztzl/ newzndw/sdsf/09/254912.shtml (2011).
}

year and reduces $\mathrm{CO}_{2}$ emissions by 18,488 tonnes annually. ${ }^{37}$

3. Henan University of Economics and Law microgrid project

The project is located at the university campus. The microgrid comprises one $380 \mathrm{~kW}$ solar photovoltaic (PV) system and a $2 \times 100 \mathrm{~kW} / 100 \mathrm{kWh}$ energy storage system. It supplies seven dormitory buildings. The microgrid controls the power distribution system for the buildings and canteens in Power Distribution Zone IV at the university, including two energy storage systems and 32 low voltage power distribution lines. It also communicates with the power scheduling system. During operation, the

\footnotetext{
${ }^{37}$ State Grid Energy Research Institute Co. Ltd., Analysis Report on the Development of Smart Grids in and outside China. Beijing: China Electric Power Press, 2013, pp. 103-106.
} 


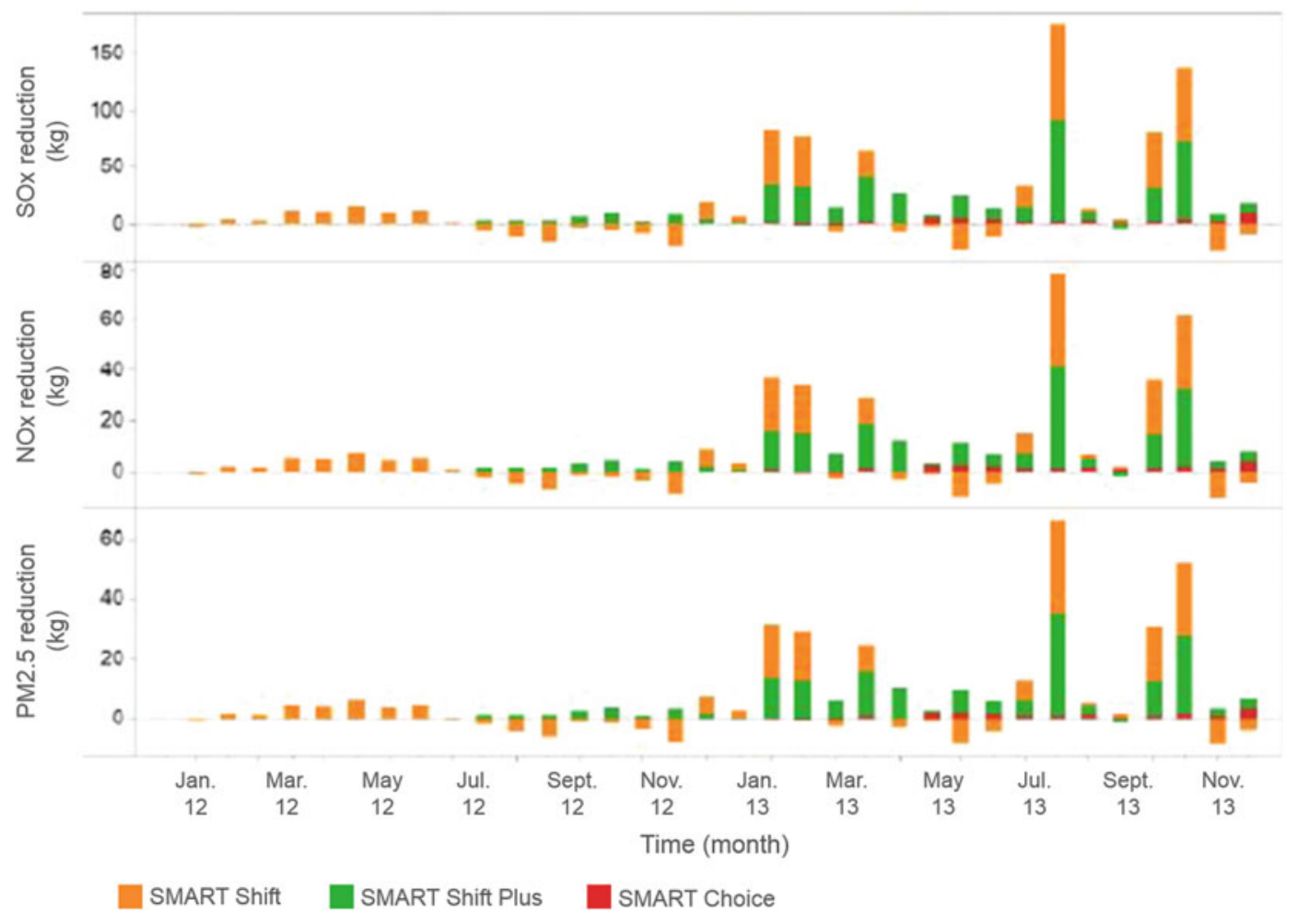

Fig. 39 Monthly increase/reduction of $\mathrm{SO}_{\mathrm{x}}, \mathrm{NO}_{\mathrm{x}}$ and PM2.5 with SMART Shift, SMART Shift Plus and SMART Choice. Source AEP Ohio, Final Technical Report, 2014, pp. 118-119

microgrid minimises power consumption from the public grid by storing excess energy from the PV system when output is greater than demand, and by releasing that stored power into the microgrid during peak hours. ${ }^{38}$

Taking into account annual sunshine hours at Henan University, PV power generation from the microgrid could supply about $880,000 \mathrm{kWh}$ of electricity per year, helping the university save RMB 492,800 annually. If its service life is 20 years, ${ }^{39}$ the cumulative power output will be 20 GWh, which means a saving of RMB 11.2 million in the university's energy spend. Calculations

\footnotetext{
${ }^{38}$ Successful joint debugging of the first distributed PV power generation and grid operation and control pilot project in Henan, http://news.163.com/11/0214/09/ 6SRI3GBM00014AED.html.

${ }^{39}$ Successful joint debugging of the first distributed PV power generation and grid operation and control pilot project in Henan, http://news.163.com/11/0214/09/ 6SRI3GBM00014AED.html.
}

based on the demonstration results show that the project will generate $2.336 \mathrm{GWh}$ of electricity per year, amounting to $58.40 \mathrm{GWh}$ in 25 years. This means direct economic benefits of RMB 32.704 million. Compared to thermal power, the microgrid could save about 21,030 tonnes of SCE and avoid 39,960 tonnes of $\mathrm{CO}_{2}, 684$ tonnes of $\mathrm{SO}_{2}, 615$ tonnes of $\mathrm{NO}_{\mathrm{x}}, 975$ tonnes of dust and 19,565 tonnes of ash. ${ }^{40}$

\subsubsection{Outlook}

The smart grid is an important enabler of the energy revolution. Statistics from the International Energy Agency ${ }^{41}$ show that energy conservation and energy efficiency improvements enabled by the smart grid can reduce $\mathrm{CO}_{2}$

\footnotetext{
${ }^{40}$ Successful joint debugging of the first distributed PV power generation and grid operation and control pilot project in Henan, http://news.163.com/11/0214/09/ 6SRI3GBM00014AED.html.

${ }^{41}$ IEA, Technology Roadmaps: Smart Grids, 2011, p. 28.
} 


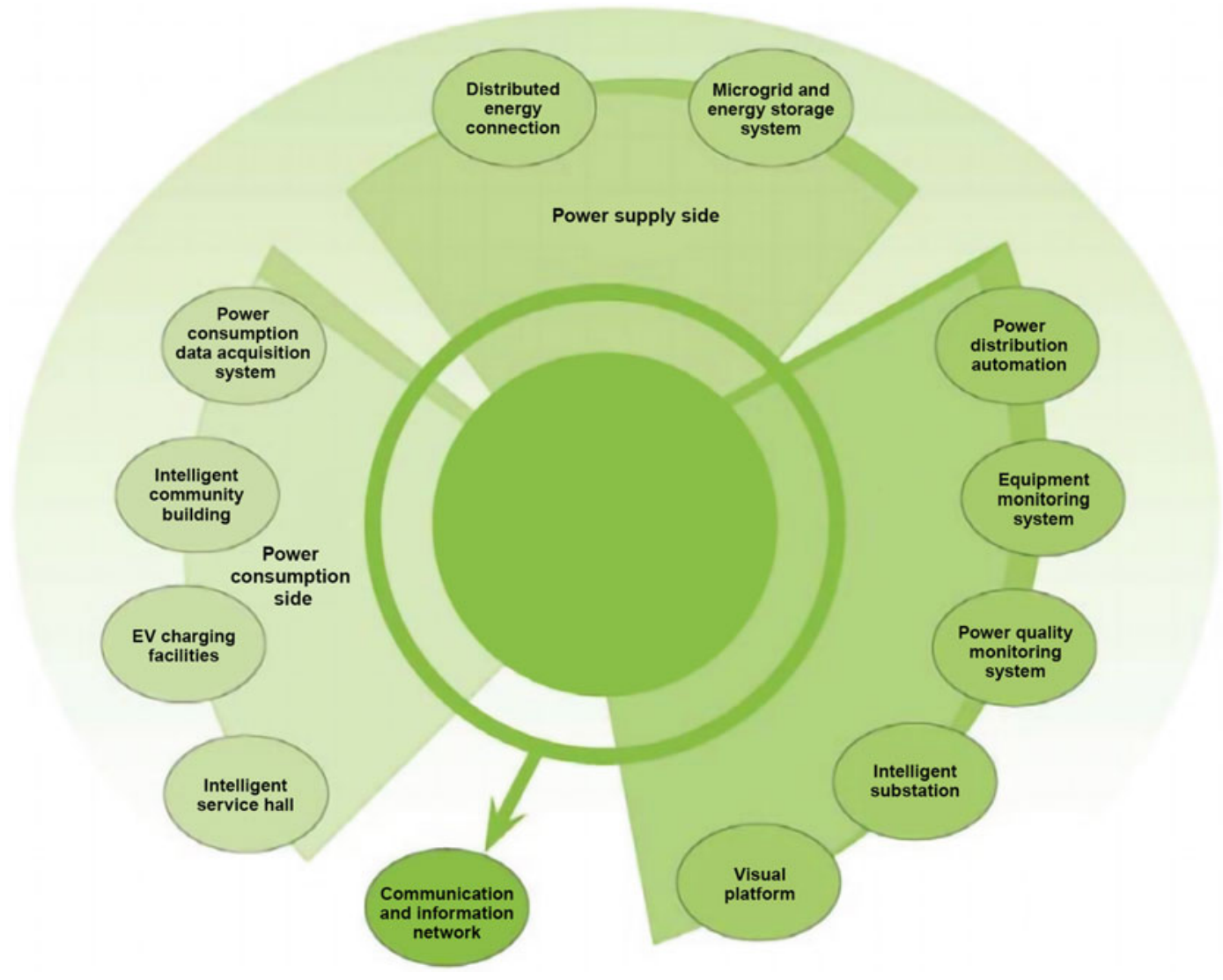

Fig. 40 Architecture of Sino-Singapore Tianjin Eco-City Smart Grid demonstration project. Source State Grid Energy Research Institute Co. Ltd., Analysis Report on

emissions by more than 840 million tonnes by 2030, and renewable energy and EV charging can reduce $\mathrm{CO}_{2}$ emissions by more than 3 million tonnes. As exploration deepens, technology innovation will expand the scope and forms of the smart grid.

First, the smart grid will continue to grow at high speed. Global power demand in 2030 will be double that of $2000 .^{42}$ To meet increasing demand, more investment will be needed in smart grids. According to the International Energy Agency, ${ }^{43}$ China will invest at least $\$ 96$ billion in the smart grid by 2020 , and the world will invest $\$ 2$ trillion by 2030 . $^{44}$

\footnotetext{
${ }^{42}$ IEA, Technology Roadmaps: Smart Grids, 2011, p. 26.

${ }^{43}$ IEA, Technology Roadmaps: Smart Grids, 2011, p. 21.
}

the Development of Smart Grids in and outside China. Beijing: China Electric Power Press, 2013, pp. 103-106

Second, the share of new energy in the energy mix will be higher. Climate change is a global concern. Most countries base their energy strategies on greenhouse gas emission targets, using those targets to calculate the share of new energy needed. The Institute of Electrical and Electronics Engineers (IEEE) predicts that by 2030, wind and solar will account for more than a third of global power supply. ${ }^{45}$ The EU has set the following targets for 2030: the share of renewable energy will be at least $32 \%$, the

\footnotetext{
${ }^{44} \$ 2$ Trillion will be Invested in the Global Smart Grid Market by 2030, http://smartgrids.ofweek.com/2012-01/ ART-290010-8470-28595501.html.

${ }^{45}$ IEEE, IEEE Vision for SG 2030, 2013, pp. 80-81.
} 

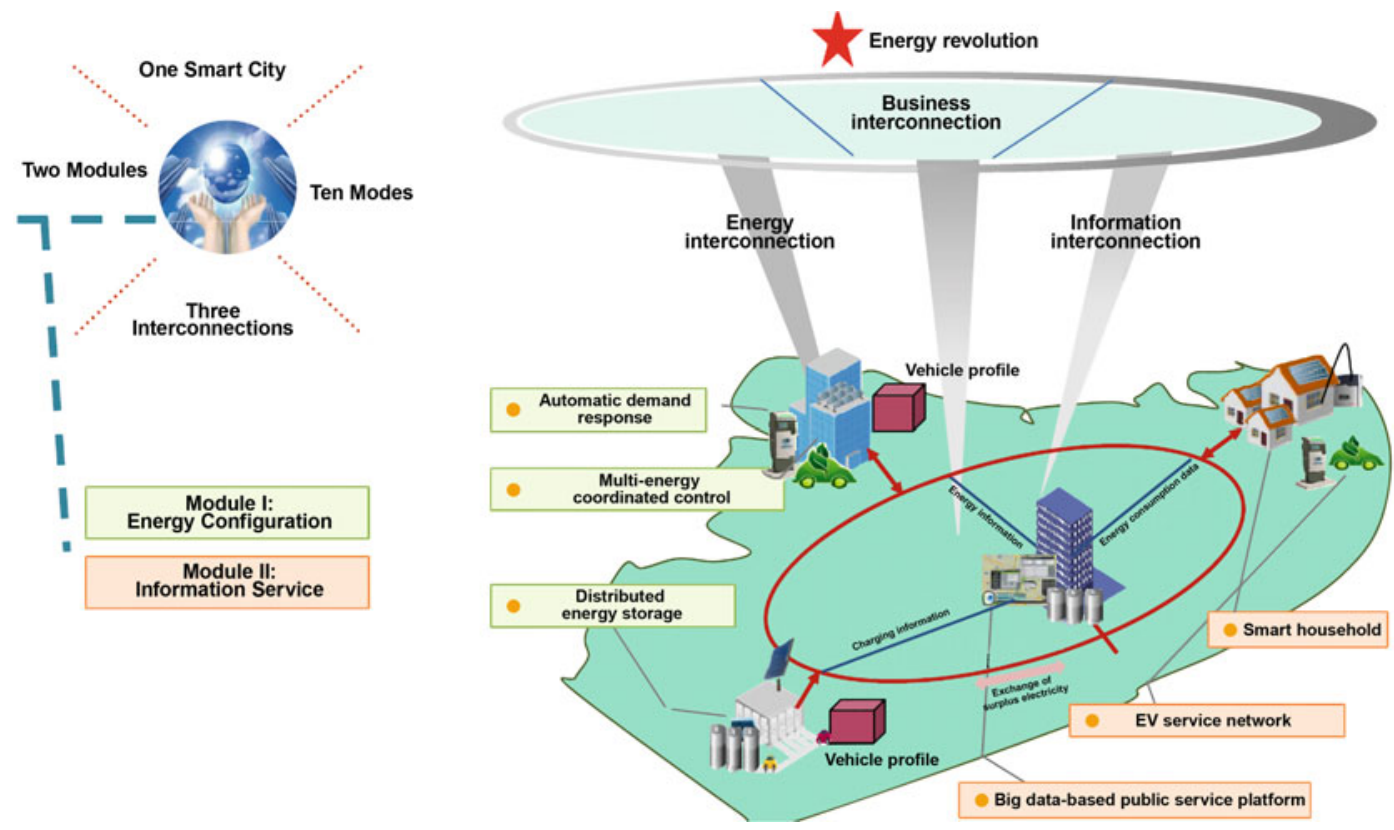

Fig. 41 Sino-Singapore Tianjin Eco-City Smart Grid demonstration project. Source Full Record of Smart EcoCity Part of deployment: Overview of the Sino-Singapore

improvement in energy efficiency will be at least $32.5 \%$, and greenhouse gas emissions will be at least $40 \%$ lower than in 1990. The Energy Innovation Strategies unveiled by the Ministry of Economy, Trade and Industry of Japan aim to increase the share of renewable energy to 22$24 \%$ by 2030 and reduce greenhouse gas emissions by $26 \%$ (compared with 2013). Thanks to continuous innovation, China expects to make breakthroughs in wind, solar, biomass, geothermal and marine energy technologies in terms of efficiency, costs and flexibility. Distributed energy systems, comprising multiple types of energy — wind, solar, energy storage and small gas turbines - will be widely deployed and efficiently integrated. This will help China achieve its goal of increasing the share of non-fossil energy in primary energy consumption to around $20 \%$ by 2030.

Third, large-scale grid connection of intermittent energy makes customer requirements increasingly demanding and grid operation more complex. To improve grid visibility and control, IT and automation technologies will be widely
Tianjin Eco-City Smart Grid Demonstration Project, http://www.sgcc.com.cn/ztzl/newzndw/sdsf/09/254912. shtml, (2011)

applied, making grid operation and control more intelligent. IEEE holds the view that ${ }^{46}$ full integration of grid and information and communications technologies (ICT) will improve grid monitoring speed by about 1,000 times. ICT-related equipment will become a major component of modern grid investment. Global grid modernisation needs around $\$ 6.9$ trillion invested by 2030 , of which about $\$ 1.7$ trillion (one-fourth of the total) will be invested in ICT-related equipment. By 2030, China's smart grid will achieve deep integration of information and power flows and become a highly integrated information and physical network. Power system coordination and control of energy source, grid and load will become more intelligent and efficient, and operation safer and more stable. Low-cost and secure quantum communications technologies will become an $\mathrm{R} \& \mathrm{D}$ priority to ensure information security in the smart grid.

Fourth, two-way interaction between supply and demand will improve. Deep integration

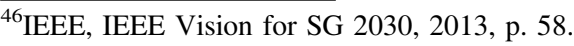


between the grid, big data, cloud computing, the Internet of things, mobile Internet and Internet + (the Energy Internet) offers huge opportunities to enrich power services. By innovating new services and creating win-win business ecosystems, power utilities can smooth load volatility and reduce grid investment. According to Power Perspectives $2030,{ }^{47}$ demand response will account for $10 \%$ of daily load in the EU by 2030 , reducing demand for grid and backup capacity by $10 \%$ and $35 \%$ respectively, thereby saving EUR 7 billion and EUR 25 billion. The International Energy Agency ${ }^{48}$ forecasts that more than 20 million battery electric vehicles and hybrid EVs will be sold worldwide by 2030 . The Japanese government, through its Japan Revitalisation Strategy, plans to increase the proportion of new energy vehicles in Japan to $50-70 \%$ by 2030 . EV upstream and downstream industry chains in China see continuous growth and breakthroughs in battery manufacturing and battery charging and swapping in the coming years. EVs will be faster and easier to charge. High-density and low-cost energy storage technologies will be innovated, driving commercial operation of large-capacity distributed energy storage systems and contributing to peak shaving and grid efficiency.

Fifth, the smart grid can conserve energy and make energy use more efficient, delivering significant economic and environmental benefits. According to the All-of-the-Above Energy Strategy as a Path to Sustainable Economic Growth, ${ }^{49}$ if the USA achieves its energy efficiency improvement target of more than $70 \%$ it will reduce $\mathrm{CO}_{2}$ emissions by 3 billion tonnes in 2013-30 and save hundreds of billions of dollars in investment. Research by the $\mathrm{EU}^{50}$ shows that

\footnotetext{
${ }^{47}$ European Climate Foundation, Power Perspectives 2030: On the Road to a Decarbonized Power Sector, 2015, p. 11.

${ }^{48}$ IEA, Technology Roadmaps: Smart grids, 2011, p. 12.

${ }^{49}$ Executive Office of the President of the United Stated, The All-of-the-Above Energy Strategy as a Path to Sustainable Economic Growth, 2014, p. 8.

${ }^{50}$ European Climate Foundation, Power Perspectives 2030 - On the Road to a Decarbonized Power Sector, 2015 , p. 53.
}

energy efficiency improvements will reduce its load demand by $14 \%$ by 2030 . This will lower demand for grid and backup capacity by 55\% and 31\% respectively, saving about EUR 299 billion in investment. China needs to improve energy use efficiency. Energy efficiency technologies will become more integrated and intelligent. Industry, buildings and transport will be priority fields for innovation. Integrated energy use technologies, including cascading, will evolve in the future. Energy monitoring and measurement will be more accurate, substantially improving energy system use efficiency.

\subsubsection{Problems and Suggestions}

\section{(1) Problems}

First, creating the smart grid is a huge, wide-ranging project. It involves social, economic, policy, regulation and science and technology aspects, as well as numerous stakeholders - government, power system users, equipment and service suppliers, financial institutions, research institutions and consultancies. The interests and requirements of these stakeholders vary greatly. Existing management, pricing, investment and financing mechanisms need to be improved, and the various stakeholder interests taken into consideration and balanced.

Second, breakthroughs need to be made in core technologies. China has mastered and locally manufactured some key smart grid technologies and equipment, but it still relies on imports, especially in the fields of direct current, power electronics and renewable energy. There is much room for performance improvement and cost reductions in key technologies and equipment. Moreover, industry and national standards for the smart grid have yet to be developed, putting China behind in terms of international smart grid standards.

Third, business models need to be improved. Successful business models can move smart grid development forward and demonstrate the benefits. Many new and value-added businesses are starting up in intelligent EV charging, coordinated operation of renewable power and energy 
storage systems, one-stop services for intelligent electricity use, and demand response. However, they are not yet mature, and their profitability is weak, slowing down their commercialisation.

\section{(2) Suggestions}

First, government should lead smart grid innovation. Plans should be made to motivate power utilities, equipment manufacturers, users and other market players to collaborate on smart grid development and achieve win-win results. Finance and taxation, science and technology, and the support policies necessary to create the smart grid should be researched and implemented. A scientific electricity pricing system that reflects key aspects of the power market should be established, including ancillary services like frequency regulation and peak shaving. International communication and cooperation should be strengthened to help smart grid technologies, equipment and standards go global.

Second, R\&D of key smart grid technologies should be improved. Attention should be paid to big data, cloud computing, the Internet of things, mobile Internet, artificial intelligence and other new technologies. Investment in scientific research should be made at an early stage to encourage innovation. New theories, methods and technologies should be explored. A complete and open system of domestic smart grid technical standards should be drawn up. International cooperation on smart grid standards should be bolstered, and businesses and research institutions encouraged to participate in defining a body of international smart grid standards.

Third, smart grid business models should be created. The decisive role of the market in resource allocation should be brought into full play, and industry alliances should be established to facilitate development of consistent technology and product standards. Smart grid development and operation should benefit businesses and users to drive innovation and change in the power services industry. Technologies and approaches that combine the Internet and energy should be explored to facilitate innovation in smart grid business models.

\subsection{New Energy Technologies}

\subsubsection{Developments in, and Outlook for, New Energy Technologies}

\section{(1) New energy technologies}

There is no single definition of new energy at present. Generally, new energy refers to the new energy sources and technologies that differentiate it from conventional (old) energy. Broadly speaking, new energy means new sources and technologies, including those for energy development, conversion, use and support. In a narrow sense, new energy refers to sources only, including non-hydro renewables, unconventional and future energy. For the purpose of this report, new energy refers to the latter, especially non-hydro renewable energy.

Non-hydro renewable energy includes solar, wind, biomass, geothermal and marine energy. Power generation is the principal way to use non-hydro renewable energy. Non-hydro renewables can be used by consumers after conversion into power. Global installed capacity of non-hydro renewable energy is increasing in step with technical progress.

Wind power: Wind can be divided into onshore and offshore generation. Onshore wind turbine manufacturing technologies have already matured. As onshore wind has reached saturation point in some European countries, wind power generation has moved gradually from onshore to offshore, and from offshore to deep water. Wind energy is now the most mature (technically) and promising (in terms of large-scale development and commercialisation) new energy.

Solar power: Solar can be divided into solar heating and solar power generation. Solar water heating and solar photovoltaic (PV) power generation are the most mature technologies at present. Solar PV converts sunlight directly into 
power through photovoltaic panels. Concentrated solar power (CSP) technology produces electricity by focusing solar radiation onto heat absorbers with light concentrating technology. The heat is then used to convert water into high-pressure steam to power steam turbines.

Biomass energy: As a renewable energy source that contains carbon, biomass can be used to generate power, or heat (gas) or produce liquid or gaseous fuels or used directly or indirectly for materials. Biomass use spans hybrid systems, where it is used to partially substitute fossil fuels in existing assets, for example in power station cofiring; blended biofuels; and dedicated uses such as biomass-fuelled combined heat and power.

Geothermal energy: Geothermal energy is used to generate heat and power. Shallow geothermal and hydrothermal energy heating and cooling technologies are basically mature. Shallow geothermal energy is used mainly with heat pumps. In geothermal power generation, high-temperature dry steam power is the most mature and cheapest technology, followed by high temperature wet steam. The cost efficiency of low- and medium-temperature geothermal power generation technologies needs to be improved.

Marine energy: Marine energy is used mainly to generate power in tidal, wave, current, temperature difference and salinity gradient applications. The development cost is generally high. Tidal power generation is the most mature and competitive.

\section{(2) Global deployment of new energy technologies}

New energy technologies (NET) can be classified in four stages according to their technological maturity. NET at the commercialisation stage refers to those technologies with great potential that have been widely accepted, such as wind and solar photovoltaic. NET at the demonstration stage refers to those that are proven in industrial-scale demonstration projects and are about to be commercialised, but which are faced by uncertainties in terms of go-to-market, such as concentrated solar power. NET at the quasi-demonstration stage refers to those that have reached, or are about to reach, industrial demonstration, like second-generation biofuels. NET that have yet to be verified refers to those whose potential is recognised but that still have a long way to go to be commercialised, such as, nuclear fusion and combustible ice.

Wind and solar photovoltaic (PV) are deployed at scale and therefore promising. Wind and PV power are characterised by: (i) predictable cost-with technical progress and scale-up, their cost will be comparable with conventional power in the future; (ii) clear and great resource potential; and (iii) the ability to be scaled up because of the vast size of China. Wind and PV power generation require little water and have very limited impact on the environment.

Considering the maturity, resource potential and development cost of different new energy technologies, this study focuses on wind, solar PV and concentrated solar power (CSP). In wind power generation, large-capacity, low-speed wind turbines will be the future trend. Breakthroughs continue to be made in solar power technologies and efficiency.

Wind turbine capacity, height and output continue to increase across the globe. Developed countries made great breakthroughs in wind turbines in the 1980s, with capacity reaching $75 \mathrm{~kW}$ and the hub height $20 \mathrm{~m}$. In the 1990s, turbine capacity rose to $300-750 \mathrm{~kW}$ and hub height to about 30-60 m. These wind turbines dominated medium and large wind farms. In the 21 st century, to generate more power and use land more effectively, turbine capacity increased to several megawatts and hub height to 70-100 m.

Lightweight high-tower low-velocity wind turbines predominate. High tower is the key to low wind speeds and high-shear wind farms. Vestas is now the leader in the field of 
lightweight high-tower wind turbines. Its all-steel $120 \mathrm{~m}$ towers weigh only 226 tons, $30 \%$ lighter than other all-steel or steel-concrete towers. Goldwind, GE and Siemens' wind turbines with $120 \mathrm{~m}$ towers are mostly prototypes. ${ }^{51}$

Solar PV technologies are divided into crystalline silicon, thin-film and new cell technologies according to the cell material and manufacturing process used.

1. Crystalline silicon cell technology. This is the mainstream technology at present. It includes monocrystalline and polycrystalline silicon. Crystalline silicon cell manufacturing is becoming more and more diversified. Aluminium back surface field monocrystalline and polycrystalline silicon cells are manufactured at scale, and their average conversion efficiency has reached $19.8 \%$ and $18.5 \%$ respectively. The conversion efficiency of the monocrystalline and polycrystalline silicon cells using passivated emitter rear cell (PERC) technology is about 0.5 percentage points higher. With rapid technological progress, N-type crystalline silicon cells have entered small-scale production. The conversion efficiency of monocrystalline and polycrystalline silicon cells, with a new structure and using new technologies, could be improved substantially in the future. N-type crystalline silicon cells using passivated emitter rear totally diffused (PERT) technology, heterojunction with intrinsic thin layer cells (HIT), interdigitated back contact (IBC) solar cells and other back contact cells will be the future trends.

2. Thin-film cell technology. Industrial-scale thin-film cell technologies have gradually matured and have bright prospects. Thin-film cells include silicon-based thin film, copper indium gallium selenide (CIGS), cadmium telluride (CdTe) and gallium arsenide (GaAs). The innovation space of silicon-based thin film cell technology is limited, with market

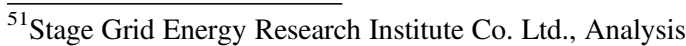
Report on Power Generation with New Energy in China, 2017, pp. 36-39.
}

share decreasing in recent years. Currently, CdTe and CIGS thin-film cells are mainstream, with the highest conversion efficiency in laboratory testing exceeding 22\%. Mass production of GaAs cells has not been achieved due to high costs.

CSP technologies are divided into trough, tower, dish-Stirling and linear Fresnel.

Trough CSP. Trough is the first CSP technology to be commercialised and has the largest share of commercial CSP plants globally. The current status of this technology is: (i) trough CSP has a simple design and is low cost; (ii) multiple concentrating heat collectors (troughs) can be connected in series or in parallel to form a large-capacity CSP system; (iii) its concentration ratio is low, typically $50-80$ suns, and it is difficult to increase the temperature of its heat transfer medium, which is usually around $400{ }^{\circ} \mathrm{C}$; and (iv) due to the long heat transfer loop, trough CSP loses large amounts of heat and has a low system efficiency of about 11-15\%.

Tower CSP. The current status of this technology is: (i) a tower CSP system has a high concentration ratio of 300-1,000 suns and a high system operating temperature of $500-1,400^{\circ} \mathrm{C}$; (ii) thanks to its short heat transfer loop, tower CSP systems have small heat loss and a high system efficiency of about 14\%; (iii) tower CSP is suitable for large-scale and large-capacity commercial applications; and (iv) the system is costly and requires heavy capital investment, and its design and control system are complicated.

Dish Stirling CSP. The current status of this technology is: (i) it has a high concentration ratio of around 1,000-3,000 suns and an operating temperature close to $1,000^{\circ} \mathrm{C}$. Its peak conversion net efficiency can reach $30 \%$; (ii) the capacity of a dish Stirling system is usually 5-50 kW, with unit costs high; and (iii) the cost of generating power does not depend on the size of the project, as the plant can be used as a distributed power system or a megawatt-level power station connected to the grid.

Linear Fresnel CSP. Linear Fresnel is a simplified version of trough CSP. The current status of this technology is (i) it uses flat tracking 
mirrors instead of the parabolic-shaped collectors in trough CSP. The mirrors are close to the ground, have a low wind load, a compact simple structure, and high land use efficiency; (ii) the heat transfer tubes do not need to be a vacuum, which simplifies the design and lowers the overall cost of the system; and (iii) the system's concentration ratio, operating temperature and system efficiency are low.

Currently, trough CSP technology is mature; tower CSP technology is approaching an early stage of maturity and has great potential; Fresnel and dish technologies are still at the demonstration stage. There is still much to do in CSP technologies.

\section{(3) Trends in related technologies}

First, wind turbines will use longer and lighter blades of modular design, thereby improving power generation efficiency. The number of direct drive (gearless) wind turbines is expected to increase.

1. Wind turbines will use longer and lighter blades with modular design. As wind resource-rich regions with low wind velocity become hot spots for development, the swept area per kilowatt generated needs to be increased to capture more energy. Compared with the past decade, the rotor diameter and rated power of wind turbines have increased by $70 \%$ and $50-100 \%$ respectively. Currently, the average rotor diameter of low-velocity turbines is $116 \mathrm{~m}$ and is forecast to reach $160 \mathrm{~m}$ in the next decade, with swept area and annual availability expected to double. However, a new problem will then arise - ultra-long blades make transport and hoisting on challenging terrain difficult. Road construction, piling and hoisting costs will get higher and safety risks could increase. Modular blade technology simplifies production, ensures product quality and facilitates transport and erection.
2. The proportion of direct drive (gearless) wind turbines is expected to rise. Direct drive (including excited and permanent magnet direct drive) wind turbines is a hot area of research. Germany-based Enercon and other vendors using excited direct drive systems have around an $8 \%$ share of the global market. These turbines feature stable performance and mature technology. Permanent magnet direct drive wind turbines have no gearbox and avoid some of the mechanical faults associated with gearboxes. The magnet remains stable, withstanding vibrations and temperature variations.

Second, improved conversion efficiency and lower cell production costs characterise solar PV technologies.

1. PV cell conversion efficiency is improving. The conversion efficiency of monocrystalline silicon cells is currently about $19 \%$, while that of third-generation polycrystalline silicon cells is around $18 \%$. New technologies will improve crystalline silicon cell conversion efficiency over time. Passivated emitter rear cell (PERC) technology improves cell conversion efficiency by adding a dielectric passivation layer to the back of the cells.

2. Cell production costs are falling. Fierce competition is forcing cell manufacturers to lower production costs in several ways. The first method is to improve conversion efficiency through technical progress, primarily through metal wrap through (MWT) and interdigitated back contact (IBC) technologies. Experience shows that when cell conversion efficiency is improved by $1 \%$, production costs are lowered by $7 \%$. The second method is to reduce material consumption and thus costs. The cost of cell processing comes mainly from the slurry. It is difficult to lower the cost of slurry because it contains silver and other commodities. Therefore, manufacturers choose to reduce 
slurry consumption per unit with various techniques. The third way is to decrease the thickness of the silicon wafers. Over the past three decades, silicon wafer thickness has been reduced from $450-500 \mu \mathrm{m}$ in the $1970 \mathrm{~s}$ to $180-200 \mu \mathrm{m}$ today, lowering cell production costs by more than half.

Third, integrated solar PV power plants will become larger. Building-integrated PV systems are already widely deployed and the number of off-grid PV systems will grow. PV power plants with a capacity of more than $1 \mathrm{GW}$ are already under construction. Building-integrated PV systems provide numerous benefits, including small footprint, lower investment costs, low transmission losses, low aesthetic impact and high energy efficiency. They are often located in load centres and easy to integrate with the local grid. Off-grid PV systems will be more widely deployed in remote regions without access to electricity.

Fourth, large-scale CSP technology will shift gradually from trough to tower and other technologies with a high concentration ratio and high conversion efficiency.

There is much scope for the future development of CSP technologies. Better efficiency and improved cost effectiveness are two examples of areas of focus. Tower CSP technology, with its high concentration ratio, large system capacity and high efficiency, is a hot area of $R \& D$ at present. Tower CSP is expected to become the main CSP technology, enabling the large-scale development of CSP across the globe. Dish Stirling technology also has a high efficiency level and will probably be used in distributed power systems in the future.

Large capacity and low heat storage costs is the way to improve CSP system efficiency. R\&D currently focuses on: (i) improving power generation efficiency by increasing the system operating temperature or expanding plant capacity or reducing heat loss from the heat absorbers; (ii) reducing solar island costs by lowering equipment expenditure and optimising design; (iii) using high-capacity heat storage to ensure 24/7 electricity supply and meet grid requirements; and (iv) reducing plant energy and water consumption.

\subsubsection{Current Developments and Difficulties in China's New Energy Sector}

\section{(1) Development environment for China's new energy technologies}

First, China's installed capacity of new energy increased substantially to 237,720 MW in 2016, accounting for $14 \%$ of the country's total. In 16 provinces, new energy has become the second largest energy form. The grid-connected capacity of wind, solar and biomass reached 148,640 MW, 77,420 MW and 11,660 MW respectively, accounting for $62 \%, 33 \%$ and $5 \%$ of the total installed capacity of integrated new energy. ${ }^{52}$ Newly added installed capacity of solar PV exceeded that of wind power for the first time and contributed half of new PV installed capacity worldwide. China passed the USA to become the leader in wind power output for the first time. China has ranked first as the country that adds the most wind and solar PV installed capacity annually for many years.

Second, the technical standards for new energy are gradually being developed. The National Energy Administration founded the Wind Power Technical Committee for Standardisation in the Energy Industry in 2011 and issued the Framework of Wind Power Standards System, ${ }^{53}$ which covers the following aspects: wind farm planning, design, construction, installation, operation, maintenance and management; wind power connection management technologies; wind machinery and equipment, and wind power electrical equipment. In 2014, the Standardisation Administration of China

\footnotetext{
${ }^{52}$ White Paper of State Grid Corporation of China on New Energy Development 2017, pp. 4-11.

${ }^{53}$ Notice from NEA on Printing and Distributing the Rules on Development of Wind Power Standards, Articles of Association of Wind Power Technical Committee for Standardisation in the Energy Industry and Framework of Wind Power Standards System (Guo Neng Ke Ji, 2010, No. 162).
} 
issued seven national standards on solar power generation, which cover quality and performance testing of solar cells.

\section{(2) Current development of China's new energy technologies}

First, wind power technologies. China has localised megawatt-level wind turbine design and manufacturing technology in place for the whole wind power value chain. Several Chinese wind power businesses are among the world's top 10 . The technical level and reliability of Chinese wind power equipment is world-class. Up to now, China has focused on the design and manufacture of wind turbines and turbine components below 3.6 MW but is now developing technologies for turbines of 5 and $6 \mathrm{MW}$.

The rotor diameter of low-velocity wind turbines continues to increase. The regions with low wind velocity in central and east China have become new hotspots for wind power development. Large-scale development of wind parks in those regions needs low-velocity wind turbine technology. A range of ultralow-velocity wind turbines was launched in 2013. Low-velocity wind areas account for more than $60 \%$ of China's exploitable wind resources.

Second, solar PV technologies. A world-leading complete PV value chain covering polycrystalline silicon purification, silicon rods, ingots and wafers, as well as cells, panels and system integration, has taken shape in China and is expanding rapidly. PV power generation has become a strategic, emerging and internationally competitive industry for China. In 2015, China had 16 polycrystalline silicon companies, with a total production capacity of 190,000 tonnes (excluding metallurgy) - they produced 165,000 tonnes of polycrystalline silicon, which was $47.8 \%$ of global output. Four of them are in the global top 10 in terms of production capacity. China's total silicon wafer production capacity in 2015 was $64.3 \mathrm{GW}$, with output reaching 48 GW, 26.3\% higher than the previous year and $79.6 \%$ of the global total. Of the 10 largest silicon wafer manufacturers in the world, nine are in mainland China. China's crystalline silicon cell production capacity in 2015 was $49 \mathrm{GW}$, with output $41 \mathrm{GW}, 24.2 \%$ higher than the previous year and about $66 \%$ of the global total. Among the top 10 cell manufacturers (in terms of output) in the world, seven are in mainland China. Total solar panel production capacity in China in 2015 was more than $71 \mathrm{GW}$, and output $45.8 \mathrm{GW}$. Among the top 10 panel manufacturers (in terms of output) in the world, six are in mainland China. ${ }^{54}$

Third, CSP technologies. CSP plants generally consist of concentration, heat absorption, a thermodynamic power cycle, power generation and heat storage systems. Key equipment includes concentrating mirrors, heat collectors and a heat storage system. Technology development in concentrating mirrors is focused on improving the durability and precision of the reflective materials. Heat collectors influence heat absorption efficiency and include evacuated collector tubes and chamber absorbers. The heat storage system-which comprises heat transfer fluid, molten salt and metal materials - is the key to large-scale and uninterrupted operation of a CSP system.

Generally, more than $90 \%$ of the equipment and materials used by CSP plants are manufactured in China and at a technical level very close to world-class. China lacks only long-term operational experience. However, core components and materials like trough ball joints, tower CSP tubes, high-temperature molten salt and molten salt pumps still need to be imported.

\section{(3) Problems with China's new energy technologies}

First, basic research on wind power is insufficient in China. Key equipment and materials are still imported. China's route to progress in wind power technologies is through introduction, digestion, absorption, integration and innovation.

\footnotetext{
${ }^{54}$ China Photovoltaic Industry Association, Roadmap for China's PV Industry, 2016, pp. 2-4.
} 
China still lags behind developed countries in terms of calculating aerodynamics and load, flow field analysis and other basic R\&D fields, as well as large wind turbine design, bearings, the main control and pitch control systems, and other high-end technologies. For example, leading overseas wind turbine manufacturers have commercialised 4-7 MW wind turbines. Prototypes of $8 \mathrm{MW}$ wind turbines are at the installation and testing stage. Wind turbine companies in Europe and North America are already designing $10 \mathrm{MW}$ turbines and are exploring and researching $20 \mathrm{MW}$ models. There is a gap between China and those countries.

Second, solar PV technologies are facing severe challenges to their leadership in the latest cell technologies. Interdigitated back contact (IBC), heterojunction with intrinsic thin layer (HIT), passivated emitter and rear cell (PERC), metal wrap through (MWT), bifacial and other efficient cell technologies are developing rapidly across the world and about to be commercialised. But there is still a gap between China and the developed world, especially in IBC and HIT cells.

Third, the cost effectiveness of CSP technologies needs to be improved. Practical experience is insufficient and technical standards are incomplete. China's CSP technologies are now at the stage of pilot demonstration. Equipment manufacturing and project development technologies are not mature. There is much to be done in technological development. The investment cost per unit of capacity is still high. CSP-related equipment manufacturing, design, construction, operation and maintenance standards are relatively undeveloped. Experience needs to be accumulated through project construction and operation. ${ }^{55}$ Even through China

\footnotetext{
${ }^{55}$ Huang Qili, Zhang Zhengling, Zhang Ke, Li Qionghui and Huang Bibin, The wind power and solar power parts of the Report on Strategic and Emerging Industries of China, 2016.
}

has introduced support policies, only a few trough and tower CSP power plants are in operation or under construction.

\section{(4) Outlook for China's new energy technologies}

First, the outlook for China's wind power technologies. The cost of wind power will further decrease to a level below that of conventional power by 2030. China's wind power industry will maintain strong momentum, but its growth will slow down. Wind power installed capacity will exceed $450 \mathrm{GW}$ by 2030 . Lighter and longer blades, integrated drive chains and taller, lighter and easier-to-install towers will be developed. The average cost per $\mathrm{kWh}$ of wind power will decrease by more than $35 \%$ to RMB $0.35 / \mathrm{kWh}$ by 2030 .

Second, the outlook for China's solar PV power technologies. The cost of solar PV will fall to a level lower than conventional power by 2030, and installed capacity will increase. China's solar PV industry will maintain strong momentum. PV installed capacity will exceed $400 \mathrm{GW}$ by 2030 . The conversion efficiency of monocrystalline and polycrystalline silicon cells in commercial applications will reach $25 \%$ and $21 \%$ respectively, and that of thin film cells will reach around $18 \%$. The average cost per $\mathrm{kWh}$ of PV power will fall by more than $50 \%$ to RMB $0.31 / \mathrm{kwh}$ by 2030 , making it more competitive than wind power.

Third, outlook for China's CSP technologies. Tower technology will mature by 2030 to lead the global CSP sector into the stage of large-scale development. China's CSP industry will see rapid development, with installed capacity expected to reach $30,000 \mathrm{MW}$ by 2030 . Air solid-state particle heat absorbers will be deployed gradually. Ceramic, solid-state concrete heat storage technologies will be developed, but molten salt heat storage will still be the mainstream technology for large CSP plants. The average cost per $\mathrm{kWh}$ of tower CSP power will decrease by more than $40 \%$ to RMB $0.42 / \mathrm{kWh}$ by 2030 , getting closer to PV power and thus more competitive. 


\subsubsection{The Role of New Energy in China's Energy Technology Revolution}

First, new energy technologies have become an important means for China to ensure energy security and sustainable supply and overcome the challenge of climate change. New energy provides great support for the energy transition. Given the complexity of geopolitics, transnational energy flow will see great change. Energy security is at the heart of national energy strategies. Global climate change is a huge challenge. Onshore wind and solar energy resources are abundant, more than enough to meet global energy demand. With technological progress and the use of new materials, the efficiency of wind, solar, marine and other new energy sources will be improved. Their cost effectiveness and market competitiveness will be enhanced, making them the dominant energy types of the world.

Second, new energy technologies have become a strategic, emerging and internationally competitive industry in China. The energy technology revolution will shift energy development from resource-dependence to technologydependence. Innovation in energy and power technologies has become a priority for all countries to sharpen their competitiveness and strive to become technology leader. New energy is an emerging industry with great potential, but it is also a strategic and internationally competitive sector for China.

Third, replacing fossil energy with new energy has become a strong driving force behind the fourth industrial revolution. Innovation in energy technologies, integration of information technologies, the Energy Internet and smart grids, energy storage, power system interconnections, plug-in and fuel cell electric vehicles, will all be pillars of the fourth industrial revolution.

\subsubsection{Policies for Promoting New Energy Technologies}

First, more effort should be invested in scientific research. This would enable breakthroughs in $\mathrm{R} \& \mathrm{D}$ and the design and manufacture of software and equipment, and it would enhance
China's proprietary technologies and manufacturing level. National R\&D centres for wind power technologies should be set up. Basic research in key wind power technologies should be carried out to help businesses tackle common technical difficulties. These should include: (i) $\mathrm{R} \& \mathrm{D}$ of advanced and large wind turbines, low-velocity turbines and other key wind power technologies, supported by renewable energy development funds and national scientific and technological research projects; (ii) national $R \& D$ and testing platforms for blades, drive systems and other wind power components should be built to improve the performance of wind turbines, wind farms and wind power equipment.

Second, innovation in PV technologies should be driven forward and R\&D in key CSP technologies strengthened. China should: (i) increase innovation in PV technologies and continue to focus on improving the conversion efficiency and production cost of cells and panels. Solar power technologies should be digitalised to make plants more intelligent and harness the benefits of big data and cloud computing; (ii) strengthen R\&D in key CSP technologies. More investment should be channelled into R\&D of solar tracking controllers, plant control, manufacturing and system integration technologies. Research on mirrors and heat collector technologies, heat storage, heat transfer materials and thermal-to-power conversion systems suitable for west China should be carried out. Materials, technologies and processes should all be improved. Generating efficiency should be enhanced and costs lowered to enable China to become the largest producer and biggest user of CSP technologies.

Third, demonstration projects for CSP, marine and other new energy technologies with great potential in the short and medium terms should be built to accelerate technological progress and accumulate planning, design, construction, operation and management experience. This would also lay a solid foundation for policy studies, commercialisation, international competitiveness and cost reduction. These projects could explore different technical routes to find 
the best solutions for China's geographical and meteorological conditions.

Fourth, the development of new energy technologies should be closely coordinated with smart grid, energy storage and Internet + (Energy Internet) technologies. China should: (i) regard the smart grid as an important tool to promote renewable energy development and use and, therefore, a major component of the future power grid. The smart grid would facilitate the integration of renewable power, including distributed power and large-scale wind farms; (ii) use the Internet to revolutionise energy production and consumption, improve energy efficiency and reduce emissions. Information sharing between upstream and downstream businesses should be strengthened to coordinate operations between power plants and grids. Both non-fossil and fossil energy should be used to generate power; and (iii) energy storage is a key technology and an important means to integrate new energy in the power system, because it can mitigate voltage fluctuations and stabilise the grid. Research and projects in and outside China show that large-scale energy storage is an important solution to connect new energy to the grid and facilitate its use.

\subsection{Energy Storage}

\subsubsection{Current Developments and Trends in Global Energy Storage Technologies}

\section{(1) Current technology developments}

After more than a decade of development, energy storage technologies are beginning to take off. Statistics up to 2017 show that the cumulative installed capacity of global energy storage projects was 169.2 GW. Pumped storage and electrochemical energy storage accounted for the largest share of installed capacity at $97 \%$ and $1.3 \%$ (ranking No. 3) respectively. The installed capacity of electrochemical energy storage projects worldwide was $94.4 \mathrm{MW}$, up $551 \%$ year-on-year and 50\% month-on-month.

The UK, Australia, the USA and China markets see rapid growth. In 2017, the UK, China and Japan were the top three countries in terms of installed capacity. Nearly all these projects were deployed in grid-connected centralised renewable energy and ancillary services. Australia, the USA and the UK were the top three in terms of the installed capacity of projects planned or under construction. These projects would likewise mainly be deployed in grid-connected centralised renewable energy and ancillary services, accounting for $91 \%$ of the total capacity of such projects.

By application, up to 2017, the installed capacity for ancillary services was $31.5 \mathrm{MW}$, accounting for $33 \%$ of the total installed capacity of energy storage projects worldwide. These projects were located mainly in the UK, Germany and Belgium, for example, those in Bristol and Darlington in England. They became part of the European balancing market in the form of independent energy producers or in joint operation with gas power plants to provide primary frequency modulation.

In terms of current energy storage market capacity, pumped storage remains dominant (98\% market share), although electrochemical energy storage is rapidly gaining market share. In the global market, the top three electrochemical energy storage technologies are lithium-ion, sodium-sulphur and lead-acid batteries, accounting for $53 \%, 29 \%$ and $9 \%$ of the total market respectively. In China, the top three electrochemical energy storage technologies are lithium-ion, lead-acid and flow batteries, which account for $57 \%, 28 \%$ and $10 \%$ of the total market respectively.

Mainstream energy storage technologies comprise four categories: physical, chemical, electromagnetic and others. Physical energy storage refers mainly to pumped storage, compressed air energy storage and flywheel energy storage. Chemical energy storage technologies are developing fast and attracting the most attention, mainly in lead-acid, lithium-ion, flow, 
and sodium-sulphur batteries. Electromagnetic energy storage includes super capacitors and superconducting magnetic energy storage. Others includes fuel cells and metal-air batteries. In addition, there are many technologies at the frontier stage of development. These can be divided into two categories - the first is improving or optimising conventional technologies like lithium-sulphur batteries and liquefied air energy storage; the second is designing and developing new technologies, such as lithium-air and aluminium ion batteries.

\section{(2) Global development trends}

Energy storage is about to become an important driver of change in the energy sector. The International Energy Agency (IEA) forecasts that the USA, Europe, China and India will increase their energy storage capacity for grid-connected electricity by $310 \mathrm{GW}$ by 2050 , at a cost of at least $\$ 380$ billion. A study by McKinsey \& Company says energy storage will play a game-changing role and have significant impact on the global economy by 2025 . Its predicted market value is $\$ 0.1-0.6$ trillion.

The USA, Japan and Europe have made national $R \& D$ plans for energy storage technologies. As a result, their technology development and demonstration activities are making rapid progress. Utilities like grid operators, large energy equipment manufacturers and some small- and medium-sized technology companies see a great future for, and are making inroads into, the energy storage market.

According to the IEA's Technology Roadmap: Energy Storage (2017), energy storage is of value for most energy systems, but the technologies vary greatly in terms of maturity. Currently, some small-scale energy storage systems are cost-competitive in remote communities and off-grid applications. Large-scale heat storage technologies are cost-competitive in heating and cooling applications. But more public support for research and development of energy storage technologies is needed.

The European Commission has introduced the EU Strategic Energy Technology (SET) Plan and materials roadmaps for energy applications and low-carbon energy technologies. They describe the research and innovation activities for materials critical to the development of 11 energy technologies (wind, photovoltaic, concentrated solar power, geothermal, electricity storage, power grids, bioenergy, novel materials for fossil fuels-including carbon capture and storage, hydrogen and fuel cells, nuclear fission and energy-efficient materials for buildings) over the next 10 years.

The Materials Roadmap Enabling Low Carbon Energy Technologies considers energy storage an important technology that can improve the controllability and flexibility of the European electricity system. Currently, most energy storage technologies are too costly and technically inadequate for system-level deployment and integration. Materials often restrict performance improvement, and are a decisive factor in the cost-effectiveness, efficiency and reliability of energy storage deployment in the grid. The commercialisation of large-scale energy storage technologies is a priority task.

The Electrical Energy Storage Roadmap describes an overall $R \& D$ plan for energy storage systems and technologies. For instance, low-cost, safe and sustainable electrochemical and electrolyte materials have super-electrochemical, thermal and mechanical properties, as well as a long life and the ability to withstand extreme conditions. They can be used to innovate design and manufacturing processes in lithium-ion and redox-flow batteries, pumped storage, compressed air energy storage (CAES), electrolytic capacitors, superconducting magnetic energy storage and flywheel energy storage.

The roadmap focuses on the development of new electrochemical pathways and on verifying emerging technologies like metal-air and solid-state batteries and liquid metal systems. It describes four pilot projects that demonstrate industry-scale, high-speed and low-cost deployment of electrical double-layer capacitors, lithium-ion batteries, flywheel rotors and motors, and compressor and dielectric materials resistant to high heat and pressure that are used in CAES heat storage containers. It also describes another 
five pilot projects for testing and verifying whether these advanced storage technologies are durable and can be reused in different market environments. The roadmap and pilot projects complement the formation of a pan-European network that pools industrial and scientific resources for research and innovation activities. In addition, the Roadmap also suggests establishing an education and training centre for electrochemical and energy storage.

\subsubsection{Current Developments in Energy Storage in China}

(1) Policies related to energy storage in China

Since 2005, China's policies on energy storage have gradually evolved, from early-stage technical exploration to a technology roadmap, industry guidelines and support mechanisms. China's early polices focused on funding scientific research in battery materials and technologies and proof of concept. As technologies and applications progressed, the government introduced policies to reform the electricity system, incentivise energy storage and create support mechanisms.

Energy storage is part of the national energy strategy and industry development plan. The government has issued a series of 13th Five-Year Plans (2016-20) for Strategic Emerging Industries Development, Renewable Energy Development, Energy Development, and Energy Technology Innovation, all of which develop the positioning and direction of energy storage.

The government has also introduced several support policies for energy storage development. Examples are polices like the National Energy Administration's for promoting energy storage in electricity ancillary services market mechanisms in north, north-west and north-east China; and guidelines for developing energy storage technologies and an energy storage industry.

The former of the two policies was issued in 2016. It stipulated that each province should select no more than five electric energy storage facilities to be part of a pilot project on peak load and frequency regulation ancillary services. It encouraged power generators and end users to take part in the market. And, it set out the principles of results-based compensation.

The second of the two policies was introduced in 2017. It defines the pathway and describes application scenarios for China's energy storage development. In the future, compensation policies for the application scenarios will be defined and the standards for those advanced energy storage technologies eligible for compensation will be introduced. In combination with electricity system reform, the policies for energy storage pricing will be researched and a timetable for their introduction drawn up. In Stage 1 of the policy, during the 13th Five-Year Plan (2016-20), the following focus areas will drive energy storage to early commercialisation: start up pilot and demonstration projects, research and develop key technologies and equipment, draw up a preliminary system of standards for energy storage technologies, create new business models and foster competitive market players. By Stage 2, during the 14th Five-Year Plan (2021-25), energy storage projects will be widely deployed to enable the transition from early commercialisation to scale development, thus becoming a new growth point in the energy sector.

The energy storage industry is increasingly attracting attention and its importance is growing. Many energy planning policies introduced by the Chinese government-including the Outline for the 13th Five-Year Plan (2016-20), the Strategic Action Plan on Energy Development (2014-20), and the Action Plan for Innovation in the Energy Technology Revolution (2016-30) identify energy storage as a major research and development field for the future. Energy storage will play an important role in connecting renewable energy to the grid and in electricity ancillary services and retailing.

\section{(2) Current developments in China's energy storage technologies}

In the 12th Five-Year Plan (2011-15), China's energy storage technologies and industry development had three characteristics.

First, different technologies were developed in a coordinated way and were characterised by 
continuously and rapidly decreasing costs. As costs fell, new technologies and materials were developed.

Second, pilot applications gradually evolved into commercial demonstration and the most promising energy storage applications were identified. There were two stages to this process. In 2011-13, demonstration projects were designed mainly to verify the technology and application-they lacked financial considerations. By 2013-15, the projects began to explore business models and payback periods, gradually transiting to commercial demonstration. At the same time, it became clear which applications held the most promise for development: power generation, ancillary services, power transmission and distribution, renewable energy and user consumption, electric vehicles and the Energy Internet.

Third, the energy storage industry explored pathways to large-scale commercial development. In 2015, China's installed electrochemical energy storage capacity was $141.1 \mathrm{MW}$, compared to only $2.4 \mathrm{MW}$ in 2010. As installed capacity grows, the energy storage value chain improves, and manufacturers are motivated to invest.

The energy storage industry is now using three mainstream commercial application models, each of which offers several market opportunities. For example, wind farms equipped with energy storage can reduce wind curtailment and increase revenues by providing ancillary services. And consumers can use energy storage to save money by not using electricity - or they can earn money by releasing stored energy into the grid-at peak periods.

Energy storage is growing rapidly. In 2017, the cumulative installed capacity of energy storage projects in China was $27.7 \mathrm{GW}$. Of this, pumped storage had by far the largest share at $99 \%$, followed by electrochemical energy storage at $318.1 \mathrm{MW}$ or $1 \%$ of the total, an increase of $18 \%$ on the previous year. The installed capacity of China's newly opened energy storage projects was $22.8 \mathrm{MW}$, up $114 \%$ year-on-year.

By region, east China has the largest installed capacity of newly opened energy storage projects at $12.2 \mathrm{MW}$, which is $53 \%$ of the total. All these projects were deployed by users, mainly by industrial parks, helping companies reduce their electricity costs by adapting to peak and off-peak prices.

By application, the newly opened projects were deployed in grid-connected centralised renewable energy plants and end-user applications. End-user installed capacity was the largest at $17.8 \mathrm{MW}, 78 \%$ of the total. This equates to $67 \%$ growth year-on-year and $287 \%$ month-onmonth (Table 12).

\subsubsection{The Role of Energy Storage Technologies in China's Energy Revolution}

First, energy storage may be the best solution to address the grid connection challenge facing large-scale clean energy. Energy storage is an important factor in the energy transition, because when large-scale renewable energy enters the transmission system, it impacts the entire power system due to its unstable supply. China has severe wind, solar, hydro and nuclear curtailment problems, with more than $100 \mathrm{GWh}$ of electricity wasted annually. Energy storage can help coordinate unstable renewable energy supply with energy consumption and smooth over fluctuations in production and demand. It shares this role with IT technologies like the smart grid, Internet of things, and big data analysis and management.

Second, energy storage is a key enabler for the deep integration of IT and energy technologies. Unlike other types of energy-oil, gas and coal - electricity is used as soon as it is produced. Historically, it could not be stored cost effectively, with the exception of pumped storage, which is costly and is used in hilly and mountainous regions. Energy storage has the potential to break this constraint, allowing electricity to be stored until needed or when prices are lowest. When integrated with the Energy Internet, it enables generation, distribution and consumption to be optimised in a way not previously possible.

Third, energy storage will be a key enabler to start the smart electricity revolution. As electricity is a carrier of both energy and information, 
Table 12 China supports energy storage related development policies

\begin{tabular}{|l|l|l|} 
Date & Department & Document \\
\hline 2005 & NDRC & $\begin{array}{l}\text { Guidelines for the Development of } \\
\text { the Renewable Energy Industry }\end{array}$ \\
\hline
\end{tabular}

Main content

2009 NPC Standing Committee

2010 State Grid Corporation of China

2010 China Southern Power Grid

2011 National Energy Administration (NEA)

2012 The Ministry of Finance, the Ministry of Science and Technology, and NEA

2014 General Office of the State Council

2014 NEA

2015 CPC Central Committee and State Council

2015 NEA

2016 CPC Central Committee and State Council

2016 NEA
The Amendment to the Renewable Energy Law of the People's Republic of China

The 12th Five-Year Plan for the Smart Power Grid

China Southern Power Grid on Supporting New Energy Development

The 12th Five-Year Plan for National Energy Technologies

Circular on Implementing the Golden Sun Solar Demonstration

Strategic Action Plan on Energy Development (2014-20)

Circular of the NEA General Office on the 13th Five-Year Plan for Solar Energy Development

On Deepening Reform of the Electricity System

Guidelines for Developing New Energy Microgrid Demonstration Projects

Outline for the 13th Five-Year Plan

Circular of the National Energy Administration on promoting energy storage in electricity ancillary services market mechanisms in north, north-west and north-east China
Identifies two battery projects as priorities and promotes the pilot deployment of energy storage technologies

Policies to support the new energy and energy storage industries

Development of smart grids

Deployment of new energy and energy storage technologies

Lists the critical technologies for developing energy storage and multi-energy systems

Considers introducing subsidies for energy storage facilities

Names energy storage as one of nine major innovation fields for the first time; proposes energy storage support capabilities to effectively address wind, hydro and solar curtailment

On creating a new energy system that combines distributed solar power, solar thermal, geothermal, energy storage and distributed natural gas

Encourages the deployment of energy storage and IT technologies to make energy use more efficient

Energy storage as a critical microgrid technology

Large-scale energy storage is listed as a critical technology. It is needed to support the development of strategic emerging industries, including distributed energy. China should develop distributed new energy technologies for scale deployment

Energy storage is clearly defined as part of the electricity market. Power generation, retail companies and users are encouraged to invest in energy storage facilities. Provinces are (continued) 
Table 12 (continued)

Date Department

2016 National Development Reform Commission (NDRC), NEA
Document

Action Plan for Innovation in the Energy Technology Revolution (2016-30)

Made in China 2025-Energy

Equipment Implementation Plan and Information Technology, NEA

\section{NDRC and NEA}

\section{NEA}

The 13th Five-Year Plan for Electricity Development

The Administrative Regulation for National Electricity Demonstration Projects
Main content

encouraged to include energy storage facilities when planning new centralised power generation bases and ensure their operation is coordinated and optimised with the grid

Create an integrated and intelligent energy technology system by: (i) improving the flexibility and cost-effectiveness of energy storage and peak shaving; (ii) promoting deep integration between energy technologies and IT;

(iii) optimising the entire energy system to ensure energy resources are used effectively; and (iv), prioritising distributed energy, energy storage, smart grids, the Energy Internet and energy efficiency in industry, buildings and transport

Identifies 15 fields for energy equipment development, including nuclear power, oil and gas exploration and development, gas turbines, smart grids and energy storage

Advanced grid and energy storage technologies are listed as one of 18 priorities. The Plan says China will develop many energy storage demonstration projects, including large-scale mechanical and electrical energy storage, molten salt and chemical energy storage. The goal is to reduce significantly the construction costs per kilowatt of capacity and accelerate development and deployment

It states that electricity demonstration projects will be included in the national electricity development plan and defines clear requirements for their evaluation, selection and approval. It also makes clear that demonstration projects are covered by the support policies in the Circular of the National Energy Administration on the Regulations for Major National Energy Technology Demonstration Projects 
Table 12 (continued)

\begin{tabular}{|l|l|l|}
\hline Date & Department & Document \\
\hline 2016 & NDRC and NEA & The 13th Five-Year Plan for \\
& & Energy Development
\end{tabular}

2016 NDRC

2016 State Council

2017 NEA

\section{NEA}

2017 The Special Committee of Energy Storage under the China Strategic Alliance of Smart Energy Industrial Technology Innovation, the Special Committee of Energy and Water Supply Prices under the Price Association of China
The 13th Five-Year Plan for Renewable Energy Development

The 13th Five-Year Development Plan for Strategic Emerging Industries

Guidelines for Developing Energy Storage Technologies and an Energy Storage Industry

Guidelines for Energy Work 2017

Energy Storage Subsidy Policy Consulting Meetings (1st, 2nd and 3rd rounds)
Main content

The plan states that China will channel resources into renewable energy, especially into connecting new energy, energy storage and microgrids to the grid; build the Energy Internet (Internet + ); improve grid regulations; develop advanced and energy-efficient technologies; and strive to become the leader in energy technology

Identifies eight priority tasks, one of which is to develop energy storage technology demonstration projects in renewable energy and improve the cost-effectiveness of energy storage

Develop a new energy industry; accelerate the development of advanced nuclear power, solar PV and CSP, large-scale wind power, energy storage and distributed energy; improve the cost-effectiveness of new energy and build and adapt the electricity system to support a large share of new energy; facilitate

multi-energy systems and their coordination and optimisation; and lead the energy production and consumption revolutions

The strategic importance of energy storage in China's energy industry is made clear for the first time. It sets out the development goals for energy storage over the next 10 years and underscores five priority projects related to energy storage

\section{Identifies several energy storage} projects throughout the country that were to be completed or started in 2017

Energy storage subsidy proposals for flow cell and all-vanadium redox flow batteries, and from Chinese battery manufacturers CATL and Lishen

In the first meeting, companies differed greatly in their proposals on how to subsidise energy storage. In the third meeting in 2017 , the focus was on reaching agreement on the best way to proceed 
the integration of power and electronics provides a powerful platform for the smart grid. As energy storage technologies and electricity market reform progress, large-scale renewable energy can be used to power industrial production for the whole of society; and data storage, information processing and decision analysis can be integrated into the industrial system and become the engine that starts the smart electricity revolution, after which it will then undertake the historical mission of driving the energy revolution and providing industrial civilization with green energy.

\subsubsection{Strategy and Policies for Energy Storage Development}

First, the strategic positioning of energy storage in the energy revolution should be clarified. The energy revolution is an important engine for China to develop a modern energy system and accomplish the energy transition. Energy storage will play an important role in this. Physical and chemical energy storage, hydrogen and fuel cells, and heat storage technologies will be developed and compete against each other. Eventually, one or two of them will win out. Energy storage will be widely deployed and change the structure and business model of the power sector, thus helping to build a modern energy system.

Second, technology and the energy system should evolve in a coordinated fashion. The biggest obstacle facing energy storage is high cost. The most practical applications are likely to be with users. Other applications like generation and transmission have limited growth potential. Energy storage should be coordinated with other technologies like heat storage and control to deliver synergies and avoid rushing into the market alone. It should be used as a support service for the power distribution network, industrial parks and similar applications.

Third, effort should be made to tailor a market mechanism conducive to the value of energy storage. China should: (i) identify cost-effective niche markets and support the deployment of energy storage technologies in these markets. It should incentivise the development of existing energy storage technologies to improve their efficiency and flexibility; (ii) create a strong market and regulatory environment by eliminating price distortions and vested interests; and support $R \& D$ and demonstration projects for early-stage energy storage technologies, including high-temperature heat storage and scalable battery and hybrid energy storage systems; (iii) use the market mechanism to tap the potential of pumped storage power stations; (iv) follow the market economy principle of "who benefits and who shares costs" to adjust the two-part tariff mechanism; and (v) in combination with the electricity market reform process, create a competition-based pricing system and bidding rules for electricity ancillary services to encourage pumped storage power stations to participate in the market.

Fourth, a standards system should be developed for the energy storage industry. China should: (i) benchmark its industry against international leaders, make incremental improvements in energy storage technologies, assess existing energy storage facilities, and evaluate the potential for energy storage in regions and energy markets; (ii) develop international and national collaborations on data to speed up research, monitor progress and unblock $R \& D$ bottlenecks; and (iii) based on the experience from pilot projects, improve the related industry standards.

\subsection{Long-Distance Power Transmission}

\subsubsection{Drivers and Characteristics of Long-Distance Power Transmission}

\section{(1) Drivers}

Misalignment between energy sources and load centres is common in many countries and regions. Load centres generally do not have abundant energy sources. They enjoy strong economic growth and have high population concentrations, resulting in a large and increasing demand for power. In contrast, regions with 
abundant energy sources are often characterised by low power consumption due to an underdeveloped economy and small population. For example, more than $80 \%$ of Russia's power generation resources are distributed in the east (Siberia has abundant hydropower and coal resources), but load centres are located in the west. Historically, China's load centres are in the central and eastern regions, but its energy sources are mainly in the west and north. For instance, coal, wind and solar power and other new energy sources are largely in west and north China, and hydropower resources in south-west China.

Such misalignment is determined by geography, but shaped and intensified by social and economic development. In countries like China and Russia, large-scale, long-distance and efficient power transmission is needed to connect energy resources with load centres.

\section{(2) Characteristics}

Long-distance power transmission technologies are mainly divided into: extra-high voltage and ultra-high voltage (EHV/UHV) AC, EHV/UHV $\mathrm{DC}$, flexible AC/DC power transmission, multi-terminal direct current (MTDC) power transmission, and new technologies like fractional frequency transmission, superconducting transmission, half-wavelength transmission, etc.

$10-220 \mathrm{kV}$ AC transmission is the most common technology in large power systems. AC transmission at low voltage over hundreds of kilometres results in substantial electrical losses. One solution is to increase the voltage level to EHV. Another is to convert AC to DC for long-distance transmission (DC has lower power losses). EHV generally refers to $330-765 \mathrm{kV} \mathrm{AC}$ and \pm 500 to $\pm 660 \mathrm{kV}$ DC transmission technologies.

UHV means a voltage level of at least $1,000 \mathrm{kV}$ for $\mathrm{AC}$ transmission and $\pm 800 \mathrm{kV}$ or more for DC transmission. UHV transmission systems can carry more power at a higher voltage over longer distances and with lower losses than EHV.

\subsubsection{Current Trends in Global Long-Distance Power Transmission}

\section{(1) Application analysis}

First, technological progress.

Several major economies have developed technologies and equipment critical to long-distance power transmission since the 1960s. The former Soviet Union, Japan, the USA and Italy initiated UHV power transmission.

The former Soviet Union was one of the earliest countries to investigate UHV transmission, and the only country (except China) to have UHV AC transmission projects in operation up to now. The former Soviet Union started to construct the Siberia-Kazakhstan-Ural 1,150 kV UHV AC transmission project in 1980 to transmit electricity from Siberia to load centres in the European part of the country. The project started to operate at its intended rated voltage in 1985 but was later reduced to $500 \mathrm{kV}$ due to technical difficulties.

Research and experiments in UHV technology have been carried out in the USA but have not been deployed. In 1974, American Electric Power and General Electric conducted audible noise, radio jamming and other tests at the UHV test station at Pittsfield, Massachusetts. A 1,000$1,500 \mathrm{kV}$ three-phase test line was constructed by the Electrical Power Research Institute in 1974. It provided experience in electromagnetic operating environments, tower installation and transformer design.

Japan started to construct $1,000 \mathrm{kV}$ transmission and substation projects in 1988. By 1999 it had built two $1,000 \mathrm{kV}$ power transmission lines with a 
total length of $430 \mathrm{~km}$ and one $1,000 \mathrm{kV}$ substation. One of the two lines, called the North-South Line, is $190 \mathrm{~km}$ long and starts from the nuclear power plants along the north-west coast to the Tokyo region further south. The second line, the East-West Line, is $240 \mathrm{~km}$ long and connects power plants along the east coast of the Pacific Ocean This line has been operating at reduced voltage because of lower load requirements.

Italy started to build a $1,050 \mathrm{kV}$ UHV experimental line of $3 \mathrm{~km}$ in 1984 at the Suvereto experiment station. It was completed in October 1995 and operated until December 1997 at a rated voltage of $1,050 \mathrm{kV}$, providing some operational experience.

Second, practical deployment in projects.

Countries in Europe, Africa, Asia and the Americas have constructed long-distance power transmission projects and developed long-term plans for them in recent years. These plans include the European Ten-Year Network Development Plan, US Grid 2030, and EHV/UHV power transmission projects in India, Brazil and countries within China's Belt and Road Initiative for global development.

The European Network of Transmission System Operators for Electricity (ENTSO-E) published the draft of a new pan-European Ten-Year Network Development Plan (TYNDP) in July 2014. TYNDP sets 2030 as the milestone for Europe to achieve its energy targets and it describes the coming investment programmes for the European power transmission network. Its guidance is mandatory and ensured by legislation. According to TYNDP 2014, Europe needs to invest EUR 150 billion in the construction and upgrading of about $48,000 \mathrm{~km}$ of high voltage power transmission lines for the pan-European grid. This investment is needed to transfer renewable energy from around the North Sea to other parts of Europe. The large-scale development of renewables will require the construction of more long-distance and large-capacity transmission projects to interconnect countries in a pan-European power grid. TYNDP 2014 expects the average transmission capacity of the European grid to be doubled by 2030 .
In Brazil, the Belo Monte UHVDC transmission project ${ }^{56}$ connects vast hydropower resources along the Amazon River and branches in the north with the Rio de Janeiro and Sao Paulo load centres in the south-east, up to $2,500 \mathrm{~km}$ away. Long-distance, large-capacity UHV power transmission is the only way to harness these hydropower resources and transport the energy to where it is needed.

The joint venture between the State Grid Corporation of China and the Brazilian utility Electrobras won the order for the $\pm 800 \mathrm{kV}$ UHVDC power link in 2014. The line, 2,092 km long, starts from the Belo Monte hydropower plant on the Xingu River and ends at the Estreito converter station in Iberaci. It is the first $\pm 800 \mathrm{kV}$ UHVDC power transmission line in the Americas. It was inaugurated in 2017.

In 2015, State Grid Corporation of China won a 30-year concession to build and operate a second $\pm 800 \mathrm{kV}$ UHVDC transmission link from the Belo Monte hydropower station. Belo Monte has an installed capacity of $11.2 \mathrm{GW}$, the second largest in Brazil. The transmission project includes one $\pm 800 \mathrm{kV}$ UHVDC power transmission line of $2,518 \mathrm{~km}$, a converter station at each end and auxiliary projects. The link has a power transmission capacity of $4 \mathrm{GW}$ and is scheduled to start commercial operation in 2020 (Fig. 42).

India $(\mathrm{UHVDC})^{57}$ : to transmit hydropower from the north-east and thermal power from central regions, India has built two $\pm 800 \mathrm{kV}$ UHVDC links: Biswanath Chariali-Agra $(1,728 \mathrm{~km})$ and Champa-Kurukshetra $(1,365 \mathrm{~km})$. The two links transmit surplus power from eight states in the north-east to the north, where there is a shortage of electricity. This not only powers industrial development in the north, but delivers economic benefits to the north-east, where the economy needs development.

\footnotetext{
${ }^{56}$ Official website of Ministry of Commerce of China: http://www.mofcom.gov.cn/article/i/jyjl/1/201507/ 20150701052029.shtml.

${ }^{57}$ Electric Power Construction in India and its UHV DC/AC Power Transmission Plans, He Dayu, Electric Power, Issue 2, 2008.
} 


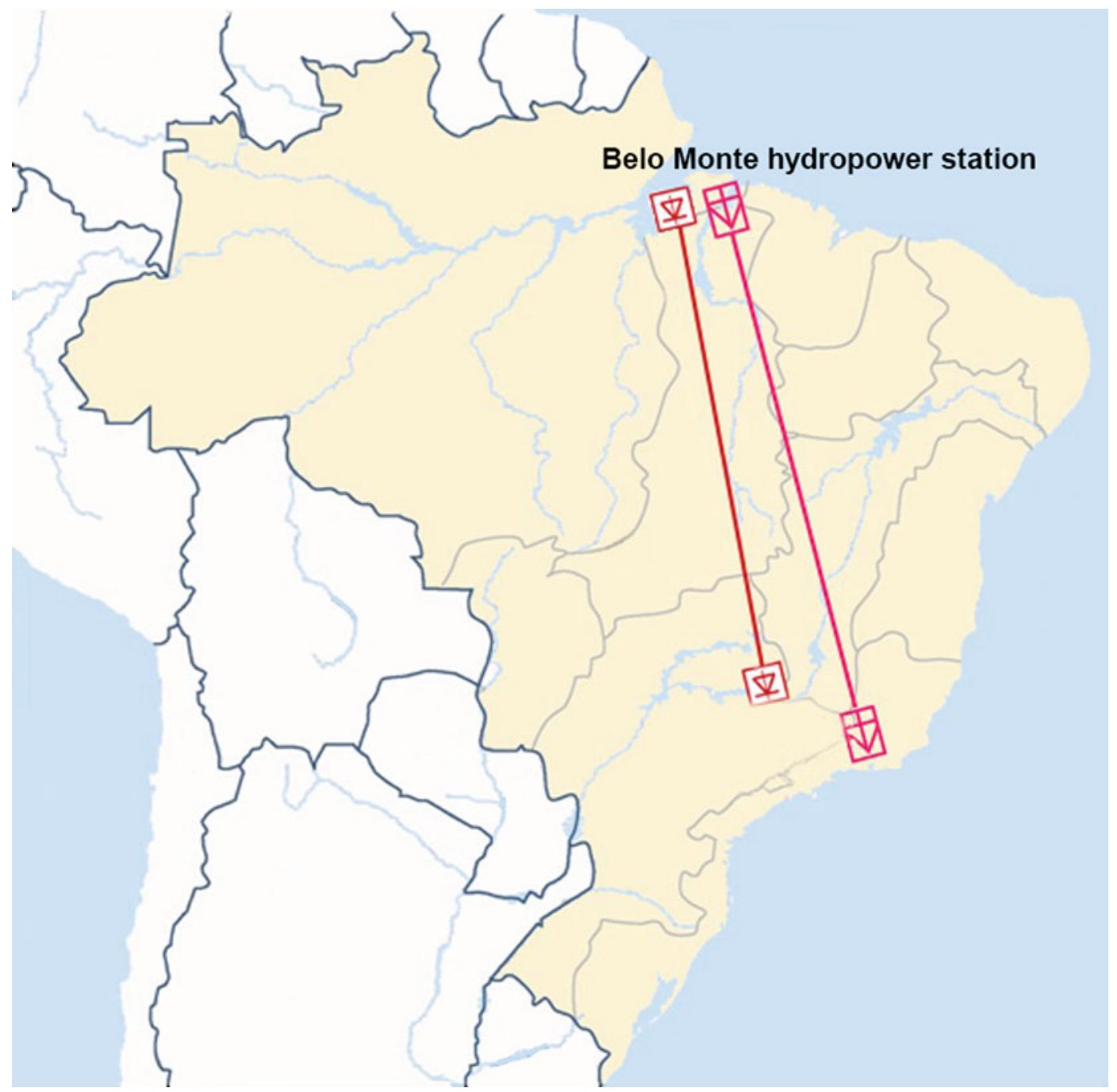

Fig. 42 Belo Monte UHV DC project, Brazil. Source White Paper on Global Energy Internet Development Strategy, Global Energy Interconnection Development

In addition, India is researching and testing $1,200 \mathrm{kV}$ UHVAC power transmission links. It plans to construct six $1,200 \mathrm{kV}$ UHVAC lines to interconnect its power networks by 2020 and transfer hydropower from north-east India to the rest of the country.

In Egypt, the Egyptian Electricity Transmission Company's (EETC) $500 \mathrm{kV}$ power transmission project $^{58}$-about $1,210 \mathrm{~km}$ long and

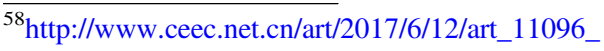
1397882.html.
}

and Cooperation Organization, Feb. 22, 2017, Beijing, http://www.chinasmartgrid.com.cn/news/20170223/ 622201.shtml costing around $\$ 760$ million-is the first deal concluded under Sino-Egyptian capacity cooperation in the BRI framework. It is the largest power transmission line with the highest voltage and widest coverage in Egypt. The project was executed on an engineering, procurement and construction (EPC) basis by China Electric Power Equipment and Technology Co., Ltd., a wholly owned subsidiary of State Grid Corporation of China. It has increased transmission capacity from the gas-fired power plants in the 
Nile Delta, strengthened the national grid, and improved economic development and the efficient use of electricity. In addition, the project boosted upstream and downstream industries including power supply, electrical equipment and raw materials in Egypt and the Middle East. It created about 7,000 jobs for Egypt and achieved win-win results for Sino-Egyptian cooperation.

In Pakistan, the Matiari-Lahore HVDC power transmission project is a priority of the China-Pakistan Economic Corridor of infrastructure projects. The link will be about $900 \mathrm{~km}$ long and have a capacity of $4 \mathrm{GW}$. State Grid Corporation of China is developing the project on a BOOT (build, own, operate and transfer) basis. When completed in 2021 the link will transport much-needed power from the south, where it is generated, to load centres in central Pakistan.

The EuroAsia Interconnector is an HVDC project that will connect the Greek mainland with Crete, Cyprus and Israel using multi-terminal flexible DC technology. The interconnector is part of the European network of interconnected electricity grids that provide bi-directional electricity supply through national transmission operators. It will enable the three partner countries (Israel, Cyprus and Greece) to better utilise their recently found offshore natural gas by converting it into electricity for their own use and for transmission to the rest of Europe. When completed in 2023, the interconnector will be the longest HVDC cable link in the world at $1,518 \mathrm{~km}$ and the deepest subsea cable at $3,000 \mathrm{~m}$. The link will have a power capacity of 2 GW.

In the USA, Grid 2030-A National Vision for Electricity's Second 100 Years $^{59}$ is a report published in 2003 by the U.S. Department of Energy. The report clearly defines the vision for the future US grid and emphasises the importance of nationwide interconnection and interconnection with Canada and Mexico. Grid 2030 consists of three major elements: (i) a national electricity framework of high-capacity

\footnotetext{
${ }^{59}$ https://energy.gov/oe/downloads/grid-2030-nationalvision-electricity-s-second-100-years.
}

transmission corridors that link the east and west coasts and connect with Canada and Mexico; (ii) interconnected regional grids-power from the corridors is distributed to regional networks by long-distance AC transmission or, in some cases, by expanded DC links; and high-capacity DC interties are used to link adjacent, asynchronous grids; (iii) local, mini-grids and microgrids. The nation's local distribution systems are connected to the regional networks, and through them to the national corridors. Real-time monitoring and information exchange enable markets to process transactions instantaneously and on a national basis. Customers have the ability to tailor their electricity supply.

\section{(2) Related technologies}

1. Long-distance power transmission technologies Factors such as growing demand for power, the challenges of integrating new energy with the grid, intelligent power consumption and ever stricter environmental requirements, are making it increasingly difficult for conventional transmission links to meet future requirements. Many countries have carried out research on EHV and UHV and other new power technologies.

UHV power transmission delivers many benefits, including large capacity, long distance, low energy losses, small footprint and cost effectiveness. Other new power transmission technologies have some obstacles to overcome and have yet to be widely deployed, but they offer superior benefits over conventional methods in certain applications. With development and progress, those technologies are expected to be deployed in projects.

First, UHV power transmission. AC and DC hybrid power networks represent the future for UHV power transmission. UHVAC and UHVDC have their own characteristics, but they are also complementary. UHVAC is economically competitive for distances from 1,000-2,000 km. UHVDC power transmission is more cost effective for distances of more than $1,500 \mathrm{~km}$. UHVDC is, therefore, used to transmit large volumes of electricity from energy bases over long or ultra-long distances. UHVAC is used for 
grids with higher voltage levels and for cross-regional interconnections.

Second, flexible DC power transmission. Flexible DC is now used to connect wind farms to the grid, transfer high-quality power to city centres, and create DC networks for remote regions and islands - these are the main applications. Flexible power transmission improves the quality of unstable renewable energy in the grid. For some remote regions characterised by low and fluctuating loads and long transmission distances, HVAC and conventional HVDC power transmission technologies are not technically and economically feasible. Flexible DC power transmission transports power through DC lines to remote regions and load islands, supporting local economic development with emission-free electricity.

Third, multi-terminal DC (MTDC) power transmission transports electricity from multiple power sources to multiple load centres. It is more cost effective than conventional HVDC power transmission, which links one converter station to another via HVDC transmission lines or cables. For example, Tibet has great hydropower potential and will be an important energy source for China in the future. However, the existing power transmission corridor is inadequate, and the single hydropower station that generates power from the Jinsha, Lancang and Nujiang rivers in east Tibet is small. An MTDC system could be used to transfer power from multiple plants on the three rivers to multiple receiving terminals near load centres. Several MTDC power transmission systems are already in operation in China, Africa, Europe, the USA and shortly in India. MTDC power transmission projects will play an important role in future long-distance and large-capacity power transmission in many countries.

Fourth, superconducting power transmission has already been demonstrated in power distribution because of its low voltage level and short power transmission distance. Many countries are researching its application in long-distance power transmission. For example, the Netherlands is researching superconducting transmission at a rated voltage of $50 \mathrm{kV}$, and South Korea is examining high-temperature applications. The USA is researching three-phase resistance and a saturated core high-temperature superconducting fault current limiter using the second generation of high-temperature superconducting materials. Superconducting DC power transmission could become a future technology trend. It is more efficient than superconducting AC because it loses less power in transmission. It is also more cost effective than AC at the same transmission capacity. China and Japan have both carried out experiments in superconducting DC power transmission. The Institute of Electrical Engineering at the Chinese Academy of Sciences is constructing a demonstration project to supply power to an electrolytic aluminium plant.

Fifth, fractional frequency power transmission has become a research priority for transporting large-scale offshore wind power, as it is potentially more cost effective and reliable than alternative technologies. However, research is still at the theoretical and simulation stage. Although it does merit deeper study and deployment in real projects. The technology is a combination of fractional frequency power transmission and power electronics, which together have the potential to produce benefits in terms of system design, control, capacity, reactive power and harmonics. Another application for this highly promising technology is hydropower.

Sixth, half-wavelength AC power transmission means that the electrical distance of power transmission is close to one power frequency half-wavelength, i.e. $3,000 \mathrm{~km}$ or $2,600 \mathrm{~km}$ ultra-long distance three-phase AC power transmission. A lossless half-wavelength AC line is like an ideal transformer with a transformation ratio of -1 . Sending-end and receiving-end voltage is at the same level but opposite in phase. It is suitable for ultra-long distance and ultra-large capacity power transmission. A.A. Wolf and his colleagues in the former Soviet Union came up with the idea of half-wavelength AC power transmission as early as 1940. Potentially, half-wavelength AC power transmission has several advantages over conventional $\mathrm{AC}$ power transmission over long distances - such as no need for reactive compensation equipment and 
switching stations; high transmission capacity; and it is less costly than UHVDC. Although there is no half-wavelength power transmission project at present, the potential cost-effectiveness of UHV half-wavelength power transmission makes it promising for the future.

\section{Selection criteria}

The research and development of EHV and UHV technologies and equipment provides a strong foundation for the future application of long-distance power transmission. Demand for large-capacity, long-distance power transmission is the main driver. Technology selection is influenced by national conditions and trends.

Future growth in global power demand will come mainly from non-OECD countries. India, Brazil and other developing countries with escalating demand need to build large power source bases to supply electricity to load centres, which often lie far away. UHV AC and DC is the technology of choice.

North America and Europe are characterised by low growth in power demand and a transition to low-carbon and green energy. They have plans to develop large wind power, solar energy and clean energy bases. Advanced technologies including MTDC, flexible AC/DC and UHVAC could be used to construct power transmission networks with higher voltage levels and more flexibility, enabling renewable energy to be connected to the grid and consumed in more areas.

\subsubsection{Current Developments in Long-Distance Power Transmission in China}

\section{(1) The policy environment}

China's energy sources and load centres are separated, often thousands of kilometres apart, making long-distance power transmission important. China's energy sources are abundant in the west and north, and scarce in the east and south. Large energy bases are located mainly in the north, north-east, north-west and south-west where the power load is low. The distance between these bases and load centres in central and east China is $1,000-3,000 \mathrm{~km}$, longer than the cost-effective distance of conventional EHV power transmission. The size and distance of energy flows will continue to grow, imposing challenges on power transmission in terms of capacity, distance and efficiency.

Long-distance power transmission is also a means to address the severe ecological and environmental problems caused by pollution and haze in east and central China. It can help improve the environment both in energy bases and load centres, enabling high-efficiency coal-fired power plants to be built in coal-producing regions in the west and north. This power can be transmitted in large volumes over long distances to central and east China, sharing the environmental burden more equally across regions and easing environmental pressure in load centres.

At the policy level, the central government attaches great importance to the energy transition. It has introduced policies and plans to develop long-distance power transmission and strengthen energy security. From 2005, UHV was included in national strategic plans, including the Outline of the National Medium- and Long-term Science and Technology Development Program (2006-20), ${ }^{60}$ published in 2006, and the 12th Five-Year Plan for the National Economic and Social Development of China, ${ }^{61}$ issued in 2011.

The Strategic Action Plan on Energy Development (2014-20) ${ }^{62}$ released in 2014 proposed the clean and efficient development of coal power, the construction of large coal power bases and power transmission corridors and the development of long-distance and large-capacity power

\footnotetext{
${ }^{60}$ http://www.most.gov.cn/mostinfo/xinxifenlei/gjkjgh/ 200811/t20081129_65774.htm.

${ }^{61}$ http://www.gov.cn/2011lh/content_1825838.htm.

${ }^{62}$ http://www.mlr.gov.cn/xwdt/jrxw/201411/t20141119_ 1335668.htm.
} 
transmission technologies. It also proposed expanding the capacity of the West-East power transmission project and implementation of the North-South transmission corridor. The National Energy Administration issued the Circular on Accelerating and Promoting the Construction of 12 Major Power Transmission Corridors under the Air Pollution Prevention and Control Action Plan, ${ }^{63}$ also in 2014. These corridors include the Xilingol League-Shandong, Huainan-NanjingShanghai, West Inner Mongolia-South Tianjin and Yuheng-Shandong UHVAC projects; the East Ningxia-Zhejiang, Xilingol League-Taizhou, Shanghaimiao-Shandong, North Shanxi-Jiangsu and North-west Yunnan-Guangdong UHVDC projects; and three $\pm 500 \mathrm{kV}$ power transmission lines.

In 2016, the National Energy Administration released the 13th Five-Year Plan for Electricity Development. ${ }^{64}$ Among other things the plan proposes to add $130 \mathrm{GW}$ of capacity to the West-East transmission project by 2020. This will increase the project's capacity to around 270 $\mathrm{GW}$, reducing annual standard coal equivalent (SCE) consumption by more than 100 million tonnes in east and central China, thereby reducing emissions and air pollution in the receiving regions.

\section{(2) Current developments}

China began to study UHV technologies in the 1980s. Large-scale research and demonstration projects began in 2004. China has made breakthroughs in UHV in recent years, developing key technologies and the ability to manufacture UHV transformers, reactors, 6 in. thyristors, highcapacity converter valves and other key equipment. China has built the South-east ShanxiNanyang-Jingmen $1,000 \mathrm{kV}$ UHVAC pilot and demonstration project, Yunnan-Guangdong (5,000 MW) and Xiangjiaba-Shanghai (7,000 MW) $\pm 800 \mathrm{kV}$ UHVDC demonstration

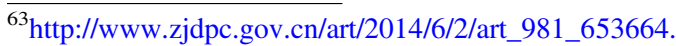
html.

${ }^{64}$ http://www.nea.gov.cn/2016-11/07/c_135811086.htm.
}

projects, which have been operating safely and stably for a long time, proving that China's UHV power transmission technologies are mature and can be deployed widely.

Up to June 2017, China had built 18 UHV projects, with two more under construction. Among the $20 \mathrm{UHV}$ projects, seven are AC and 13 are $\mathrm{DC}$, with a total length of nearly $30,000 \mathrm{~km}$. The East Junggar-South Anhui $\pm 1,100 \mathrm{kV}$ UHVDC power transmission project is the world-record holder in terms of length $(3,324 \mathrm{~km})$, voltage $(1,100 \mathrm{kV}$ DC) and capacity (12,000 MW) (Tables 13 and 14).

The longest UHVDC power transmission line in service is Jiuquan-Hunan $\pm 800 \mathrm{kV}$. It opened in June 2015 and runs through Gansu, Shaanxi, Chongqing, Hubei and Hunan. The two converter stations, one at either end, have a combined converter capacity of $16,000 \mathrm{MW}$. At $2,383 \mathrm{~km}$, Jiuquan-Hunan is the longest UHVDC line in the world at present. It is a trans-regional power transmission corridor mainly for wind, solar and other renewables. In time it will become a west-east power transmission super-highway, enabling the bulk transmission of wind and coal power from Gansu to meet the current power shortage in central China.

The first UHVAC link in China is the South-east Shanxi-Nanyang-Jingmen $1,000 \mathrm{kV}$ UHVAC power transmission pilot and demonstration project: The line is $640 \mathrm{~km}$ long. Phase 1 was energised in January 2009 and was the world's first UHVAC line to enter commercial operation. Phase 2 opened in December 2011. It has a transmission capacity of 5,000 MW and can transport 25,000 GWh of power per year. The project connects the north China and central China power grids and is an important north-south transmission corridor. It delivers coal-fired power from north China to the south in winter and surplus hydropower from central China to the north in summer. It also provides backup power in case of outages, delivering substantial economic and social benefits.

The longest UHVAC power transmission line in service is Yuheng-Weifang. The $1,000 \mathrm{kV}$ UHVAC project opened in May 2015. It runs through Shaanxi, Shanxi, Hebei and Shandong. 
Table 13 UHV transmission in China (up to June 2017)

\begin{tabular}{|c|c|c|c|c|c|c|c|c|}
\hline DC & Project & $\begin{array}{l}\text { Starting } \\
\text { point }\end{array}$ & Destination & $\begin{array}{l}\text { Capacity } \\
\text { (MW) }\end{array}$ & $\begin{array}{l}\text { Voltage } \\
\text { level } \\
(\mathrm{kV})\end{array}$ & $\begin{array}{l}\text { Construction } \\
\text { commencement } \\
\text { date }\end{array}$ & $\begin{array}{l}\text { Operation } \\
\text { date }\end{array}$ & $\begin{array}{l}\text { Length } \\
(\mathrm{km})\end{array}$ \\
\hline 1 & $\begin{array}{l}\text { Jinping-South } \\
\text { Jiangsu }\end{array}$ & Sichuan & Jiangsu & 7,200 & \pm 800 & 2009 & 2012 & 2,100 \\
\hline 2 & $\begin{array}{l}\text { Xiluodu—West } \\
\text { Zhejiang }\end{array}$ & Sichuan & Zhejiang & 8,000 & \pm 800 & 2012 & 2014 & 1,700 \\
\hline 3 & $\begin{array}{l}\text { Xiangjiaba- } \\
\text { Shanghai }\end{array}$ & Sichuan & Shanghai & 6,400 & \pm 800 & 2007 & 2010 & 1,907 \\
\hline 4 & $\begin{array}{l}\text { Kumul- } \\
\text { Zhengzhou }\end{array}$ & Xinjiang & Henan & 8,000 & \pm 800 & 2012 & 2014 & 2,210 \\
\hline 5 & $\begin{array}{l}\text { East Ningxia- } \\
\text { Shaoxing }\end{array}$ & Ningxia & Zhejiang & 8,000 & \pm 800 & 2015 & 2016 & 1,720 \\
\hline 6 & Jiuquan-Hunan & Gansu & Hunan & 8,000 & \pm 800 & 2015 & 2017 & 2,383 \\
\hline 7 & $\begin{array}{l}\text { North Shanxi- } \\
\text { Jiangsu }\end{array}$ & Shanxi & Jiangsu & 8,000 & \pm 800 & 2015 & 2017 & 1,119 \\
\hline 8 & $\begin{array}{l}\text { Xilin Gol League } \\
\text { - Taizhou }\end{array}$ & $\begin{array}{l}\text { West } \\
\text { Inner } \\
\text { Mongolia }\end{array}$ & Jiangsu & 10,000 & \pm 800 & 2015 & 2017 & 1,628 \\
\hline 9 & $\begin{array}{l}\text { Shanghaimiao-- } \\
\text { Shandong }\end{array}$ & $\begin{array}{l}\text { West } \\
\text { Inner } \\
\text { Mongolia }\end{array}$ & Shandong & 10,000 & \pm 800 & 2015 & 2017 & 1,240 \\
\hline 10 & $\begin{array}{l}\text { Chuxiong- } \\
\text { Huidong }\end{array}$ & Yunnan & Guangdong & 5,000 & \pm 800 & 2006 & 2010 & 1,412 \\
\hline 11 & Pu'er-Jiangmen & Yunnan & Guangdong & 5,000 & \pm 800 & 2011 & 2015 & 1,400 \\
\hline $\mathrm{AC}$ & Project & $\begin{array}{l}\text { Starting } \\
\text { point }\end{array}$ & Destination & $\begin{array}{l}\text { Capacity } \\
\text { (MW) }\end{array}$ & $\begin{array}{l}\text { Voltage } \\
\text { level } \\
(\mathrm{kV})\end{array}$ & $\begin{array}{l}\text { Construction } \\
\text { commencement } \\
\text { date }\end{array}$ & $\begin{array}{l}\text { Operation } \\
\text { date }\end{array}$ & $\begin{array}{l}\text { Length } \\
(\mathrm{km})\end{array}$ \\
\hline 1 & $\begin{array}{l}\text { Southeast Shanxi } \\
\text {-Nanyang- } \\
\text { Jingmen }\end{array}$ & Shanxi & Hubei & 5,000 & 1,000 & 2006 & 2009 & $1 \times 654$ \\
\hline 2 & Anhui_-East China & Anhui & East China & 6,000 & 1,000 & 2011 & 2013 & $2 \times 656$ \\
\hline 3 & $\begin{array}{l}\text { North Zhejiang- } \\
\text { Fuzhou }\end{array}$ & Zhejiang & Fujian & 3,000 & 1,000 & 2013 & 2014 & $2 \times 603$ \\
\hline 4 & $\begin{array}{l}\text { Xilingol League- } \\
\text { Shandong }\end{array}$ & $\begin{array}{l}\text { West } \\
\text { Inner } \\
\text { Mongolia }\end{array}$ & Shandong & 7,000 & 1,000 & 2014 & 2016 & $2 \times 730$ \\
\hline 5 & $\begin{array}{l}\text { West Inner } \\
\text { Mongolia-South } \\
\text { Tianjin }\end{array}$ & $\begin{array}{l}\text { West } \\
\text { Inner } \\
\text { Mongolia }\end{array}$ & Tianjin & 6,000 & 1,000 & 2015 & 2016 & $2 \times 608$ \\
\hline 6 & $\begin{array}{l}\text { Huainan-Nanjing } \\
\text {-Shanghai }\end{array}$ & East China & Ring Grid & 6,000 & 1,000 & 2014 & 2016 & $2 \times 738$ \\
\hline 7 & Yuheng-Weifang & Shaanxi & Shandong & 6,000 & 1,000 & 2015 & 2017 & $2 \times 1,048$ \\
\hline
\end{tabular}

The $2 \times 1,049 \mathrm{~km}$ double-circuit line is the bases to supply power to other regions. It has longest UHVAC line in the world. Part of the also increased the capacity of the north China north China UHV AC/DC grid, the link has power grid and effectively reduced power shorthelped Shaanxi and Shanxi develop their energy ages in central and east China. 
Table 14 UHV projects under construction in China (up to June 2017)

\begin{tabular}{|c|c|c|c|c|c|c|c|c|}
\hline $\mathrm{AC}$ & Project & $\begin{array}{l}\text { Starting } \\
\text { point }\end{array}$ & Destination & $\begin{array}{l}\text { Capacity } \\
\text { (MW) }\end{array}$ & $\begin{array}{l}\text { Voltage } \\
\text { level } \\
(\mathrm{kV})\end{array}$ & $\begin{array}{l}\text { Construction } \\
\text { commencement } \\
\text { date }\end{array}$ & $\begin{array}{l}\text { Operation } \\
\text { date }\end{array}$ & $\begin{array}{l}\text { Length } \\
(\mathrm{km})\end{array}$ \\
\hline 1 & $\begin{array}{l}\text { East Junggar } \\
\text { - south } \\
\text { Anhui }\end{array}$ & Xinjiang & Anhui & 12,000 & $\pm 1,100$ & 2016 & 2018 & 3,324 \\
\hline 2 & $\begin{array}{l}\text { Jarud- } \\
\text { Qingzhou }\end{array}$ & $\begin{array}{l}\text { East Inner } \\
\text { Mongolia }\end{array}$ & Shandong & 10,000 & \pm 800 & 2016 & 2018 & 1,234 \\
\hline
\end{tabular}

\section{(3) Economic and social benefits}

First, the South-east Shanxi-Nanyang-Jingmen UHVAC power transmission project.

As the first $1,000 \mathrm{kV}$ UHVAC link in the world, this pilot and demonstration project has played an instrumental role in optimising grid resources in the 10 years since it opened. In dry winter seasons, it transfers thermal power from the north to Hubei. In wet summers, it delivers surplus hydropower from south-west China, including Sichuan, to the north China power grid, relieving power shortages in Shandong. The complementarity of hydropower and thermal power not only avoids hydro curtailment in the wet season, it reduces coal consumption in north China and increases the use of clean energy.

Fossil energy sources are scarce in Hubei. Its coal reserves account for less than $1 \%$ of China's total. $98 \%$ of the coal used for Hubei's power generation needs to be procured from other provinces. Its hydropower has been fully developed and is transmitted to other regions. $60 \%$ of Hubei's power consumption is supplied by thermal power, exposing it to increasingly serious energy constraints. The South-east Shanxi-Nanyang-Jingmen UHVAC project supplies 5,000 MW of thermal power from north China to Hubei. This avoids the transport of more than 7 million tonnes of thermal coal per year, which if converted into electricity would be equal to the output of the 2,700 MW Gezhouba hydropower plant in Hubei. Up to the end of October 2016, the link, which has a capacity of $5,720 \mathrm{MW}$, had transmitted 55,600 GWh of electricity, effectively eliminating the power shortage in Hubei. Calculations show that the price of electricity transmitted by the link to
Hubei is RMB $0.02-0.07 / \mathrm{kWh}$ lower than the current benchmark thermal power price in Hubei. According to a report published by Greenpeace, the transmission of every $100 \mathrm{GWh}$ through UHV reduces particulate matter (PM2.5 and $\mathrm{PM} 10)$ and sulphur dioxide/nitrogen oxide $\left(\mathrm{SO}_{2} /\right.$ $\mathrm{NO}_{\mathrm{x}}$ ) from load centres by about 7 tonnes, 17 tonnes and 450 tonnes respectively. ${ }^{65}$

Second, the Anhui-East China UHVAC power transmission project.

The Anhui-East China $1,000 \mathrm{kV}$ UHVAC power transmission line, which starts at Huainan and ends at Shanghai, has been operating since 2013, delivering multiple benefits to Huainan and east China. Huainan's power generation companies transmit around 24,000 GWh of electricity to east China through the UHV project every year, generating more than RMB 17 billion in sales revenue and RMB 3 billion in taxes annually, which boost the local economy. In addition, coal is used locally in Anhui at RMB 30/tonne, rather than being transported over long distances to Shanghai at RMB 70/tonne. This reduces transport-related pollution. The dust, exhaust gas and lines of trucks on the roads of Huainan are no longer to be seen. In addition to supplying Shanghai and Zhejiang with $6,000 \mathrm{MW}$ of capacity and 24 billion $\mathrm{kWh}$ of electricity, the link enables Shanghai and Zhejiang to reduce coal consumption by 10.8 million tonnes per year, equivalent to six 1,000 MW thermal generating units. This has cut emissions of $\mathrm{CO}_{2}, \mathrm{SO}_{2}$ and $\mathrm{NO}_{\mathrm{x}}$ in Shanghai by 21 million

\footnotetext{
${ }^{65}$ http://www.cet.com.cn/, "Power Expressway" Empowered by UHV Technology Brings Enormous Economic Benefits, http://power.in-en.com/html/power-2269268. shtml.
} 
tonnes, 50,000 tonnes and 56,000 tonnes per year, significantly improving the air quality in China's second biggest city. ${ }^{66}$

\section{(4) Main problems}

Generally, China's UHV technology is world-class in terms of technology and capacity. However, there are still some issues to be resolved.

First, UHV increases the complexity of the power system and puts it at greater risk. Effective precautions need to be taken to ensure system security. AC-DC interconnections and increasing volumes of new energy change the system profoundly. Once interconnected, regional grids are interdependent and impact each other mutually. This increases overall complexity, risk and uncertainty. If a commutation failure occurs on a $\pm 800 \mathrm{kV} \mathrm{DC}$ line, it generates an 8,000 MW power surge, which is 3-4 times that of AC. If a DC commutation failure occurs, requiring multiple restarts, an instantaneous 21,000 MW power surge and 8,000 MW repeat surges will be generated, which could cause an outage. ${ }^{67}$ Higher transmission voltage levels and larger amounts of new energy increase the risk to grid security.

Second, there is still a quality gap between locally manufactured UHV equipment and advanced international technologies. Some key components still need to be imported. Supply channels for drawings, materials, user manuals, software, and some other spare parts are simplex. This increases the cost and complexity of operating and maintaining UHV projects.

\footnotetext{
${ }^{66} \mathrm{http}: / /$ www.xinhuanet.com/, Calculation of Economic and Environmental Benefits of UHV Technology from the Perspective of Anhui-East China UHV Power Transmission Project, http://news.xinhuanet.com/2016-11/01/c_ 1119830177.htm.

${ }^{67}$ Tang Yong, speaker at the 5th China Power Development and Technology Innovation Forum, April 27, 2017, http://shupeidian.bjx.com.cn/news/20170428/822880. shtml.
}

\subsubsection{The Role of Long-Distance Power Transmission in China's Energy Revolution}

Long-distance power transmission provides strategic support for the development of clean energy in China. It is an important tool to shape a national market and optimise resource allocation, and an integral part of the modern power system.

First, long-distance power transmission enables electricity to be transferred in bulk across the country. As China's energy sources and load centres are in different regions, trans-regional electricity flows with multiple sending and receiving ends is the future. The capacity, distance and types of electricity flow will only increase. As a result, China needs to speed up development of long-distance power transmission and plan in a centralised manner the links between sending and receiving regions.

Second, the development of long-distance power transmission delivers comprehensive benefits, including regional interconnections, inter-basin hydropower transfer, trans-regional allocation, peak shaving, the complementary and coordinated use of hydropower and thermal power, and less need for backup capacity. Trans-regional allocation reduces the need for receiving regions in east and central China to build coal-fired power plants. New power demand is supplied mainly with local nuclear power and with electricity from other regions. Peak shaving is used to optimise the power mix and better integrate clean renewable energy.

Third, long-distance power transmission can help connect and consume clean energy. As clean energy is intermittent and far from load centres, grid connection is faced with two challenges: (i) clean energy poses more demanding requirements than conventional power on the grid's peak shaving capacity; and (ii) the ability of clean energy-abundant areas to use all the energy locally is limited. China can make the most of its national peak-shaving resources and new energy capacity only when grid connection and consumption of clean energy in large areas is 
possible. To allocate its hydro, wind and solar resources optimally, China must develop long-distance, large-capacity and low-loss power transmission technologies.

\section{(2) Medium- and long-term development of China's grid}

The separation of energy resources from load centres determines the development pathway of the grid. China now has six AC synchronous power grids: North China-Central China, East, North-east, North-west, South China, and Tibet, which operate according to jurisdiction and grid requirements. Connection between these grids and the ability to allocate energy resources are weak.

State Grid Corporation of China has issued a national grid development plan in which China will optimise its six regional power grids into two UHV synchronous grids characterised by clear sending-receiving terminals and AC-DC coordinated development in the medium and long terms. The two grids are: West (North-west and Sichuan, Chongqing and Tibet), East (North, East and Central China; Heilongjiang; Jilin and Liaoning; and Inner Mongolia). ${ }^{68}$

The two grids will enable the coordinated generation and bulk UHV transmission between regions of hydropower and thermal and of wind and solar power. This will allow clean energy to be deployed and used at scale in west China and to be consumed efficiently and sustainably in east China.

\subsubsection{Strategy and Policies for Long-Distance Power Transmission}

\section{(1) Strategic positioning}

Long-distance power transmission is the key to a modern electricity-centred energy system. China is faced with energy security challenges, including shortage of fossil fuels, rising demand

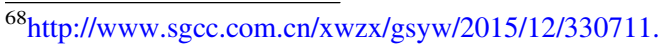
shtml.
}

for energy and import dependency. In addition, pollution is becoming more and more serious. The way to overcome these challenges is by following the electricity-centred energy strategy. This will give full play to electricity's role as an energy conversion hub, allowing multiple types of energy to be converted into power and used efficiently. In an electricity-centric China, power transmission will reduce the need to transport primary energy and allow renewables to be integrated and transmitted at scale, ultimately replacing fossil energy.

Long-distance power transmission is a sector in which China can exercise its Go Out strategy. China has the largest number of UHV projects in the world. It has UHV engineering experience and expertise, a strong UHV product R\&D programme, and experience in delivering huge transmission projects. It has world-class UHV technologies and production capacity. Thanks to the smooth delivery and operation of Belo Monte in Brazil and other overseas projects, China's UHVDC technology is yet another national business card alongside high-speed rail.

China also dominates the development of international UHV standards. Three Institute of Electrical and Electronics Engineers (IEEE) UHV standards, developed under the leadership of China, have been published in recent years: the Guide for Voltage Regulation and Reactive Power Compensation for Systems of $1,000 \mathrm{kV}$ AC and Above (IEEE P1860), the Guide for On-Site Acceptance Tests of Electrical Equipment and System Commissioning of $1,000 \mathrm{kV}$ $\mathrm{AC}$ and Above (IEEE P1861), and the Recommended Practice for Overvoltage and Insulation Coordination of Transmission Systems at $1,000 \mathrm{kV}$ AC and Above (IEEE P1862). The IEEE UHVAC Power Transmission System Technical Committee, founded in 2013 and chaired by China, significantly strengthens China's influence in the field of global grid standards. The fact that China's UHV standards have become international ones means that China's UHV technologies are internationally advanced.

Long-distance power transmission is an important facilitator of China's Belt and Road Initiative (BRI), enabling power interconnection 
with surrounding countries. Interconnected infrastructure is a priority of the BRI. Countries taking part in the BRI, with their sovereignty and security concerns respected, can build an infrastructure network connecting Asia, Europe and Africa. By planning infrastructure construction and aligning technical standards, BRI strengthens cooperation between countries and promotes the construction of cross-border power transmission corridors. With large-capacity, low-loss long-distance power transmission technologies, China can build a corridor that interconnects grid infrastructure across Asia-Pacific. Given the resource endowment differences and strong energy complementarity of the countries of the Silk Road Economic Belt (a component of BRI that applies to countries along the original Silk Road between China and Europe), China can import surplus power from neighbours through long-distance power transmission, stimulating economic development in those countries and securing power for China at lower cost.

\section{(2) Policy proposals}

First, the intensive development of large-scale renewable energy bases should drive research on UHV and other new long-distance power transmission technologies. These wind, hydro and solar power bases require grid connection and super-large capacity and ultra-long distance transmission systems, both within China and across neighbouring national borders. These technologies require further research and development, especially in UHV AC and DC and in new transmission technologies like half-wavelength, superconducting, wireless and pipeline.

Second, China should expand research on UHV grid control and simulation to minimise the risk of cascading power outages. Currently UHV power transmission technologies are faced with three major challenges to grid reliability: (i) the wider application of power electronics increases the possibility of cascading outages and makes grid stabilisation more complex and simulation analysis more difficult; (ii) an outage can have a greater impact on interconnected grids, and power fluctuations can increase the risk of a grid-wide outage; and (iii) poor voltage stability at the receiving end can increase if large changes are made to the power source mix. China therefore needs to increase its research on UHV power grids in areas such as simulation analysis, grid analysis, voltage stability and grid control.

Third, China should consolidate UHV's Go Out advantage. China needs to maintain its international leadership in DC transmission technologies, strengthen UHV's going-global advantage, build a world-class brand characterised by Made in China 2025 and Lead by China, increase the influence of Chinese businesses in target markets, thus laying a solid foundation for the export of China's UHVAC power transmission technologies and equipment.

Fourth, China should evaluate the economic and social benefits of long-distance power transmission in a comprehensive, scientific and systematic way. UHV power networks are characterised by high safety risks, heavy investment and large scale. They should be assessed according to their input-output ratio and in relation to their economic and social benefits and safety.

Fifth, China should strengthen early-stage planning and demonstration of UHV projects. UHV has helped China become a world leader in power transmission. However, UHV projects are a long process requiring precise and scientific preliminary studies. Project execution usually takes 5-8 years or even longer. The projects often run through many provinces and over long distances, resulting in much cross-provincial coordination work and high safety risks. Research institutes need to be engaged at each stage of the planning process. Targets and schedules should be adjusted dynamically as conditions change during the planning period.

\subsection{Nuclear Power}

The next 10 years will be a watershed for nuclear power development. Between the first oil crisis in 1973 and the Three Mile Island nuclear accident in the USA in 1979, around 170 units were built 


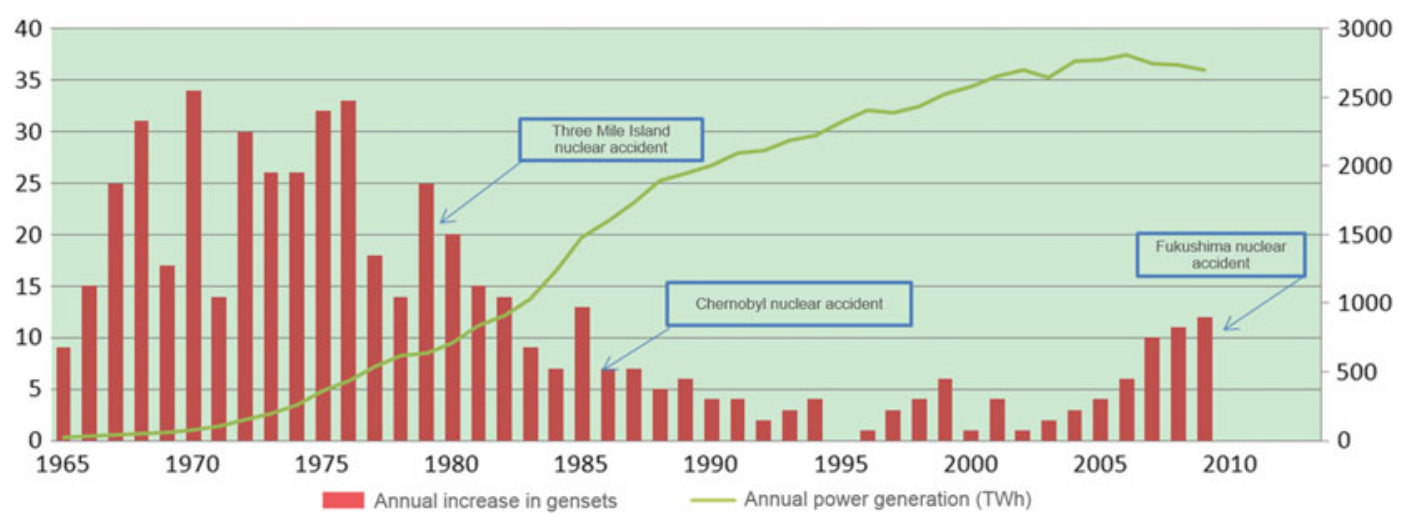

Fig. 43 Annual installed capacity and output of nuclear power

and put into operation across the globe. Many of those plants have a 40-year lifespan that will expire by 2020 . Nearly a third of them will be decommissioned in the following 10 years if their operating life is not extended. Although new nuclear power capacity can replace decommissioned plants, it remains to be seen if this new capacity can smoothly deliver sustained development of the nuclear power industry.

\subsubsection{Global Nuclear Power History}

\section{(1) Cyclical fluctuations}

Global nuclear power history is cyclical. It is a history of fast expansion that is halted by a nuclear accident. Driven by global economic growth and an energy shortage, nuclear power entered the first rapid expansion cycle in the 1960s and 1970s. At times more than 30 nuclear power units were put into operation annually. After the Three Mile Island nuclear accident, the expansion of nuclear power slowed down. The second growth cycle occurred in the late 1990s when climate change and energy security made nuclear power attractive again. Three Mile Island and the Chernobyl nuclear disaster in the former Soviet Union in 1986 brought safety technologies and safety supervision to the fore. The Fukushima nuclear accident in Japan in 2011 brought nuclear power into hard times again. After Fukushima, safety and supervision again became an issue. Nuclear power is now in a third cycle (Fig. 43).

\section{(2) The impact of accidents on nuclear power development}

The three nuclear power plant accidents-Three Mile Island, Chernobyl and Fukushima-had far-reaching effects on the development of nuclear energy. First, the annual increase in installed capacity shrank from 25 units to fewer than five after Chernobyl. Second, nuclear power technologies were upgraded to increase safety and procedures were improved to minimise human error. Multiple layers of independent and redundant protection were added (defence in depth) to strengthen response to failures, accidents or fires. Generation 2 technologies were improved, and Generation 3 and 4 reactors were developed, significantly enhancing safety and security. Third, supervision of nuclear safety became more and more sophisticated. After Three Mile Island, the USA improved its safety culture. The Institute of Nuclear Power Operations (INPO) was formed to set industry-wide performance objectives, criteria and guidelines for nuclear power operations. After Chernobyl, the International Atomic Energy Agency (IAEA) improved its nuclear safety standards, guidelines and procedures. In 1986 it published two treaties: the Convention on Notification of Nuclear Accident, by which states agree to notify others if 
a nuclear accident occurs within their jurisdiction; and the Convention on Assistance in Case of Nuclear Accident or Radiological Emergency, by which states that have signed the convention agree to help other states in which a nuclear accident has occurred. Fourth, more importance was attached to risk communication and public engagement. The complexity of nuclear power technologies makes it difficult for the public to understand, which creates antipathy. Nuclear accidents made people concerned about nuclear radiation. Governments started to focus on risk communication and public engagement to win the public over to nuclear energy.

\section{(3) Occurrence and resolution of safety issues}

The main line of nuclear power technology development is characterised by initial attention to engineering equipment, later to human operation, then to response to natural disasters. Increasingly reliable engineering equipment and standard operating procedures gradually replace human actions.

\section{(4) Safety challenges}

Nuclear power has characteristics that no other power generation technology has. It is safe, clean and sustainable, but if an accident occurs it has the potential to destroy people and the environment. International governance and oversight are therefore essential to ensure that safety is prioritised and risk is minimal.

The special characteristics of nuclear power pose numerous challenges on nuclear power safety. Nuclear power is highly sensitive clean energy with far-reaching effects if a major accident occurs. It needs the support of modern national governance. Its special characteristics pose strict requirements for scientific decision-making, public engagement and safety supervision. The rapidly decreasing cost of renewable energy and ever-stricter regulations on nuclear power safety supervision challenge the cost-effectiveness of nuclear power.

The US Nuclear Regulatory Commission's (NRC) safety standards have played an important role in minimising risk. After Three Mile Island, the NRC defined two safety thresholds. First, the risk of instantaneous death to the individuals around a nuclear power plant, due to a nuclear accident, should not exceed one thousandth of the sum of the risks of instantaneous death to the whole of society from other accidents. Second, the risk of death by cancer to individuals around an operating nuclear power plant should not exceed one thousandth of the sum of the risk of death by cancer to the whole of society from other causes. Over the past 30 years and within the framework of the two thresholds, safety standards were improved, facilitating the safe and long-term development of nuclear power.

Experience shows that global nuclear power plants meet the two thresholds. However, the public does not accept nuclear power. Even though nuclear power does not increase the risk of death and cancer, the public's concern about nuclear power remains strong. Why? The two millesimal safety thresholds set more than 30 years ago do not meet current safety requirements. Fukushima exposed their shortcomings. Part of the public's concern after Fukushima is about the impact of radiation on marine life. The same goes for China's inland nuclear power plants, where the public is concerned about the impact on the Yangtze River's ecology. Environmental safety is not included in the two NRC safety thresholds.

The absence of environmental safety standards causes many problems. It is difficult to measure and compare the environmental impact of different industrial sectors effectively. The public's faith in nuclear power is therefore ambivalent. The lack of quantitative environmental safety thresholds means there is insufficient scientific evidence to justify improvements to safety standards. But more and more safety 
features are added, increasing the construction and operating costs of nuclear power plants. But the real effect of these features is hard to evaluate. These problems accumulate and increase the complexity of decision-making regarding nuclear power.

\subsubsection{Global Experience of Nuclear Energy}

\section{(1) Long-term, clearly defined strategies are essential for the development of nuclear power}

France defines nuclear power as an important strategic choice for energy development. After the first oil crisis in 1973, the French government introduced a policy to generate all its electricity with nuclear energy. The government established standards and a development programme, then gradually replaced fossil fuel-fired power plants with nuclear power stations. Nuclear power currently supplies three-quarters of the country's electricity. France has maintained continuity in nuclear power since the 1970s, winning first-mover advantages and blazing an independent trail to success.

In Japan, the strategic positioning of nuclear power is clear. The Long-term Plan for the Development and Use of Atomic Energy, issued in 1956 and revised every five years, provides a guideline for Japan's nuclear power industry. In 1978, nuclear power was defined by Japan as its base energy for the 21st century, helping the public and business community clearly understand national policies and facilitating the creation of a nuclear power industry, including $\mathrm{R} \& \mathrm{D}$ and nuclear fuel systems. In the 20 years following the Chernobyl disaster, Japan developed from an importer of nuclear power technologies to an exporter. Nuclear power generates a third of Japan's electricity.

South Korea's nuclear power strategy and programme enabled it to develop nuclear power independently. To realise its long-term nuclear energy objectives, South Korea established its Comprehensive Nuclear Energy Promotion Plan (CNEPP) in 1997, which it updates every five years. CNEPP includes long-term nuclear policies and objectives, targets, budget and investment plans. Clear planning and a firm strategy have enabled South Korea to use its limited human and financial resources in the best possible way. As a result, it has an independent nuclear power industry, innovative national brands and a sharp competitive edge in the nuclear world.

\section{(2) Government policies support nuclear energy development}

The USA has introduced preferential policies to encourage nuclear power investment and construction since the1950s. In the initial phase of nuclear power (1955-62), the United States Atomic Energy Commission (AEC) clearly defined government and business responsibilities. It introduced four rounds of preferential policies to attract investment in nuclear power. The AEC became the US Nuclear Regulatory Commission (NRC) in 1975. The new organisation significantly enhanced nuclear power development efficiency by reforming the licence issuing system and simplifying the approval process. In 2005, to encourage business to invest in and construct nuclear power plants, Congress passed the Energy Policy Act, which provided tax incentives, loan guarantees and other investment support policies.

Japan granted different tax benefits for each stage of a nuclear power plant project to reduce the cost of development and deployment. Technologically, the government cooperated with power utilities to construct the first generating unit of each series, developed new technologies to test pilot plants and then transferred proven technologies to businesses for use. In terms of finance and taxation, investment funds were raised through fiscal means. For example, the Power Development Promotion Tax Law stipulates that tax benefits should be granted to nuclear power and other emerging energy industries every year through special accounts.

India reduced business risk by granting government subsidies and financial support. The financial budget allocated by India's Department 
of Atomic Energy to support the development of nuclear energy in 2004-05 reached \$963 million, of which $\$ 540$ million was awarded to atomic energy projects and $\$ 424$ million to nuclear power projects.

\section{(3) Sustained, stable and large-scale}

To create a nuclear power industry, major nuclear power countries adjusted their industrial systems, gradually forming an industry suitable for their national conditions. Adjustment is characterised by government steering, relatively centralised control of the nuclear power industry, marketisation, and capacity building of the main suppliers, plant owners and advanced engineering firms.

In the USA, a market-oriented industry, dominated by large businesses and involving many project owners, was shaped in the industry's early years. In the middle of the last century, Westinghouse and GE were the first to master civil nuclear power technologies and become suppliers of nuclear power equipment, after taking part in the development of military nuclear power technologies. In the initial stages of nuclear power development, key suppliers provided turnkey services or advanced engineering to the project owners. During later stages, the market players became stronger and more diversified. When nuclear power grew in the 1970s, powerful and professional project management companies entered the field to provide project services to plant owners. They soon became major players in nuclear power plant construction. Some nuclear power plant owners chose to construct and manage projects themselves, combining project ownership with advanced engineering. Such a hybrid system is possible because of the USA's size, maturity and large number of small and medium-sized power utilities.

France formed a system with a single project owner, and with advanced engineering separated from the main suppliers. Having introduced technologies and management methods from the USA, France reformed its original nuclear industry to the system it has today: the Atomic
Energy Commission oversees research and development of military nuclear technologies and infrastructure, while nuclear fuel recycling is operated by professional companies. The Atomic Energy Commission and Électricité de France (EDF) formed Framatome, which later became the nuclear power business of Areva, before changing its name back to Framatome in 2018. Framatome, which is $75 \%$ owned by EDF, designs, manufactures and installs components, fuel, and instrumentation and control systems for nuclear power plants. EDF manages all nuclear power plants in France.

Japan's solid industrial base accelerated the formation of an approach using multiple project owners, suppliers and advanced engineering companies. After starting with technologies from Westinghouse and GE, Japan switched to its own local suppliers - Mitsubishi, Toshiba and Hitachi - to provide turnkey nuclear power plants to project owners. Japan's power transmission system is divided into 10 zones, each operated by an electric utility. After accumulating experience in how to build and operate nuclear power plants, the 10 utilities started to develop and invest in nuclear power plants independently, with the support of the main suppliers.

In South Korea, the government gradually deregulated the nuclear power industry. As the only nuclear power project owner, Korea Electric Power Corporation plays multiple roles as an investor, constructor, owner and operator. It held $41 \%$ of the shares of Korea Heavy Industries, through the assistance of the government, which enabled it to develop into a key nuclear island equipment supplier. Once this was achieved, Korea Electric Power Corporation divested its holding in Korea Heavy Industries, enabling the company to operate independently. Korea Heavy Industries was acquired by Doosan in 2001.

\section{(4) Re-innovating older technologies is a path- way to success for late-mover countries}

Some late-mover nuclear power countriesJapan and South Korea in particular-gained much valuable experience as they progressed 
through the nuclear power process, from technology introduction to independent operation.

First, a strong organisation and huge investment by government strengthen the independence of national nuclear power technologies. Proven nuclear technologies were researched under the auspices of the government, or jointly with businesses funded by the government, until they reached the pilot stage or commercialisation. To develop a nuclear power capability independently, Japan and South Korea invested in R\&D and developed new technologies. The ratio of investment to independent $R \& D$ and technology development is 1:4 in South Korea and 1:8 in Japan.

Second, human and material resources are allocated in a centralised manner by government to achieve nuclear power independence. This process of resource allocation includes adapting the country's industrial system; creating a network of main suppliers; developing a professional advanced engineering capability; and establishing an entire integrated supply chain, from design to equipment supply, construction and operation.

(5) The public has the right to know and participate in decision-making on major issues of nuclear power

Nuclear power developers in the West regard the public's right to know and participate in decision-making as crucial to the smooth development of nuclear energy. Nuclear power countries have established a public intervention mechanism for nuclear power development and safety management.

Two rounds of public consultations are carried out before a nuclear power plant is approved in the USA. The Atomic Energy Act stipulates that a public hearing must be held, which covers a range of issues, including licence approval, suspension and abolition; construction permits; and licence-related regulations.

In France, nuclear power plants have to go through a national debate procedure that is open to the public at various levels, from special community sessions to local government.
France's nuclear power safety authorities emphasise that nuclear power decisions must be public and transparent. Government authorities allow residents living near nuclear power plants to track the status of the plants and provide information and even risk evaluation.

Japan adopted the right to public veto in 1996. Construction of a nuclear power plant must be approved by the public first. In Japan, nuclear power safety authorities disclose nuclear facility accidents and radioactivity control data to the public on dedicated websites.

\section{(6) Laws and regulations ensure the safe and orderly development of nuclear energy}

The legal system is the basis for policymaking. Major nuclear power countries passed their version of an atomic energy act early. These acts typically included regulations for each subsector of nuclear power development. This resulted in a sophisticated legal system that ensures the peaceful use of nuclear power and a strong foundation for policymaking.

The USA passed the Atomic Energy Act in 1946 and amended it in 1954. The act covers civil and military nuclear activity, the use and management of nuclear materials, the research and development of nuclear facilities, the organisational and management system, international activities, and the rights and responsibilities of stakeholders.

Japan developed the Atomic Energy Basic Law in 1955, which regulates management organisations and R\&D institutions, the development and procurement of nuclear materials, nuclear fuel and reactor management, patents, radiation prevention, compensation, and so on.

India's Atomic Energy Act was passed in 1948 and amended in 1962. The act stipulates that all nuclear power and nuclear fuel recycling activities are controlled by the central government.

South Korea, France and other nuclear power countries have also established comprehensive legal systems to govern their atomic energy industry. 
(7) Strong, independent supervision and administration ensure the safety of nuclear power facilities

Developed nuclear power countries value nuclear radiation safety supervision. They set up relatively independent nuclear safety regulators and provide human, material and financial resources for them. This ensures that the safety supervision laws are implemented effectively, and that the quality and safety of nuclear facilities during construction and operation are guaranteed.

The US National Regulatory Commission (NRC) is an independent nuclear safety supervision and management agency tasked with protecting public health and safety related to civil nuclear facilities and materials. It has two independent advisory committees and one nuclear safety and licence deliberation panel. The panel is responsible for providing advice and holding hearings on major nuclear safety supervision issues. The government ensures the NRC can perform its tasks effectively in terms of funds and people.

The Direction générale de la sûreté nucléaire et de la radioprotection (DGSNR), the main nuclear safety regulator in France, ensures nuclear safety and radiation protection in France on behalf of the government. DGSNR develops and implements safety policies and measures for civil nuclear facilities and discloses nuclear safety information to the public. The Institut de radioprotection et de sûreté nucléaire (IRSN) is the main technical backup force under DGSNR; it researches, examines and appraises nuclear facilities and activities. In addition, France has cross-ministry agencies and an atomic energy commission to coordinate its nuclear power sector on issues such as policy, military and civil nuclear power, and to prevent nuclear energy regulators from making one-sided decisions that prejudice the development of France's nuclear power industry.

Japan's nuclear safety regulators include the Cabinet Office; the Ministry of Education, Culture, Sports, Science and Technology; and the Ministry of Economy, Trade and Industry, each of which undertakes different nuclear safety supervision duties. The Atomic Energy Committee and Nuclear Safety Commission under the Cabinet Office review nuclear research, development and use policies, assess the safety review of the administrative departments and hold public hearings. The Ministry of Education, Culture, Sports, Science and Technology supervises safety at nuclear power facilities except for the plants themselves. The Nuclear and Industrial Safety Agency (NISA), set up by the Ministry of Economy, Trade and Industry, supervised nuclear and industrial safety. It was replaced by the Nuclear Regulation Authority in 2012, following the Fukushima nuclear disaster.

\subsubsection{The Development of China's Nuclear Power Safety Strategies}

\section{(1) Scientific scope of safe nuclear power development}

Human beings have been exposed to safety issues since ancient times. Safety threats can be divided into two categories. The first is survival threats in nature like wild animals, natural disasters and hunger. The second is safety threats from human factors, such as wars, the struggle for land and global warming.

Safety is a measurement of risk affordability. It is a relative concept, rather than an absolute one. Safety is also dynamic not static, which means the objective is to strike a balance between interests and cost. Safety is measured against several criteria. When evaluating a safety risk, its probability and consequences should be taken into consideration. The scientific community usually measures safety with risk: risk = the frequency of an event multiplied by its consequences.

In nature, safety means that risks are controlled at an acceptable level. Complete elimination of safety risks is not possible. Most of the factors affecting nuclear safety are technical ones. First, thanks to the massive investment in research and development over the past 50 years, most safety problems in nuclear power plants are 
technically solvable and a plant's technical safety level can be assessed. Second, effective technical protection measures are taken against radiation hazards during the whole nuclear energy project cycle - site selection, design, manufacture, construction, commissioning, operation and decommissioning. The same applies to the fuel cycleexploration, mining, milling, conversion, enrichment, fabrication, power generation and waste disposal.

\section{(2) Nuclear power safety strategies in the new era}

The objectives of China's nuclear energy programme are national safety, energy security and environmental protection. To achieve these goals China should develop an advanced and world-class nuclear power industry that operates at the highest levels of safety, technological innovation, closed nuclear fuel cycle systems, and environmental protection.

The first priority is energy development. China will fight two battles during the energy transition for a long time to come. The first battle is to meet energy demand while completing the processes of industrialisation and urbanisation. The second battle is to cope with the increasing pressure to safeguard the environment. This means that China desperately needs clean energy. Nuclear power is indispensable to China's development.

The second priority is environmental protection. The policy of safety first is the key to public and environmental safety. Nuclear accidents are sudden, extremely impactful and hard to recover from. Safety requirements are far stricter in nuclear power than in other types of energy. A nuclear accident would jeopardise not only the momentum of the nuclear power industry in China, but also social and political stability. China has promised the international community that it will uphold its national responsibility for nuclear safety.

Third, an industry-wide nuclear power safety system needs to be established. Safety risks could be present during the whole process of nuclear energy development, generation and use, involving all participants in the value chain. Independent safety supervision is an important measure to ensure safety. But ultimately, safety comes from great site selection, design, manufacture, construction, commissioning, operation and decommissioning. The same factors ensure a high level of plant availability and power supply and a sharper competitive edge for China's nuclear power industry.

The objectives of independence should be realised by relying on industry projects to enhance China's nuclear power technologies and equipment manufacture. Nuclear power regulations need to be developed and improved, and the nuclear power safety management mechanism put in place and optimised. The nuclear power safety supervision system needs to be improved for plants under construction and in service. A national nuclear accident response mechanism should be established to enhance China's emergency response capabilities. A national nuclear energy technology innovation programme consisting of key technologies, equipment, demonstration projects and technical innovation platforms needs to be established. Advanced pressurised water reactors in the million-kilowatt category should be mainstream, and efforts should be made to develop new technologies like high temperature gas-cooled reactors, fast reactors and small modular reactors. Nuclear fuel supply and spent fuel treatment systems should be improved to secure nuclear power's long-term development.

Fourth, environmental safety standards for nuclear power need to be explored. Exploring environmental safety standards in nuclear power is an historical mission for China to be among the world's best. China is expected to reach this top level in third-generation technology. The countries at the peak of nuclear power technology are being replaced-Russia and South Korea's nuclear power technologies are still highly rated in the global market, and China has started to enter the UK's nuclear power market.

Environmental safety standards are an important step from industrial to ecological civilisation. The development of environmental safety standards will be an important phase in the 
transition and reform of industrial civilisation. The emergence of any civilisation is the outcome of a successful response to tough environments. The Fukushima nuclear accident highlighted the shortcomings of global industrial civilisation. In this sense, the nuclear power industry has been pushed to the front of the transition of industrial civilisation.

\subsubsection{Pathways and Measures to Develop Nuclear Power Safely}

(1) Develop safe, authoritative, stable and efficient nuclear energy development strategies

Guided by the principles of "strategic necessity, environmental safety, guiding standards, coordination and stability", the strategy and policy of "efficiently developing nuclear energy while ensuring safety" should be enriched and improved. A mandatory, authoritative and strategic development plan should be drawn up, guided by the Scientific Outlook on Development (one of the guiding socioeconomic principles of the Communist Party of China), which emphasises the comprehensive, harmonious and sustainable development of China for the Chinese people. After adequate and scientific demonstration, the plan should cover strategic positioning, development guidelines and objectives, the technical route to achieve those objectives, R\&D, the nuclear fuel cycle, resource guarantees, independent equipment manufacture, training people in nuclear power, and make the plan into an integral part of national energy programmes.

First, the Scientific Outlook on Development should be followed to promote the development of nuclear energy, improve nuclear energy's position in China's energy development strategies, and include nuclear energy in the national energy development programmes.

Second, China should strengthen research and development of nuclear energy strategies and plans, put in place the relevant organisations and funds, draw up nuclear energy development strategies and plans, define the targeted installed capacity of nuclear power and priority projects, optimise project schedules, and prepare an authoritative medium- and long-term national nuclear energy development plan.

Third, the actions and procedures to implement strategic plans should be consistent, and the duties and rights of government agencies, businesses and scientific research institutions should be defined, thus truly implementing the strategic plans and generating good results.

Fourth, when developing strategy studies, policy discussions and plans around "independent design, independent $\mathrm{R} \& \mathrm{D}$, independent manufacturing and independent operation", some important strategic decisions, technology pathways and policies should be included in national policy papers and implemented in the projects.

(2) Establish a nuclear energy law and regulatory system based on the Atomic Energy Law

Atomic energy legislation is urgently needed to provide a reference point for important decisions on nuclear activities. More than 20 years have passed since China proposed the Atomic Energy Law. Today, the principles of the Atomic Energy Law are still being discussed. Requisite laws for the development of nuclear energy are absent. Due to the severe delay in passing legislation, conflicts and problems that arise in nuclear energy development are regulated with temporary policies. This is not in line with China's nuclear power development requirements.

First, the Atomic Energy Law should be drafted as soon as possible to provide legal protection for the development of nuclear energy. The legislation should be effective, practical and focused, and it should define in a comprehensive manner the timelines and protocol for disclosing information on nuclear accidents.

Second, legislation for specific aspects of nuclear energy should be drawn up in an orderly manner and by priority. The regulations for nuclear damage compensation, spent fuel management and radioactive waste management should be introduced as soon as possible. 
A relatively complete Atomic Energy Law should be introduced by 2020 .

Third, safe and smooth operation of nuclear power plants should be ensured by finalising nuclear power safety regulations and procedures, tightening safety law enforcement and supervision, adopting strict labour discipline and standard operating procedures, and strengthening the nuclear accident emergency system.

(3) Establish a separate, independent, authoritative and specialised nuclear power safety supervision system

In light of the nuclear supervision reform trends in other countries and the actual problems in China, four nuclear power safety supervision reform principles - "separate, independent, authoritative and specialised"- should be followed to strengthen nuclear safety supervision and enable China to develop nuclear power at large scale in the future.

First, the correct separation of functions. In China, management and safety supervision of nuclear power are already separated. The major task at present is to clearly define departmental functions.

Second, focus on specialised legislation and functions. Legislation on nuclear energy should contain provisions on not only promoting nuclear energy development, but also ensuring nuclear power safety. Absence of either will have negative impacts on the healthy development of the nuclear power industry. In addition to basic safety supervision for nuclear facilities and materials, it is vital that liabilities and the emergency response of third parties are included in the nuclear power safety assurance system.

(4) Explore and develop environmental safety standards for nuclear power within the framework of the three millesimal safety targets

Environmental safety standards for nuclear power should be developed within the framework of the three-millesimal safety targets in a three-step approach.
Step 1: China should focus on the key concerns of the people by assessing the risk to public health and the potential impacts of radiation and thermal pollution on the environment. It should select typical evaluation objects, launch pilot and demonstration projects, and compare the impacts of other industrial activities. A pilot risk evaluation project on environmental safety should be launched using existing data and facts. And an environmental safety standard development mechanism - based on data and evidence that can be communicated, questioned and optimised - should be established.

Step 2: The scope of environmental safety targets should be enriched with the experience gained from the pilot and demonstration projects to expand risk evaluation and evaluation objects. Evaluation capacity building should be strengthened by standardising safety evaluation guidelines. A mechanism to upgrade nuclear power environmental standards should be established through information disclosure and public engagement.

Step 3: As data and facts are accumulated and the environmental risk evaluation system improved, environment insurance and reinsurance systems need to be introduced. These in turn will substantially improve China's environmental risk evaluation, prevention and mitigation ability, allowing it to be an integral part of the state's governance capability. Nuclear power environmental safety standards should be improved by comprehensively comparing risks and through a mature risk evaluation system. A development mechanism featuring interaction between, and checks and balances for, environmental safety standards, nuclear power technologies and environmental safety insurance should be formed.

\section{(5) Invest more in scientific research to enhance nuclear technologies}

Investment in nuclear science capacity building should be centralised and improved. In particular, investment in major nuclear science projects and research and testing facilities should be 
secured to ensure stable financial support for basic nuclear research.

First, investment in key disciplines should be extended to gain approval for national projects of large advanced pressurised water reactors. More investment should be made in $R \& D$ of third-generation nuclear technologies, especially on technology demonstration projects of large advanced pressurised water reactors. Production facilities for these Chinese reactors should be in place by 2020, laying a solid foundation for the future large-scale development of nuclear power.

Second, the research and development of prototype fast reactor nuclear power plants and their fuel cycle technologies should be strengthened. More money should be invested in basic R\&D to support independent innovation in nuclear energy.

Third, a high-quality, competitive and open nuclear power education system should be established by taking full advantage of China's nuclear energy education resources at universities and research institutions. A programme should be initiated to improve the development of professional technicians, operations and management personnel and skilled workers.

Fourth, talent development channels should be expanded. High-level talent should be given a leading role through talent development programmes and by promoting international cooperation and exchange. Scientific and technological innovation team building should be strengthened. Motivation should be enhanced by increasing remuneration and incentives for nuclear researchers, thus improving innovation and creativity.

\section{(6) Establish a scientific decision-making and interaction mechanism to convince the public of nuclear energy's strategic importance}

The public's right to know and participate in the decision-making process on nuclear power development should be protected. Information on risk and benefits evaluation should be provided, and public participation in the debate about nuclear power should be allowed. The national strategic requirement for the harmonious development of energy, society and the environment should be met through interactive decision-making with the public. Public opinion should be eased scientifically through the main issues, using various channels and approached from different perspectives to eliminate the fear of nuclear power. Third parties, including independent associations, should be encouraged to help supervise the process. Energy education facilities should be built to popularise nuclear knowledge free of charge to increase the public's faith in safety.

First, industrial management and decisionmaking authorities should cherish and value the public's trust in nuclear power and protect their right to know and take part in the making of nuclear power development decisions. Public participation in the discussion about nuclear power plans should be allowed, and the national strategic requirement for the harmonious development of energy, society and the environment should be met through interaction with stakeholders.

Second, safety regulators, including the National Nuclear Safety Administration and the Ministry of Ecology and Environment, should strengthen their supervisory role and establish transparent report channels to eliminate public concern. Nuclear power monitoring facilities should be set up to make the disclosure of radiation information more transparent and alleviate the public's concern about nuclear power. The risk and benefits evaluation results should be made public to help people better understand the risks and benefits of nuclear power.

Third, nuclear knowledge should be popularised among sensitive groups to eradicate irrational perceptions. In particular, basic information on radiation and nuclear accidents like Chernobyl should be provided scientifically and objectively to reduce rumour-spreading.

Fourth, the government should do its best to involve local communities and leverage their public influence through diverse media channels, thus boosting trust and winning the public's support.

Fifth, residents living close to nuclear power plants should be rewarded. Local government 
should, together with environmental authorities and nuclear power companies, bear people's interests in mind and create long-term health records to eliminate unnecessary fears. In addition, thermal pollution and electricity tariffs should be researched, and benefits and compensation awarded.

\subsection{Unconventional Gas}

\subsubsection{Current Developments and Trends in Global Unconventional Gas}

\section{(1) Definition and classification of unconven- tional gas}

Unconventional gas refers to gas resources that previously could not be explored and exploited economically by conventional methods and techniques. It is characterised by its abundance, poor physical properties of reservoir (porosity: less than 10\%; permeability: lower than $1 \times 10^{-3} \mu \mathrm{m}^{2}$ ).

Unconventional gas usually includes tight gas (short for tight sandstone gas), shale gas, coalbed methane and natural gas hydrate. Tight gas means that the natural gas deposits in sandstone (carbonatite, volcanic) strata are tighter than in conventional reservoirs. In China, tight gas is called low, very low or ultra-low permeability gas. Coalbed methane refers to the gas absorbed on the surface of coal and in micro-fissures in the coal bed. Shale gas means that natural gas exists in a free state in minute pores or fissures inside the shale and adsorbed on the surface of minerals and organics. Natural gas hydrate is a solid crystalline compound composed of water and natural gas formed at low temperature and high pressure, also called combustible ice.

\section{(2) Current developments in unconventional gas in major countries}

First, tight gas. Tight gas resources are abundant (about $210 \times 1,012 \mathrm{~m}^{3}$ ) across the globe and distributed widely in Asia-Pacific, North
America, Latin America, the former Soviet Union, the Middle East and North Africa. Survey results from the U.S. Geological Survey show that around 70 basins with tight gas have been discovered in the world.

A dozen or so countries and regions, including the USA, Canada, Australia, Mexico, Venezuela, Argentina, Indonesia, China, Russia and Egypt are exploring and exploiting tight gas deposits. The USA and Canada are leaders in this regard. Tight gas exploration and exploitation in the USA started in the late 1970s when national gas output decreased substantially, aggravating the imbalance between supply and demand. So, the US government introduced a series of tax incentives and subsidy policies to encourage the development of unconventional gas and low-permeability gas deposits, leading to significant breakthroughs. As a result of the support policies, tight gas became a major part of US gas production, hitting 60 billion cubic meters (bcm) and $100 \mathrm{bcm}$ in 1990 and 1998 respectively and amounting to $175.4 \mathrm{bcm}$ in 2010 (accounting for about $29 \%$ of total US gas output). Currently, in the USA, tight gas is being developed in the Greater Green River, Denver, San Juan, Piceance, Powder River, Uintah, Appalachian and Anadarko basins in the Rocky Mountains region. Canada's tight gas is mainly distributed in Alberta in west Canada. Canada drilled its first industrial tight gas well in 1976. The Hoadley and the Milk River gas fields discovered later are promising prospects for tight gas. Some $6,400 \mathrm{~km}^{2}$ of land have tight gas deposits in Canada, with a geological reserve of $42.5 \times 10^{12} \mathrm{~m}^{3}$.

Breakthroughs in key technologies are an important driver behind the rapid development of tight gas in North America. The comprehensive application of horizontal well drilling, underbalanced drilling, well completion and gas reservoir protection technologies in the 1990s boosted gas yield sharply, resulting in rapid increases in tight gas production in North America.

Second, shale gas. Shale gas resources have not been evaluated worldwide yet. Most of the volume data is estimated from existing geological information. Incomplete estimates by Rogner 
Fig. 44 Gas output in the USA by product, 2007-15. Source U.S. Energy Information Administration

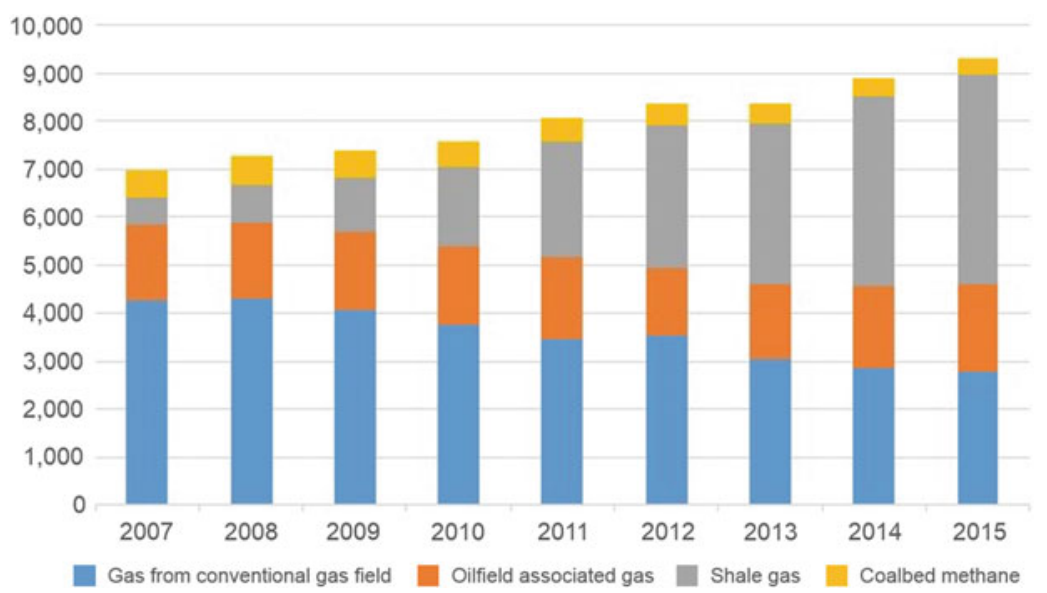

in $1997^{69}$ show there are around 922 trillion cubic metres of unconventional gas in the world, nearly half of which is shale gas (456 trillion cubic metres, mainly in North America, Asia, Latin America, the Mediterranean and Australia). Recent data released by the U.S. Energy Information Administration (EIA) show that geological reserves of shale gas in 137 sets of shale formation in 95 shale gas basins in 42 countries (including the USA) in 10 geographical regions of the world are around 1,013 trillion cubic metres. 220.69 trillion cubic metres of shale gas are technically recoverable, up 33.67 trillion cubic metres from the reserves announced in 2011.

Pre-project evaluation and fundamental research of shale gas resources have been carried out in more than 30 countries. Large-scale commercial exploitation has been achieved in the USA and Canada. China has entered the stage of massive development. Other countries are still at the initial stage of shale gas development. As the earliest pioneer in terms of shale gas exploration and exploitation in the world, the USA possesses the most mature technologies. The country produced $438.2 \mathrm{bcm}$ of shale gas in 2015 , accounting for $47 \%$ of its total gas production. Shale gas became the largest contributor in its gas mix (Fig. 44).

\footnotetext{
${ }^{69}$ H-H. Rogner, An assessment of world hydrocarbon resources, in Annual Review of Energy Environment, 1997, 22, pp. 217-262.
}

Technologies and policies empowered the rapid development of shale gas in the USA. The success of the US shale gas revolution has driven research and attempts at emulation across the world. It is widely believed that technology, policy, market, regulation and infrastructure are the five drivers behind shale gas evolution in the USA.

Technological progress is the principal driver. Thanks to continuous technological innovation, the cost of exploiting US shale gas has been reduced to only half of that of conventional gas. The cost of drilling and constructing a shale gas well at Eagle Ford in Texas, with a horizontal segment of around $1,500 \mathrm{~m}$, was $\$ 0.86$ per cubic foot, which was drilled and completed within 20 days.

Second, preferential policies provided great support for shale gas development. The US government invested significantly or set up specialised research funds to subsidise preliminary R\&D and exploration studies on shale gas. It was estimated in 2012 that the US government had invested more than $\$ 6$ billion in unconventional gas exploration and production since the early 1980s, almost \$2 billion of which was used for training and research. In addition, the US government transferred the preferential tax policies granted to the upstream development of conventional oil and gas to shale gas development. The government also introduced five tax incentives for the oil and gas industry: intangible 
drilling costs tax deduction, tangible drilling costs tax deduction, rental deduction, allowing a working interest to be classified as active income, and extending the depletion allowance to small producers. These incentives strongly encouraged drilling and development investment by mediumand small-sized enterprises, and accelerated shale gas exploration and production.

Third, the open market environment is a powerful impulse. The shale gas exploration and development market in the USA is mature and features diversified participants and sound competition. There are thousands of shale gas companies at present, with more than 2,000 drilling rigs. $85 \%$ of shale gas is produced by small and medium-sized companies, which take the lead in making technological and industrial breakthroughs. Large companies enter and participate in the market by acquiring and merging small and medium-sized ones. This creates a market environment characterised by a mix of large. medium and small companies, an optimal combination of specialisation and collaboration, and the efficient flow of capital throughout the value chain.

Fourth, reasonable regulation acts as an important guarantee for the shale gas industry. The US government values regulation in shale gas exploration and production and reasonably delegates regulatory power to state governments. The power to regulate interstate energy business activities is shared by federal and state governments. In case of conflict between federal and state regulations, the former prevails. Should federal standards be lower than state standards, both standards apply. The federal government intervenes finitely in shale gas through supervision of environmental regulations and interstate pipeline access. Specific regulatory power covering the time and place to exploit, as well as gas well standards, is delegated to states.

Fifth, complete infrastructure and third-party access supports the development of shale gas. Gas pipeline networks and urban utility gas facilities in the USA are well developed, greatly reducing the need for early development investment and market risk. Statistics from the U.S. Energy Information Administration show that the lower 48 states now have $490,000 \mathrm{~km}$ of pipelines, of which 349,000 are interstate and 141,000 intrastate. The complete separation of gas exploitation from transport, the regulation of pipeline transmission prices and the deregulation of gas prices powerfully support the commercialisation of shale gas.

Third, coalbed methane (CBM). According to the data from the International Energy Agency, global coalbed methane resources are abundantly and widely distributed in Russia, Canada, China, the USA, Australia and other countries (Table 15).

The USA, Canada and Australia are leaders in CBM development. The USA produced and used coalbed methane on a large scale in the 1990s. In 2007-09, the USA produced more than 56 billion cubic metres (bcm) of CBM, a record equivalent to $7 \%$ of US gas output. CBM output decreased year by year thereafter to $33.5 \mathrm{bcm}$ in 2015 (accounting for $3.6 \%$ of gas output). Canada and Australia made breakthroughs in CBM development and commercialisation, but on a far smaller scale than the USA. Canada's CBM output increased rapidly after 2004 to 7.5 bcm in 2010 (accounting for $6 \%$ of Canada's gas production). Australia's CBM yield in 2005 was only $1.8 \mathrm{bcm}$, which increased sharply by $40 \%$ to $7.4 \mathrm{bcm}$ in 2010 (equal to more than $13 \%$ of Australia's gas production).

Breakthroughs in key technologies and cost effectiveness are the two most important factors for CBM industrialisation. The US government conducted groundbreaking research in the 1970s by investing around $\$ 400$ million in the San Juan and Black Warrior basins. This generated the theory of desorption-diffusion-seepage and the process of drainage-depressurisation-gas

Table $15 \mathrm{CBM}$ reserves in major countries (trillion cubic metres)

\begin{tabular}{|l|l|l|}
\hline Russia & Canada & China \\
\hline $17-113$ & $18-76$ & 37 \\
\hline USA & Australia & Germany \\
\hline 22 & $8-14$ & 3 \\
\hline
\end{tabular}

Source IEA 
recovery, which established a basic theoretical system for exploiting and processing CBM. In the following decade, the US government invested more in research and completed an assessment of the nation's CBM resources. It also spent $\$ 6$ billion on drilling experiments and on proving the technical feasibility of CBM recovery, both of which are the pre-conditions for CBM industrialisation.

Canada's experience also proves that breakthroughs in exploration and production technologies are a prerequisite for the development of a CBM industry. Canada increased output per well substantially and then achieved mass production after making significant advances in multi-branch horizontal wells, coiled tubing fracturing and nitrogen foam fracturing. These successes were the result of a technology $R \& D$ programme tailored to Canada's own CBM conditions.

Around 30 years of subsidies lay behind the growth of a healthy CBM industry. The US government supported coalbed methane development projects with tax subsidy policies and a special-purpose fund started in accordance with the Crude Oil Windfall Profit Tax Act of 1980 for financing the development of unconventional energy with windfall profit taxes on conventional energy. The tax subsidy policies were implemented in two stages. During stage 1 (from 1980 to 2002), CBM was subsidised for much of the period. Stage 2 began with the new Energy Policy Act of 2003, which set the subsidy threshold at single well production capacity of no more than $56,700 \mathrm{~m}^{3}$ per day. At their highest, the subsidies accounted for half the market price of CBM. During the 30 years, the US government spent billions of dollars subsidising CBM.

Fourth, natural gas hydrate. The carbon content in gas hydrate is estimated to be more than double that in other known fossil fuels, making it a next-generation strategic energy source. Many countries and regions have surveyed hydrate deposits, discovering deposits at more than 130 sites. The first country to recover natural gas hydrates is the former Soviet Union, which pilot-produced gas hydrates in the 1970s at Messoyakha, Siberia, with depressurisation and inhibitor injection methods. After that, Canada, the USA and Japan launched pilot gas hydrate drilling and production projects and made significant progress. The pilot gas hydrate production project at Mallik, Canada in 2008 proved the feasibility of the depressurisation method.

\subsubsection{Current Developments and Challenges in China's Unconventional Gas}

\section{(1) Current developments}

First, tight gas. China has huge tight gas potential. Preliminary estimates using the analogy method show that China has 10 trillion cubic metres of recoverable tight gas. The cumulative proven reserve rate is only $18 \%$ at present. The huge potential could be tapped by speeding up exploration and production. The biggest deposits of tight gas in China are in the Ordos and Sichuan basins, followed by the Tarim, Junggar and Songliao basins, which together hold $90 \%$ of China's total tight gas resources.

The key technologies for recovering tight gas are basically mature. China has made great progress in recent years by learning from other countries about the main technologies of tight gas exploitation, including vertical, cluster and horizontal well-staged fracturing. Fracturing reformation increases output per well to $10,000-20,000 \mathrm{~m}^{3}$ per day. At the central Sulige gas field in Inner Mongolia, for example, average daily single-well output has been a steady and cost-effective $10,000 \mathrm{~m}^{3}$ for four years.

Reserves and output are increasing rapidly. In recent years, geological reserves and output of tight gas have increased by $300 \mathrm{bcm}$ and $5 \mathrm{bcm}$ respectively year-on-year. Cumulative proven geological reserves of tight gas were 3.3 trillion cubic metres at the end of 2011, accounting for $40 \%$ of China's total geological gas reserves. 1.8 trillion cubic metres of tight gas were recoverable, accounting for about a third of recoverable gas reserves in China. Tight gas output in 2011 amounted to $25.6 \mathrm{bcm}$, accounting for about a quarter of the country's total gas production.

Second, shale gas. China has huge shale gas resource potential. Although China's shale gas 
Fig. 45 Comparison of prediction data of China's recoverable shale gas reserves

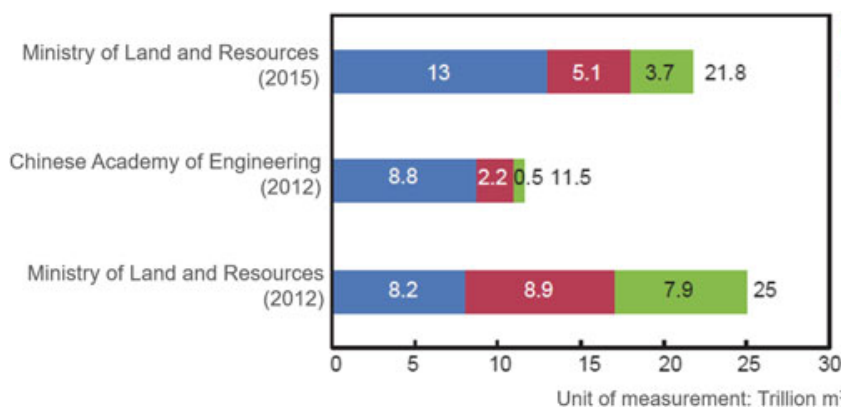

Marine facies

- Transitional facies - Continental facies reserves have not been ascertained yet, preliminary estimates by Chinese and foreign researchers show that shale gas resources in China are abundant, diversified, widely distributed and highly promising. The resource base needed for fast exploration and production is already in place. According to the report titled Results of the Survey and Assessment of Shale Gas Resource Potential of China and Favourable Zone Optimisation published by the Ministry of Land and Resources of the People's Republic of China in March 2012, China's geological reserves of onshore shale gas are 134.42 trillion cubic metres, of which 25.08 trillion cubic metres (excluding Qinghai-Tibet) are recoverable. In 2015, the resource assessment results from the Ministry of Land and Resources of the PRC showed that China had 21.8 trillion cubic metres of technically recoverable shale gas, including 13 trillion cubic metres in marine facies, 5.1 trillion cubic metres in transitional facies and 3.7 trillion cubic metres in continental facies (Fig. 45).

Breakthroughs have been made in exploration and exploitation. China had granted 44 exploration permits covering $144,000 \mathrm{~km}^{2}$ by 2015 , proving geological reserves of $544.1 \mathrm{bcm}$. Many shale gas wells in and on the periphery of the Sichuan Basin generate industrial gas flow during exploration of the marine facies shale stratum of the Silurian Longmaxi Formation, proving great resource and development potential. Exploration of the continental facies shale stratum of the Triassic system in the Ordos Basin has also generated gas.

Four national shale gas demonstration blocks have been set up in China, i.e. Sinopec's Fuling demonstration block in Chongqing, CNPC's Changning-Weiyuan demonstration block in Sichuan, CNPC's North Yunnan and Guizhou-Zhaotong demonstration block, and Yanchang Petroleum's Yan'an demonstration block in Shaanxi. China's annual shale gas production in 2016 reached $7.88 \mathrm{bcm}$, third after the USA and Canada. Commercialised and large-scale development has been achieved at the Jiaoshiba (Fuling), Changning-Weiyuan and Zhaotong blocks. Up to the end of 2016, China had invested RMB 8.8 billion in exploration and production of shale gas, leading to 50 drilled exploratory wells and 92 development wells.

Support policies and mechanisms have been strengthened. The Ministry of Finance and the National Energy Administration unveiled subsidy policies for the development and use of shale gas in 2012. From 2012 to 2015, shale gas exploitation companies received subsidies from the central budget at a rate of RMB 0.4 per cubic metre. In 2015, the two authorities announced that the subsidy would continue to apply to shale gas development and use during the 13th Five-Year Plan (2016-20), albeit at the lower rate of RMB 0.3 per cubic metre for the first three years and RMB 0.2 per cubic metre for the last two years.

The Shale Gas Industry Policies of the National Energy Administration, published in 2013, provides rules and guidance on industrial regulation, demonstration block construction, technical policies, markets and transport, economical use and environmental protection for the healthy development of the shale gas industry. The shale gas joint development mechanism for joint ventures was explored and developed 
during the 12th Five-Year Plan (2011-15). Joint ventures between Sinopec/CNPC and local enterprises have been formed at Fulin (Chongqing), Changning (Sichuan) and other shale gas blocks.

Third, coalbed methane (CBM). China has abundant CBM resources. According to the 2015 evaluation by the Ministry of Land and Resources of the PRC, China's geological reserves of CBM in the five major blocks were 30.05 trillion cubic metres, of which 12.5 trillion cubic metres were recoverable. The North China block boasts the biggest deposits, with geological reserves accounting for $46 \%$ and recoverable deposits $41 \%$ of the total. Most of China's CBM resources are in the Erdos and Qinshui basins. In 2016, another $57.612 \mathrm{bcm}$ of geological reserves were proven, a huge increase on the previous year.

The CBM industry enjoys rapid development. Driven by coal mine gas governance and a broadening supply of gas, China began to research, explore and exploit CBM in the 1990s. Small-scale industrialised production of CBM was achieved during the 11th Five-Year Plan (2006-10). By 2016 China had invested RMB 1.591 billion in CBM exploration and production, with 87 drilled wells and 97 development wells. $4.495 \mathrm{bcm}$ of CBM was produced on land in 2016.

The industrial policy system for CBM is basically in place. During the 12th Five-Year Plan (2011-15), the State Council issued Opinions on Further Strengthening Coal-mine Gas Prevention and Control, followed by Opinions on Further Accelerating Coalbed Methane (Coal-mine Gas) Extraction and Exploitation. Government authorities followed up on these policies by issuing the Coalbed Methane Industry Policies and Action Plans for Coalbed Methane Exploration and Exploitation. They also introduced preferential policies, such as refunding VAT on electricity generated with coal mine gas, which improved the CBM industrial policy system. Major coal provinces developed and implemented support policies. In addition to subsidies from central government, Shanxi and Shaanxi provinces subsidised the extraction and use of CBM at RMB 0.1 per cubic metre. In
Hunan province, each new gas-fired power plant receives RMB 800,000-1 million as an incentive. Anhui, Henan and Guizhou provinces have established special-purpose funds to support the extraction and use of coal mine gas.

Fourth, natural gas hydrate. Natural gas hydrate deposits are abundant in polar tundra sandstone and seabed sandstone. Estimated reserves are currently 83.7 trillion cubic metres, mainly in the South China Sea and Qinghai-Tibet Plateau tundra. China has made breakthroughs in natural gas hydrate development. The Blue Whale 1 rig is in production and 20 key technologies have been innovated. China is the first country to produce combustible ice in a safe and controllable pilot project in an argillaceous silt reservoir. Natural gas hydrate was successfully produced in a trial project in May 2017 in the South China Sea for 60 consecutive days. $309,000 \mathrm{~m}^{3}$ of gas were produced in total. The project set a world record in terms of duration and volume.

\section{(2) Problems and challenges}

China's unconventional gas has entered the stage of rapid development, but obstacles still exist in technology, systems, policy and costeffectiveness.

First, China does not completely master the technologies. CBM deposits in China are complex and demanding in terms of development technologies. Fundamental breakthroughs in basic theories and technical processes have yet to be made for the development of CBM from low-permeability, high-stress tectonic coal. The economical use of low-concentration coal gas and surface hole extraction in mining areas also needs to be improved. As for shale gas, China has not mastered deep-stratum development technologies yet, making the extraction of shale gas resources at depths greater than $3,500 \mathrm{~m}$ in south Sichuan a great challenge.

Second, there is insufficient market competition. Currently, the exploration and production of tight gas, CBM and shale gas are dominated by several state-owned enterprises that are supervised and regulated by the central government. 
Access channels for private capital are not smooth, making effective output difficult to achieve. Mining rights overlap is a longstanding issue. Effective constraints through the policy of "coalbed methane before coal mining" are not in place. Mining rights in favourable shale gas zones often overlap with conventional oil and gas mining rights. In addition, the technical services market is underdeveloped and averse to improving exploration and production technologies and equipment through market competition, making cost reductions and production increases difficult.

Third, effects of support policies and incentives have been weakened. Support policies, including refunded coalbed methane VAT, are not well implemented in some regions. The subsidy for shale gas is lower than during the 12th Five-Year Plan (2011-15). There are no subsidies for tight gas. Furthermore, the Chinese government has repeatedly lowered natural gas prices, which has weakened the effects of subsidies and tax reduction and exemption measures.

Fourth, exploration and production are not always cost-effective. Shale gas wells are characterised by high single-well investment costs, long implementation cycles and rapidly decreasing output over time. This brings heavy capital pressure and investment risk to shale gas development businesses. Gas content and pressure increase, and coalbed gas permeability decreases, with depth, making CBM extraction more difficult. In some regions, tight gas deposits are in difficult geological conditions. The cost of exploiting the deposits is high and the output-input ratio is low, leading to poor economic returns or even losses.

\subsubsection{The Role of Unconventional Gas in the Energy Revolution}

Unconventional gas is the key to the sustainable development of the oil and gas industry and an enabler for the global oil and gas production revolution. It can safeguard China's energy supply security, revolutionise energy production and consumption, and help sectors of the economy develop and expand.

Unconventional gas can boost China's gas production and improve gas supply security. China's gas output is forecast to increase from $135 \mathrm{bcm}$ in 2015 to $350 \mathrm{bcm}$ in 2030, of which more than $80 \%$ will come from unconventional sources. However, gas import volumes will increase and reliance on overseas gas will intensify. Between 2020 and 2030, more than $40 \%$ of gas will be imported, that figure will exceed $50 \%$ in 2050 . China, due to natural constraints, has limited potential to increase conventional gas production. Unconventional gas is, therefore, the key to keeping gas imports below $50 \%$ by 2030 . Increasing the development of unconventional gas is essential for China's gas supply security (Table 16).

Tight gas and shale gas are the two most important growth points for China in unconventional gas, as they were for the USA as well. China's tight gas reserves are relatively known and have been explored with mature technologies - the two preconditions for fast development and use. It is expected that China will build a

Table 16 China's future gas supply capacity

\begin{tabular}{|l|l|l|l|l|l|l|l|}
\hline & $\begin{array}{l}\text { Conventional } \\
\text { gas }\end{array}$ & $\begin{array}{l}\text { Tight } \\
\text { gas }\end{array}$ & $\begin{array}{l}\text { Shale } \\
\text { gas }\end{array}$ & $\begin{array}{l}\text { Coalbed } \\
\text { methane } \\
\text { (CBM) }\end{array}$ & $\begin{array}{l}\text { Total volume } \\
\text { of domestic } \\
\text { gas }\end{array}$ & $\begin{array}{l}\text { Imported } \\
\text { gas }\end{array}$ & $\begin{array}{l}\text { Proportion of } \\
\text { imported gas } \\
(\%)\end{array}$ \\
\hline 2015 & 126 & & 4.6 & 4.4 & 135 & 61.4 & 31 \\
\hline 2020 & 130 & 37 & 30 & 10 & 207 & 150 & 42 \\
\hline 2030 & 130 & 100 & 80 & 40 & 350 & 250 & 42 \\
\hline 2050 & 130 & 100 & 100 & 40 & 370 & 430 & 54
\end{tabular}

Note Unit of measurement: billion cubic metres $(\mathrm{bcm})$

Source The 13th five-year plan for natural gas, Research Institute of Petroleum Exploration and Development (2016) 
complete, efficient and low-cost tight gas technology system by 2020, and that the Erdos, Sichuan and Tarim basins will reach peak production of $37 \mathrm{bcm}$ by 2020 . Tight gas exploration and production at the Dzungaria, Songliao, Turpan-Hami, Bohai Bay and Qaidam basins will achieve breakthroughs by 2030, with output rising to $100 \mathrm{bcm}$. China has abundant shale gas resources and has made preliminary advances in their exploration and production. Development of Sichuan and Yunan's marine facies shale gas is expected to take off around 2020. Production at the Fuling, Changning, Weiyuan and Zhaotong shale gas demonstration blocks will reach $30 \mathrm{bcm}$ by 2020. Exploration and production of marine facies in the organic-rich shale formation of the Palaeozoic Erathem era in south China and of lacustrine and marine-terrigenous facies in organic-rich mudstone strata in north China could make great progress by 2030 , achieving a production capacity of $80-100 \mathrm{bcm}$ of shale gas.

Natural gas hydrate is expected to become a key contributor to the global oil and gas production revolution. In addition to boasting world-leading rigs, China has made breakthroughs in natural gas hydrate development and key technologies. It has successfully produced gas, safely and controllably in a pilot project, from combustible ice in an argillaceous silt reservoir ahead of other countries, meaning that China is a world leader in terms of natural gas hydrate development. In the past two decades, North America has led the global shale oil and gas revolution through the broad application of horizontal drilling and hydraulic fracturing. With its continuously evolving technologies and equipment, China strives to become the first country to commercially recover natural gas hydrate by around 2030. This will enable China to become internationally competitive in natural gas hydrate exploration and production and guide the revolution in global oil and gas production.

The exploration and production of unconventional gas should be strongly promoted in an orderly manner. China's unconventional gas resources are diversified, abundant and the key to the sustainable development of its gas industry. However, quality, technical maturity and extraction processes differ from one type of unconventional gas to another.

First, the development of tight gas should be regarded as a priority and implemented to effectively replace conventional energy sources. Breakthroughs should be made in multi-layer fracturing of thin reservoirs in vertical and horizontal wells and low-cost well drilling and completion technologies, so as to build a complete, efficient and low-cost tight gas technology system. Support policies should be adopted, such as tax incentives for imported equipment, tax deductions for exploration costs, and tax deductions and exemptions for businesses.

Second, more investment should be made in shale gas and coalbed methane to make them the main means to increase gas production. Establishing mature and proprietary exploration and production science and technologies, suitable for China's shale and coalbed reserves, should be accelerated through research. The survey and assessment of national shale gas and coalbed methane resources should also be accelerated. Advances should be made in key technologies and equipment, including seismic interpretation, measurement while drilling, rotary steering and fracturing monitoring.

Third, the commercialisation of natural gas hydrate as a strategic substitute should be achieved as soon as possible. Resource surveys and development studies should be completed within the next 10 years and commercial exploitation by around 2030. This will enable China to develop strong international competitiveness in natural gas hydrate exploration and production.

\subsubsection{Strategic Positioning and Policy Suggestions}

First, the positioning of unconventional gas as a major driver of gas output growth should be clearly defined. The Chinese government's Energy Production and Consumption Revolution Strategy (2016-30) clearly describes China's gas development direction and targets. The strategies and plans developed by central government should be well implemented by now. However, clear national gas development 
strategies for 2050 should be developed. The positioning of unconventional gas as a key driver of gas output growth, and the strategic goals and means of delivery, should be clearly defined. Generating huge monopoly profits by virtue of large-scale investment and the relative scarcity of resources is the traditional pathway for the international oil and gas sector. Faced with increasingly fierce competition from renewable energy sources, the oil and gas industry must be transformed and revolutionised. Low-cost, green development should be the main strategy of the oil and gas revolution.

Second, the oil and gas industry requires deep reform. The Ministry of Land and Resources of China listed shale gas as an independent mineral energy resource and invited bids for the exploration rights. Allowing non-oil and gas companies and private enterprises to bid for rights breaks the upstream monopoly of the major state-owned oil companies, which is a big step towards oil and gas reform. However, more than $70 \%$ of unconventional oil and gas resources overlap with conventional deposits. The blocks with the highest-quality resources are still being explored by the three major oil companies and Yanchang Petroleum, because bidding has not yet been introduced. The next step should be to reform the administration of mining rights for existing oil and gas blocks. It is suggested that exploration and mining rights be awarded by tender, auction or listing. In addition, a mining rights evaluation system, competitive pricing system and mining rights transfer system should be introduced to create an orderly mining rights market. This would attract more businesses to invest in and exploit oil and gas resources, thereby increasing China's oil and gas production.

Third, technology and equipment innovation should be improved. Strong technology innovation and advanced equipment are prerequisites for the oil and gas production revolution. It is suggested that exploration and production technologies suitable for the characteristics of China's unconventional oil and gas resources should be improved by importing, absorbing and innovating advanced technologies through joint
$\mathrm{R} \& \mathrm{D}$ and foreign cooperation. A key technology and equipment system with Chinese characteristics should be developed and deployed at large scale. Local equipment manufacturing should be improved to generate independent intellectual property rights. Specifically, in terms of exploration and production technologies, breakthroughs should be made in drilling and completion, reservoir stimulation, micro-seismic monitoring and other key unconventional gas development technologies. Focus should be directed on research on exploration and production technologies adapted for deep and ultra-deep quasi-continuous tight sandstone and viscous oil in the East China Sea and deep-water oil and gas in the South China Sea. In terms of equipment, priority should be given to the development of unconventional and marine oil and gas resources. R\&D of large acidification and fracturing equipment, semi-submersible rigs and production platforms, drilling ships, jack-up drilling platforms, floating production, storage and offloading vessels, geophysical prospecting ships, underwater production systems and other key systems and equipment should be supported.

Fourth, the gas pricing mechanism should be reformed to speed up the development of natural gas in China. Those parts of the value chain where price can be shaped by market competition should be deregulated to unlock market vitality. Pipeline transmission is a natural monopoly that should be priced under government regulation to ensure market fairness. Wellhead and end-user (excluding residential users) gas prices should be deregulated steadily and determined by the market. The gas transmission tariff and distribution fee should be regulated by the government, and tiered residential gas prices established to adjust the residential gas price reasonably. In addition, interruptible gas pricing and peak and off-peak prices should be introduced, and peak-shaving pricing applied to gas-fired power.

Fifth, fiscal and taxation policies should be standardised and improved as soon as possible. Because of resource constraints, the best way to reflect resource value and scarcity is by implementing a system whereby mineral resources are procured, and mining rights awarded, through the 
market. The market will link mining rights to resource reserves, quality and other objectives that reflect the value of the deposits. The businesses that win the mining rights will do their best to improve the rate of recovery, thus creating a good interest-driven mechanism.

Natural gas is urgently needed to adjust the energy mix and protect the environment. To promote the exploration and production of gas, especially shale gas, CBM and other unconventional resources with great potential, it is necessary to introduce tax incentives. In particular, resource tax reductions or exemptions, preferential policies for corporate tax and VAT for businesses that use gas as their main energy source.

Sixth, the environmental supervision of the exploration and production of unconventional gas should be improved. China suffers from frequent environmental pollution events, and the public's environmental sensitivity is rising. In the future, environmental risks will intensify as unconventional gas output increases. China must pay attention to relevant environmental issues and prevent pollution and incidents from occurring, as this would impact the industry's development. The government must therefore create an environmental regulatory regime, while deregulating market access. Specifically, China should: (i) develop an overall plan for setting up a regulatory organisation to ensure environmental regulation is efficient; (ii) accelerate the development and implementation of the laws, regulations, technical standards and specifications for environmental regulation during the development of the oil and gas sector; (iii) build fundamental environmental regulation capabilities and improve the research and development of environmental technologies to provide technical support for regulation; (iv) improve the information disclosure mechanism and broaden channels for public engagement; and (v) intensify the penalty criteria for environmental pollution and improve the reward and penalty mechanism.

\section{Strategies and Policies}

\subsection{Main Characteristics of the Evolution of China's Energy Technology Policies}

\subsubsection{Energy Technologies Pass Through Four Development Stages During Macro Energy Trends}

Energy is fundamental to the economy. It provides important material support to social and economic activities and is influenced by macroeconomic trends. The energy industry has passed through four historical stages since its initial reform and opening up. Each stage has different characteristics that match the different stages of China's economic development, its strategic orientation and support policies.

First, China's initial energy development strategies (1978-93). After the reform and opening up, and to increase energy supply as fast as possible, the Chinese government boosted investment to accelerate the development of the energy industry. However, due to the long construction cycle of energy infrastructure, the severe energy shortage became a bottleneck to China's economic growth. During this period, the guiding idea for China's energy strategies was to increase energy supply, and the energy technology strategies focused more on introducing production technologies to address the supply shortage of coal, electricity and other energy sources.

Second, adjusting and stabilising China's energy development strategies (1994-2003). The energy bottleneck in China's national economic development was more or less eliminated in the late 1990s. During this period, China's economic growth underwent a transition from overheating to soft landing, and a balance was achieved between energy supply and demand that had not been possible for years. The relative oversupply of energy changed China's strict control over consumption. 
China's energy technology strategies focused more on improving energy supply quality and the technologies themselves. The Chinese government introduced technology strategies and policies for optimising energy consumption and encouraging the use of clean energy.

Third, the rapid expansion of China's energy development strategies (2004-12). In the 21st century, China's energy-intensive industries developed rapidly thanks to industrialisation and urbanisation. This resulted in soaring energy demand and consumption. This huge change in the energy supply-demand relationship forced the Chinese government to rethink its energy strategies. Besides conventional exploration and development technologies, China's energy technology strategies now focused on industry, transport and buildings, especially on innovating and promoting energy-efficient technologies.

Fourth, optimising and improving energy development comprehensively (2012-present). As China's economy enters its new normal of slower growth, the country's energy demand growth is also slowing down. The principal objective of energy development has shifted from meeting basic energy supply requirements to satisfying people's growing need for energy to support a better life. The energy industry is also undergoing a shift from energy quantity growth to energy quality improvement. It is imperative to improve energy development quality through advanced technological innovation and widespread implementation of the green development philosophy.

Table 17 clearly shows that China has successfully explored an energy development path with Chinese characteristics that is comprehensive, coordinated and sustainable. Each energy technology strategy and policy system is created within these macro-strategies for energy development.

\subsubsection{China's Energy Industry and Energy Technology Strategies and Policies Are in Parallel and Mutually Beneficial}

China's energy technology strategies and policies have transitioned from a traditional planned economy approach to a market economy system. Policy evolution is influenced by many factors, including national economic development strategy, the development of natural resources and reserves, society's demand for energy, as well as institutional factors like China's classification of industries. China's energy technology strategies and policies run along two lines.

The first is the energy industry. Previously, China's energy technology strategies and policies were mainly initiated and promoted by former government departments like the Ministry of Coal Industry, the Ministry of Nuclear Industry, the Ministry of Electric Power, the Ministry of Petroleum, the Planning Commission, the Information Commission, and the Economic and Trade Commission. With China's institutional restructuring, energy technology strategies are now developed by ministries and agencies like the National Development and Reform Commission, the National Energy Administration, the Ministry of Industry and Information Technology, the Ministry of Housing and Urban-Rural Development, and the Ministry of Transport.

For example, the State Council published Key Points of National Energy Technology Policies in 1986, which gave the technology policy requirements for coal, oil, natural gas and hydropower. These requirements included speeding up coal development; increasing the economic benefits of oil field development; prioritising hydropower; using oil and gas resources reasonably and improving the way that petroleum refining and oil products are allocated; making coal processing, combustion and conversion technologies better and improving product allocation. In the 1990s, the government issued Outline of China's Energy Efficiency Technology Policies, which focused on energy demand. Specifically, China prioritises energy efficiency when developing energy technologies, focusing on making research breakthroughs in critical energy efficiency technologies for energy-intensive industries, and guiding private capital into energy efficiency applications.

The second is energy technology. Government departments like the Ministry of Science and Technology (MOST) and the Ministry of 
Table 17 China's energy strategy orientation in different historical periods

\begin{tabular}{l|l} 
Period & Orientation of energy strategies \\
$\begin{array}{l}\text { 6th Five-Year Plan } \\
\text { (1981-85) }\end{array}$ & $\begin{array}{l}\text { Strengthen energy development and conservation to meet the demand for national } \\
\text { economic growth; and follow the guidelines of "adapting energy development to local } \\
\text { conditions, developing multiple and complementary sources of energy, integrating energy } \\
\text { use and achieving real results" to ensure reasonable energy use and conservation in rural } \\
\text { areas }\end{array}$
\end{tabular}

7th FYP (1986-90) Put equal focus on energy development and conservation; take measures on price, tax and credit to accelerate energy production and reduce energy consumption, and thus gradually diminish the energy shortage; continue implementing the guidelines of "adapting energy development to local conditions, developing multiple and complementary sources of energy, integrating energy use and achieving real results" to ensure reasonable energy use and conservation in rural areas

8th FYP (1991-95) Put equal focus on energy development and conservation, highlighting the importance of conservation; implement the guidelines for adapting energy development to local conditions, coordinating the development of hydro and thermal power and nuclear energy; speed up the construction of coal mines, integrating coal exploitation, processing, transport, sales and use, and implement the guidelines for maintaining stable development in east China and developing west China; and improve energy infrastructure in rural areas

9th FYP (1996-2000) Put equal focus on energy development and conservation, but prioritise conservation; adjust the energy production and consumption system, and improve energy production efficiency; simultaneously carry out energy development and environmental governance, and resolve the pricing of energy products; improve the exploration and development of oil and gas resources and develop new energy with electricity at the centre and coal as the basis; speed up the commercialisation of rural energy and develop it into an industry, and improve its service system; and follow the principle of adapting energy development to local conditions to advance small-scale hydro, wind, solar, geothermal and biomass energy systems

10th FYP (2001-05) Proactively develop coalbed methane resources and make more effort to research and develop clean coal technologies; put equal focus on oil and gas, channel more effort into the development of offshore oil, increase the share of natural gas in total energy consumption, and build overseas oil and gas supply bases to diversify imported oil; establish a national strategic oil reserve to safeguard national energy security; construct and improve urban and rural power grids and increase grid interconnection across the country; deepen the reform of the electricity system to gradually separate power plants from grids and implement the policy of awarding grid connection contracts through bidding; develop new and renewable energy (hydro, wind, solar and geothermal) and nuclear power

11th FYP (2006-10) Follow the guidelines of prioritising conservation, rely primarily on domestic resources with coal as the basis, diversify energy development and optimise the energy production and consumption system; build a stable, affordable, clean and secure energy supply system to develop coal in an orderly manner and electricity and renewable energy strongly, and speed up the development of oil and gas; reinforce the policy orientation of energy conservation and energy efficiency to maximise the benefits of saving energy

12th FYP (2011-15) Drive changes in how energy is produced and used, and build a modern energy system that is secure, stable, affordable and clean; promote the clean and efficient use of conventional energy and accelerate the development of new energy-hydropower (on condition that the environment is safeguarded) and nuclear power (providing safety is assured); and develop smart grids and increase the strategic oil and gas reserves 
Education have developed a series of technology innovation strategies and policies around basic science, technological innovation and industry development that provide a solid basis for innovation in energy technologies. For instance, MOST was lead for the Outline of the National Medium- and Long-Term Development Plan for Science and Technology in 2005, which prioritised energy technologies. The plan drew up guidelines on independent innovation, major technological breakthroughs and development support to achieve progress in energy technology and sustainable energy development. The research focused on the efficient development and clean use of coal, addressing the shortage of liquid fuels, renewable energy, and energy-efficient technologies.

\subsubsection{China's Energy Technology Innovation Has Made Some Achievements, But Gaps Remain}

In recent years, China has significantly improved its ability to innovate and independently manufacture energy and equipment technologies. It has also built an impressive array of world-class energy technology demonstration projects. Specifically, China has: (i) mastered in part the critical equipment and technologies needed for exploring and developing shale gas, tight oil and other unconventional energy sources; made coalbed methane exploration and development possible at scale; independently developed and manufactured a deep-water semi-submersible drilling vessel with the ability to drill at depths of 3,000 m, and equipment packages like a large gas liquefaction system and electric motor-driven compressor unit for long-distance pipeline transmission; deployed internationally advanced oil and gas exploration and development technologies in complex terrain; and developed oil refining technologies in the 10 million tonne per year category; (ii) developed green and safe coal mining technologies, industrialised coal-intensive processing technologies, including gasification, liquefaction and pyrolysis, and carried out demonstration projects that use low-grade coal in higher-quality applications; (iii) deployed more ultra-supercritical coal-fired power generation units than any other country; made breakthroughs in large integrated gasification combined cycle (IGCC) power generation, carbon storage demonstration projects and $700{ }^{\circ} \mathrm{C}$ ultrasupercritical coal-fired power generation technologies; developed large 1,000 kV ultra-high voltage $\mathrm{AC}$ and $\pm 800 \mathrm{kV}$ ultra-high voltage DC technologies and complete equipment packages at a world-leading level; and rapidly developed smart grid and energy storage technologies; (iv) developed the AP1000 nuclear reactor and critical equipment and material manufacturing technologies; started construction of the Hualong 1 nuclear power demonstration project that uses Generation 3 technologies independently developed in China; and started construction of the first commercial nuclear power demonstration project to use high-temperature gas-cooled reactor technology and an independently designed and manufactured nuclear-level digital instrumentation and control system; and (v) taken onshore wind power technologies to an internationally advanced level, made breakthroughs in and successfully demonstrated offshore wind power technologies; and developed solar photovoltaic power at scale, demonstrated concentrated solar power technologies, and made advances in critical cellulosic ethanol.

Even though China has made great progress in energy technologies, there is still a big gap compared with the world's energy technology powers and the qualities needed to lead the energy revolution. First, China lacks core technologies - key equipment and materials need to be imported. For example, the key technologies in fields like Generation 3 nuclear reactors, new energy and shale gas are often introduced from overseas then slowly developed in China over a long time. In other technologies-like gas turbines and high-temperature materials, offshore oil and gas exploration and development - China is behind. Second, relations between industry, universities and research institutions are not close enough and the position of companies as innovation driver is not clear. Insufficient use is made of the valuable innovation opportunities that major energy projects and energy technology 
$\mathrm{R} \& \mathrm{D}$ offer; the disconnect between innovation and industry demand still exists. Third, improvements need to be made in the innovation system and mechanisms, market allocation of innovation resources, intellectual property protection and management, and talent development, management and motivation. Fourth, long-term strategic plans are absent. The current energy policy system does not put technology innovation at the centre, and national technology innovation strategies and a development roadmap for energy are absent.

China's strategies and policies are transitioning from a planned economy to a market economy in energy and other industries alike. In the traditional planned economy, China's energy policies had a direct effect on the structure, organisations and planning of the energy industry. Although planning did not focus on energy technology polices, there were technology requirements even though the policies did not exist.

\subsection{There Are Opportunities to Lead Global Energy Development During the Global Energy Transition}

\subsubsection{China Has Seized the Opportunity to Reshape Production}

In the past four decades, China has seized the opportunity offered by globalisation to reform its labour market. It has evolved from a family-centred system and used the booming manufacturing industry to grow the entire economy. As a result, China has made the historic transition from an agricultural country to an industrial one. This enabled labour to leave the land and work in industry. The tax sharing system reform triggered competition between counties and created a collective atmosphere of "competition, learning and catching up". Globalisation allowed China's industry to become the workshop of the world and the Chinese people to become rich. However, extensive energy development and use resulted in severe environmental problems, reflecting the contradiction between the people's need for a better life and unbalanced development.

\subsubsection{The New Industrial Revolution Is Driven by the Transition to Smart Power}

The global energy landscape is undergoing major change thanks to the deep integration of energy and information and technology innovation. In the next four decades, the optimal distribution of energy and information will become a key driver in the modernisation of industrial civilisation. Electricity will play an historical role in driving China to leap forward from being a rich country to a strong power. Every technology revolution is a time for substituting new for old social development drivers and is a window for replacing world powers. In the past 300 years, the two previous technology revolutions were driven by energy changes. The steam engine and the electric motor replaced human strength and created world powers like the UK and the USA respectively.

China is embracing the technology revolution driven by information and human intelligence. Electricity is a carrier of both energy and information. A pan-power network, integrating electricity and electronics, is an important platform for the deep integration of electric power and intelligence. The intelligent electricity revolution will play an increasingly important role in history. Electricity market reform is an important engine for the smart electricity revolution; it has the historical mission of integrating smart decision-making with industry and modernising industrial civilisation with green energy.

Major economies consider energy technology a breakthrough for the new technological and industrial revolution and have developed various policies and measures to achieve leadership and sharpen their national competitiveness. For example, the USA has published the All-of-the-Above energy strategy, Japan has issued the Innovative Energy Strategy for 2030, and the EU has released the Energy Roadmap 2050. 


\subsubsection{The Historical Opportunity to Deeply Integrate Energy and Information Will Help China Achieve Its World Power Strategy}

Science and technology determine the future of energy and create the energy of the future. Technology innovation plays a decisive role in the energy revolution, so it must be placed at the centre of energy development. The priorities, timetable and roadmap for innovation in the energy technology revolution should be made clear.

Energy technology policies are part of national technology policies. They are the code of conduct for energy technology development by which a country or party, under given historical and actual conditions, delivers political, economic and social goals. As part of the overall policies of a country, energy technology policies set the direction and guide the strategies of that country's energy development. They are a key to building an innovative country and one of eight major industry technology innovation pathways for the future. Energy technology innovation is an important means to drive industry forward, effectively address international competition, and make China an innovative country.

\subsection{Strategies and Policies to Achieve an Energy Technology Revolution}

\subsubsection{Overall Goals}

By 2020, China's independent energy innovation capacity will significantly improve and a batch of critical technologies will achieve major breakthroughs. China's dependence on imported energy technologies and equipment, components and materials will significantly decline, and the international competitiveness of China's energy industry will substantially increase. The energy technology innovation system will take shape and support China in building a prosperous society in a comprehensive way.
By 2035, China will have developed a relatively complete energy technology innovation system and improved its capacity to innovate energy technologies independently. Moreover, China's energy technologies will reach an internationally advanced level. They will help China to develop its energy industry in a sustainable and environmentally sound way and place China among the world's top energy technology powers.

\subsubsection{Development Ideas}

China should: (i) put independent innovation at the centre of energy technology innovation, strengthen basic research in energy, improve originality, and aim for game-changing technology innovation; (ii) give businesses the leading role and facilitate the efficient and reasonable distribution of innovation resources; (iii) accelerate the shift in government function from R\&D administration to innovation service; (iv) make breakthroughs in key and frontier technologies that constrain energy development and drive revolutionary progress, carry out pilot and demonstration activities in major energy projects; and (v) improve collaborative innovation between government, companies, universities, research institutions and users; encourage innovation in major technologies, equipment, manufacturing, demonstration projects and technology platforms; and combine international and domestic resources to deliver innovation in energy technologies.

\subsubsection{Support Policies}

The energy technology revolution needs interaction between, and the coordinated evolution of, systems, policies and markets. The government needs to develop national strategies for energy technology innovation and energy equipment development; companies need to follow the guidelines of "business is the main actor in a field of market-oriented collaboration between government, companies, universities, research institutions and users". The development of energy talent needs to be improved and the nurturing of 
exceptional talent encouraged. Specifically, the following support mechanisms need to be enhanced:

First, improve the energy technology innovation environment. China should develop and improve as quickly as possible the laws and regulations on energy, the support policies and legislation on the commercialisation of research findings, intellectual property protection, and standardisation. China should also improve the life cycle closed-loop evaluation system for energy technology projects, strengthen in-process and post-project supervision and services, and focus on evaluating innovation performance.

Second, make business more dynamic in technology innovation. China should develop a business-led energy technology innovation system to boost the motivation of business in innovation and promote "widespread entrepreneurship and innovation".

Third, consolidate the foundations of energy technology innovation. China should deepen its reform of scientific research institutions in energy and the scientific research system in universities. It should develop a team of talented inter-disciplinary managers who have knowledge and experience in markets and strategy.

Fourth, improve the investment and financing mechanism for technological innovation. China should leverage the advantages of policy and development-oriented finance and increase its support for key applications in energy technology.

Fifth, innovate the support mechanism for tax, pricing and insurance. China should implement tax policies beneficial to energy technology innovation, improve the method for calculating $R \& D$ investment by energy companies, reduce the tax burden of energy companies, and implement preferential policies on assets like resources, energy and land.

Sixth, deepen international cooperation and exchange on energy technology. China should develop international strategies for energy technology innovation and develop comprehensive, multi-level international cooperation on energy technology. China should also leverage major energy projects under the Belt and Road Initiative to evolve China's advanced energy technologies, equipment and standards into benchmarks for global energy development.

\footnotetext{
Open Access This chapter is licensed under the terms of the Creative Commons Attribution 4.0 International License (http://creativecommons.org/licenses/by/4.0/), which permits use, sharing, adaptation, distribution and reproduction in any medium or format, as long as you give appropriate credit to the original author(s) and the source, provide a link to the Creative Commons license and indicate if changes were made.

The images or other third party material in this chapter are included in the chapter's Creative Commons license,
}

unless indicated otherwise in a credit line to the material. If material is not included in the chapter's Creative Commons license and your intended use is not permitted by statutory regulation or exceeds the permitted use, you will need to obtain permission directly from the copyright holder. 